\title{
Single Crystals: The Next Big Wave Of Perovskite
}

\section{Optoelectronics}

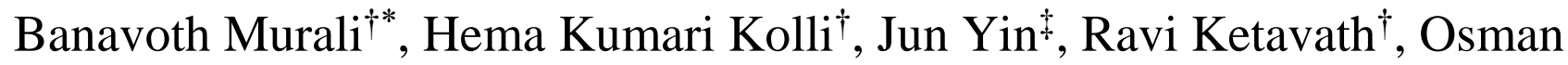 \\ M. Bakr ${ }^{\ddagger}$, Omar F. Mohammed ${ }^{*}$ \\ $\dagger$ Solar Cells and Photonics Research Laboratory, School of Chemistry, University of Hyderabad, \\ Hyderabad, Telangana, 500046, India
}

‡Division of Physical Science and Engineering, King Abdullah University of Science and Technology, Thuwal, 23955-6900, Kingdom of Saudi Arabia

\begin{abstract}
Contemporary advancements in perovskite semiconductors are visibly impacting the progress of light conversion applications. These alluring photo absorbers have gained wide consideration owing to their simple processing and striking optoelectronic properties. Although polycrystalline perovskite thin films exhibit phenomenal performance in energy harvesting devices, they suffer from severe instabilities arising from morphological disorder and surface degradation under ambient conditions. Recent progress in perovskite single-crystals, which in theory should outperform their polycrystalline thin-film counterparts, has been demonstrated to surmount these challenges due to the exceptional optoelectronic properties, such as low trap density, high mobility, low intrinsic carrier concentration and long carrier diffusion length. However, most of the growth approaches used for single-crystal syntheses produce very thick crystals and


subsequently, the related optoelectronic applications are very limited. Given the potential of perovskite single crystals, to break a new path for perovskite optoelectronic devices relies on understanding sustainable issues arising from interfacial/integration losses and developing passivation strategies to achieve performance parity in open ambient. Therefore, the current review provides a comprehensive overview of the advantages, limitations, and challenges associated with growth methods of single-crystals and their chemical stability, device configurations, photophysics, charge carrier dynamics and photovoltaic applications.

\section{TOC GRAPHICS}
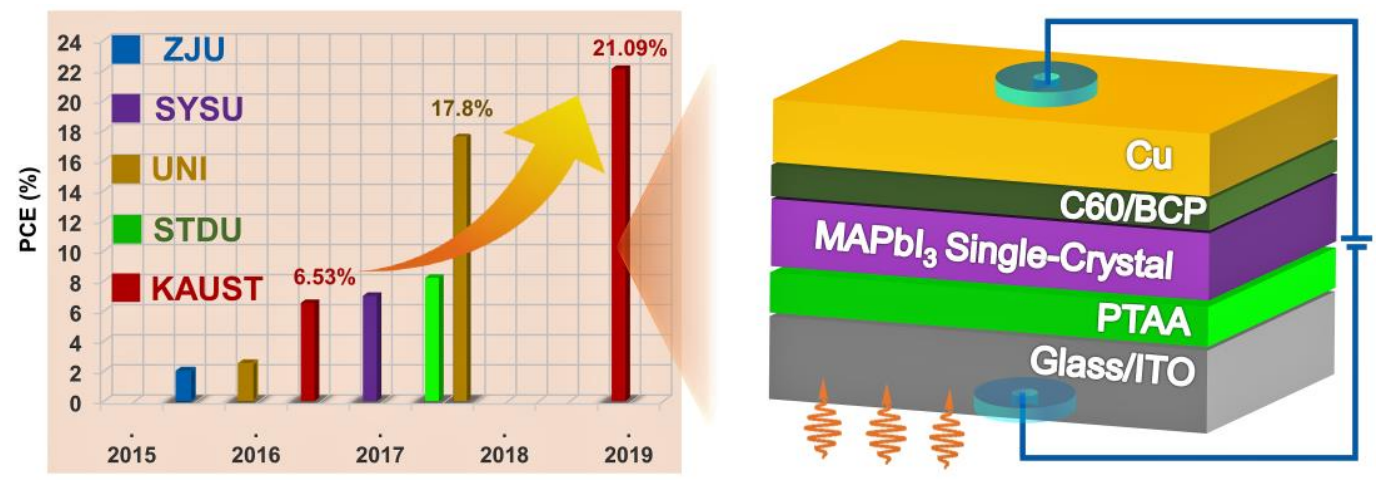

In recent years, metal halide perovskites (MHP) have captivated the interest of researchers owing to their engrossing properties and phenomenal performances in numerous optoelectronic devices. In the early 1980s, $\mathrm{MAPbX}_{3}\left(\mathrm{MA}=\mathrm{CH}_{3} \mathrm{NH}_{3}, \mathrm{X}=\mathrm{Cl}^{-}, \mathrm{Br}^{-}, \mathrm{I}^{-}\right)$and $\mathrm{MASnBr}_{\mathrm{x}} \mathrm{I}_{3-\mathrm{x}}$-based semiconductors were merely considered to be promising for photovoltaics. ${ }^{1}$ Nevertheless, their physical and chemical properties have not been meticulously studied. A turning point in the field occurred in 2009 when Miyasaka first reported a thin film-based solar cell with an efficiency of $3.81 \%$ and photovoltage of $0.96 \mathrm{~V}$ showing external quantum efficiency $(\mathrm{EQE})$ of $65 \% .^{2}$ Later, many researchers have contributed for the synthesis and device applications of single-crystal perovskite in solar cells and other optoelectronic applications. ${ }^{3,4}$ Moreover, 
single-crystal perovskites (SCPs) are a unique class of materials that have been used as solar radiation absorbers. It should be noted that the $\mathrm{MAPbX}_{3}\left(\mathrm{X}=\mathrm{Br}^{-}, \mathrm{I}^{-}\right)$perovskite single crystals possess unprecedented long charge carrier diffusion lengths $(>10 \mu \mathrm{m})$ and a striking low trap density $\left(10^{9}\right.$ to $10^{10}$ $\left.\mathrm{cm}^{-3}\right){ }^{5}$ More specifically, under 1 sun illumination, the single-crystals of $\mathrm{MAPbI}_{3}$ achieved diffusion lengths of $175 \mu \mathrm{m}$ and exceeding $3 \mathrm{~mm}$ under weak light for both electrons and holes. ${ }^{6-7}$ To achieve an efficient device performance, long-range ordered pattern in a perovskite lattice is desirable to significantly decrease the defects and to mitigate charge recombination loss of the derived devices. ${ }^{8}$ It should be pointed out that the large absorption coefficient and properties of the restructured surfaces of single-crystal in open ambient is different from those of the bulk, including the morphology, carrier mobility, photocurrent, carrier dynamics, optical bandgap and device performance. ${ }^{9-11}$ The photogenerated charge carriers are effeciently extracted from the SCPs with active layer thickness much greater than that of the thin films due to the long carrier diffusion length in the singe crystal perovskites. ${ }^{12}$ To overcome the limitations in polycrystalline perovskite solar cells (PSCs), research is focused on replacing polycrystalline perovskite films with high-quality perovskite single-crystalline thin films. Given the notable advancements in perovskite thin films, efficient photovoltaic applications can be realized by using highly ordered absorbers with a low density of trap states. Additionally, in high humidity ( $\mathrm{RH} \geq 60 \pm 5 \%)$ conditions, the devices are prone to degradation, and hence, it is imperative to exploit high-quality single-crystal-based perovskite thin films with minimal structural defects and grain boundaries. ${ }^{31}$ Therefore, advanced investigations of perovskite single-crystal and their integration into efficient optoelectronic devices have been performed but are yet to plateau. ${ }^{13}$ A variety of optoelectronic applications accomplished since then is shown in Fig. 1. 


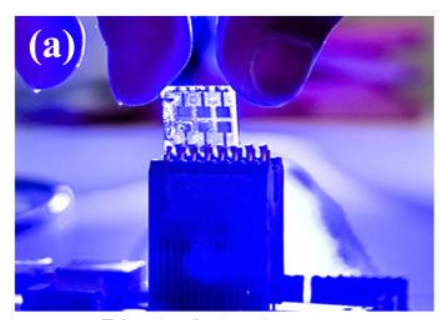

Photodetectors

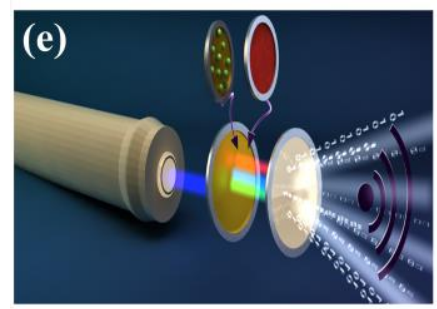

Visible Light Communication (b)

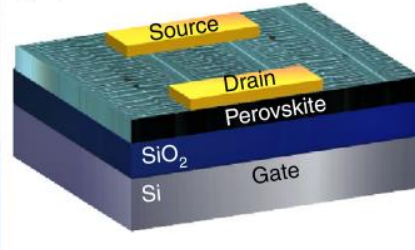

Field Emitting Transistors

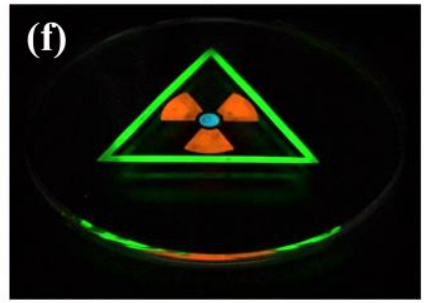

X-ray Scintillators

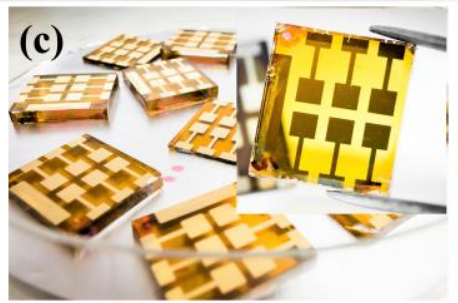

Solar Cells

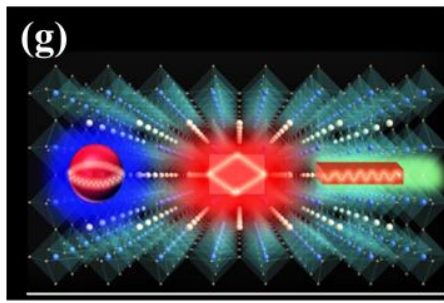

Lasers

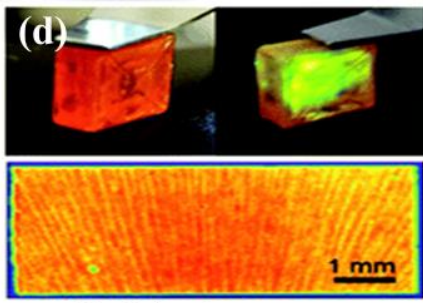

Photoluminescence

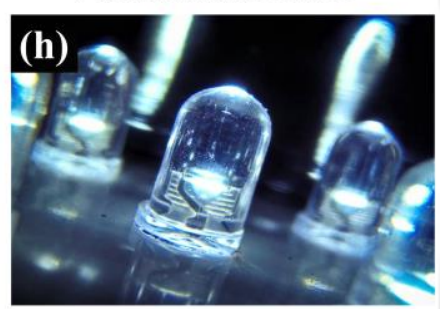

LEDs

Figure 1. Applications of $\mathrm{ABX}_{3}$ perovskites. a) Photodetectors reprinted from ref. 14. b) Field emitting transistors reprinted from ref. 15. c) Solar cell devices reprinted from ref. 16. d) Photoluminescence reprinted from ref. 17. e) Visible light communication reprinted from ref. 18. f) Multicolor X-ray scintillation (X-ray illumination at a voltage of $50 \mathrm{kV}$ ) reprinted from ref. 19. g) Small perovskite-based lasers reprinted from ref. 20. h) LEDs reprinted from ref. 21. (Panels reprinted with permission from as indicated refs. Copyrights from the American Chemical Society, Wiley and Springer Nature publishers).

The current review comprehensively summarizes the various methods for the growth of single-crystal with a primary focus on the monocrystalline thin films and subsequently achieved photovoltaic applications. Although the advancement of perovskite field in terms of various optoelectronic applications is exciting, a clear understanding of critical parameters such as the ion migration pathways in perovskites and the charge carrier/displacement transport mechanisms at the interfaces of transport layers/perovskite layers remains the key to designing efficient devices. ${ }^{22-25}$ Apart from the evolution of SCPs, the fundamental optoelectronic properties along with the stability issues and associated challenges, while fabricating the devices are discussed in detail. The advantages, limitations, and challenges of numerous growth processes have been comprehensively reviewed. Finally, this review will provide some perspectives and a future outlook on the development of sustainable SCPs photovoltaic applications. 


\section{Crystal Structure}

(a)

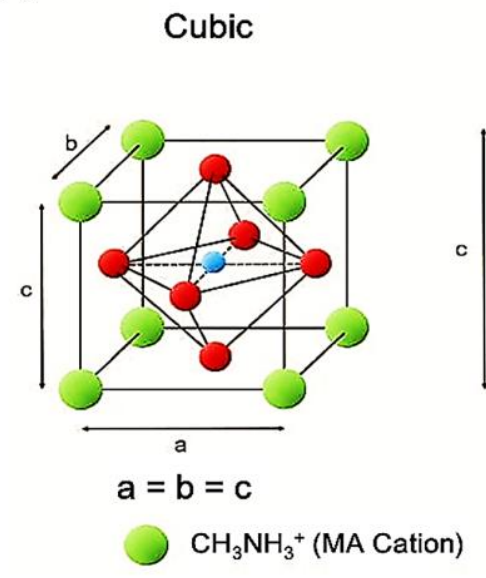

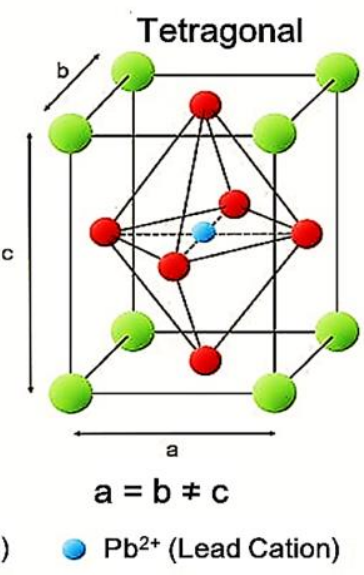

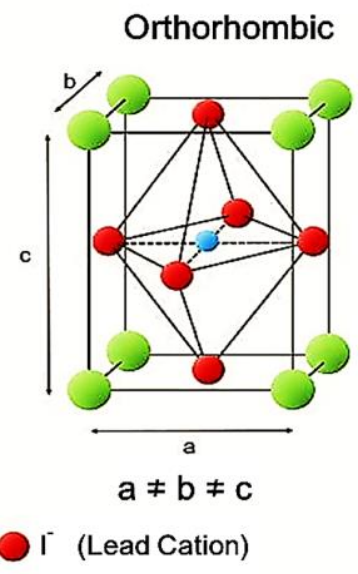

(b)

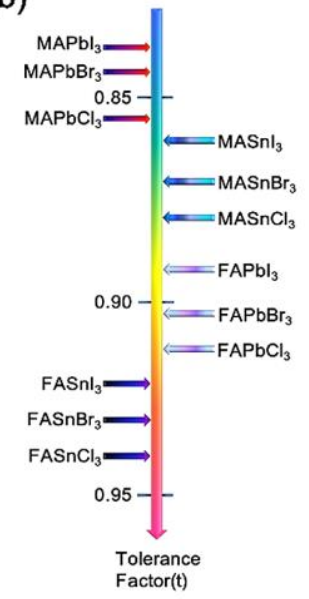

Figure 2. a) $\mathrm{CH}_{3} \mathrm{NH}_{3} \mathrm{PbI}_{3}$ perovskite cubic, tetragonal and orthorhombic crystal structures. (Redrawn from ref. ${ }^{26}$ ). b) Tolerance factors (t) of a series of halide perovskites. (Redrawn from ref. ${ }^{27}$ copyright 2015 The Royal Society of Chemistry).

MHPs crystallize in the $\mathrm{ABX}_{3}$ structure, where $\mathrm{A}$ (monovalent) and $\mathrm{B}$ (divalent) are cations of different sizes and $\mathrm{X}$ is an anion that mainly consists of halogens $\left(\mathrm{Cl}^{-}, \mathrm{I}^{-}, \mathrm{Br}^{-}\right)$. Note that the $\mathrm{ABX}_{3}$ crystal is isostructural to the perovskite oxide $\mathrm{CaTiO}_{3}$ structure. The crystal structure of $\mathrm{ABX}_{3}$ halide perovskites is built by a $3 \mathrm{D}$, corner-sharing $\mathrm{BX}_{6}$ octahedra network, where the A-site cations occupy the 12-fold coordinated (cuboctahedral) voids to maintain charge neutrality. ${ }^{28}$ The stability of the crystal structure is determined by the tolerance factor, calculated using the formula

$$
t=\frac{\left(r_{A}+r_{B}\right)}{\sqrt{2}\left(r_{B}+r_{X}\right)}
$$

where $r_{A}, r_{B}$ and $r_{X}$ are the ionic radii of $\mathrm{A}, \mathrm{B}$, and $\mathrm{X}$, respectively. ${ }^{29}$ The $\mathrm{t}$ value ranges from 0.7 to 0.9 , ascribed to structures with smaller A or larger B, at which values tetragonal, orthorhombic or rhombohedral structures easily form. The crystal structures of the tetragonal and orthorhombic phases of $\mathrm{CH}_{3} \mathrm{NH}_{3} \mathrm{PbI}_{3}$ are illustrated in Fig. 2a. ${ }^{26,30}$ The Methylammonium position is disordered in the tetragonal phase from $160 \mathrm{~K}$ to room temperature, whereas it is ordered below $160 \mathrm{~K}$ in the orthorhombic phase. ${ }^{26}$ 
The hybrid perovskites containing $\mathrm{Pb}$ and $\mathrm{Sn}$ elements and their corresponding parameters are listed in Fig. 2b.

\section{Growth Methods of Perovskite Single-crystals}

Generally, high-quality perovskite single-crystalline films solar cells were fabricated by employing the cavitation-triggered asymmetric crystallization (CTAC) and space-limited inverse temperature crystallization (SLITC) growth. ${ }^{31,32}$ Using these films, a stable prototype architecture ITO/ $\mathrm{CH}_{3} \mathrm{NH}_{3} \mathrm{PbBr}_{3} / \mathrm{Au}$ is devised, which manifested near $100 \%$ internal quantum efficiency (IQE), and power conversion efficiencies (PCEs) $>5 \%$. Very recently, a record efficiency of $21.09 \%$ and highest fill factor of $84.3 \%$ were achieved using the device architecture ITO/PTAA/MAPbI $3 / \mathrm{C}_{60} / \mathrm{BCP} / \mathrm{Cu}$, which sets a new path in single-crystalline thin-film solar cells (as discussed in details below). Therefore, seeking high-quality, and thickness controlled perovskite single crystals is indispensable for future optoelectronic applications. There are numerous growth methods to obtain single-crystal perovskites, few of them are discussed below.

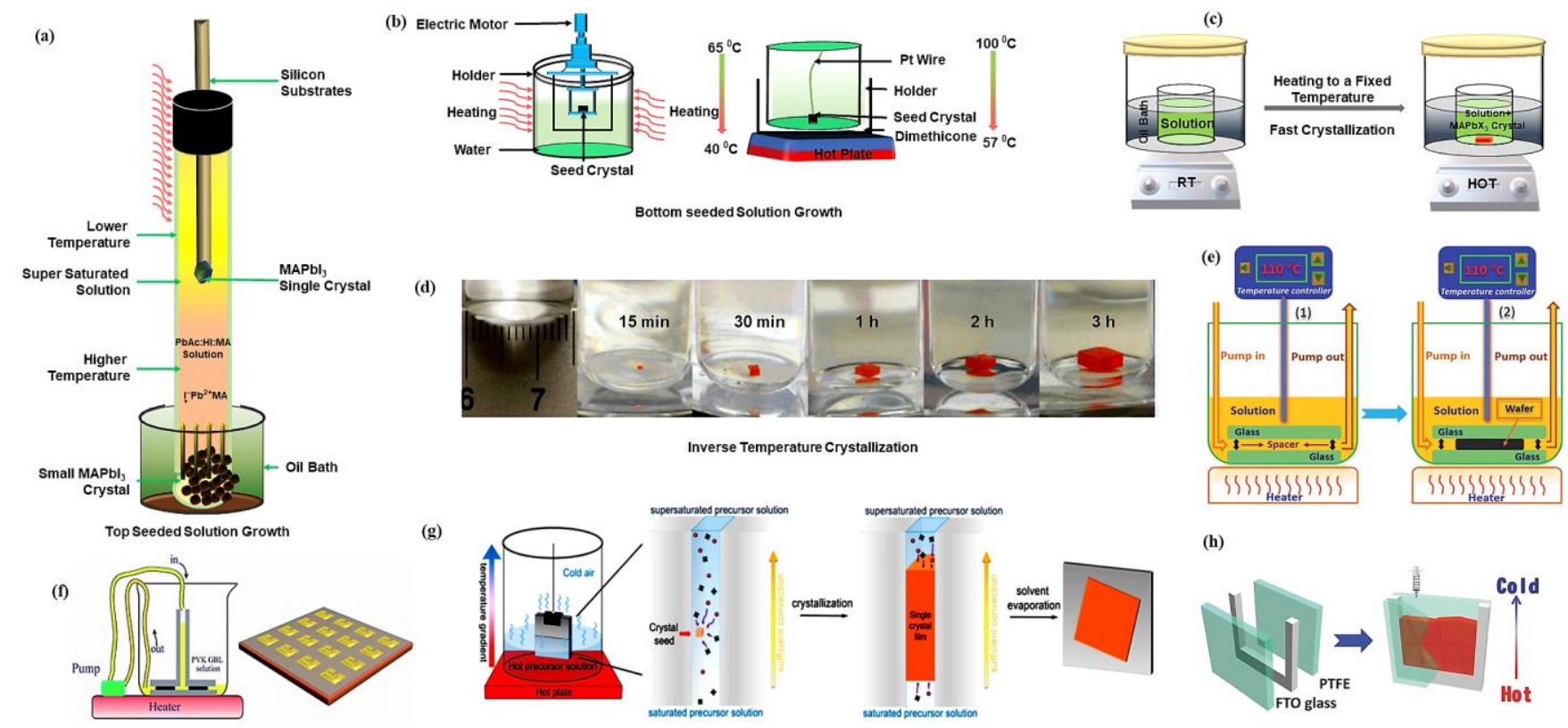

Figure 3. Syntheses of bulk SCPs. a) Schematic diagram of the top-seeded solution growth of a large $\mathrm{MAPbI}_{3}$ single-crystal. (Redrawn from ref. ${ }^{33}$ copyright 2016 The Royal Society of Chemistry). b) 
Schematic illustration of the bottom seeded crystal growth method. (Redrawn from ref. ${ }^{34},{ }^{35}$ copyright 2015 from The Royal Society of Chemistry and Nature Publishing Group). c) The ITC apparatus's schematic representation of crystallization taking place in a vial immersed in a heating bath. The solution is heated from room temperature and kept at an elevated temperature $\left(80{ }^{\circ} \mathrm{C}\right.$ for $\mathrm{MAPbBr}_{3}$ and $110{ }^{\circ} \mathrm{C}$ for $\mathrm{MAPbI}_{3}$ ) to initiate crystallization, is redrawn from ref. ${ }^{36}$. d) $\mathrm{MAPbBr}_{3}$ crystal growth at different time intervals. (Reprinted with permission from ref. ${ }^{36}$ copyright 2015 Nature Publishing Group). e) Schematic representation of ITC apparatus using the peristaltic pump. (Reprinted with permission from ref. ${ }^{37}$ copyright 2016 Wiley). f) Schematic depicts the modified setup of ITC apparatus with the peristaltic pump. (Reprinted with permission from ref. ${ }^{38}$ copyright 2018 The Royal Society of Chemistry). g) Schematic represents the space confined growth strategy of hybrid perovskite single-crystal thin films. (Reprinted with permission from ref. ${ }^{39}$ copyright 2016 American Chemical Society). h) Schematic illustrates the single crystal growth mechanism through PTFE frame stacking technique. (Reprinted with permission from ref. ${ }^{40}$ copyright 2015 Nature Publishing Group).

\subsection{Temperature Lowering Method}

The widely adopted method for the crystal growth of organometallic halide perovskites is the temperature lowering method. ${ }^{41-44}$ In general, seed-assisted growth is commonly used for growing largesized, high-quality single crystals. ${ }^{45}$ By carefully lowering the temperature, crystal growth on the preferred seed is observed when it is immersed in the appropriate solution. Through solute saturation and the use of an aqueous perovskite precursor $\mathrm{HX}\left(\mathrm{X}=\mathrm{Cl}^{-}, \mathrm{Br}^{-} \mathrm{I}^{-}\right)$, the saturated solution containing the inorganic and organic halide salts form a halide perovskite crystal. Top-seeded solution growth (TSSG) and bottom seeded solution growth (BSSG) ${ }^{29}$ methods are commonly used for the synthesis.

\subsubsection{Top-Seeded Solution Growth Method}

Dong et al. synthesized a single-crystal of $\mathrm{MAPbI}_{3}$ via the TSSG route, in which the seed crystal is fixed to a silicon substrate on top of the solution. ${ }^{6}$ Due to the dissolution of the small seed crystal induced 
by the temperature disparity between the top and bottom of the solution, the supersaturation condition results in the formation of bulk $\mathrm{MAPbI}_{3}$ single-crystals. The method is schematically illustrated in Fig. 3a, showing the formation of high-quality single-crystals with dimensions of $10 \mathrm{~mm}$ length by $3.3 \mathrm{~mm}$ thickness.

\subsubsection{Bottom Seeded Solution Growth Method}

(a)

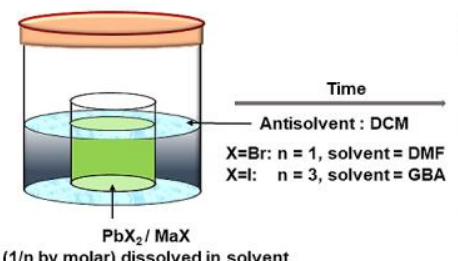

( $1 / \mathrm{n}$ by molar) dissolved in solvent

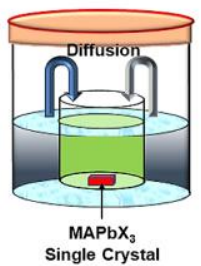

Anti-Solvent Vapor-assisted Crystallization

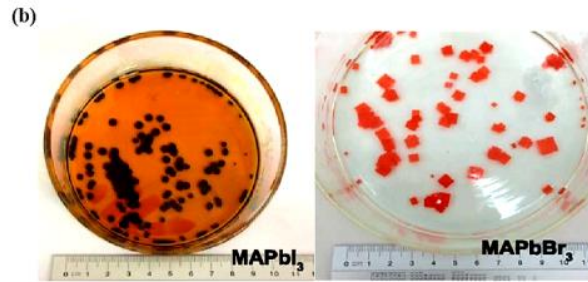

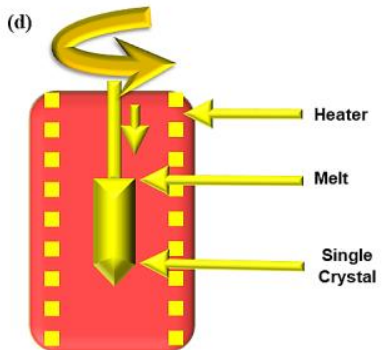

Melt Crystallization Method
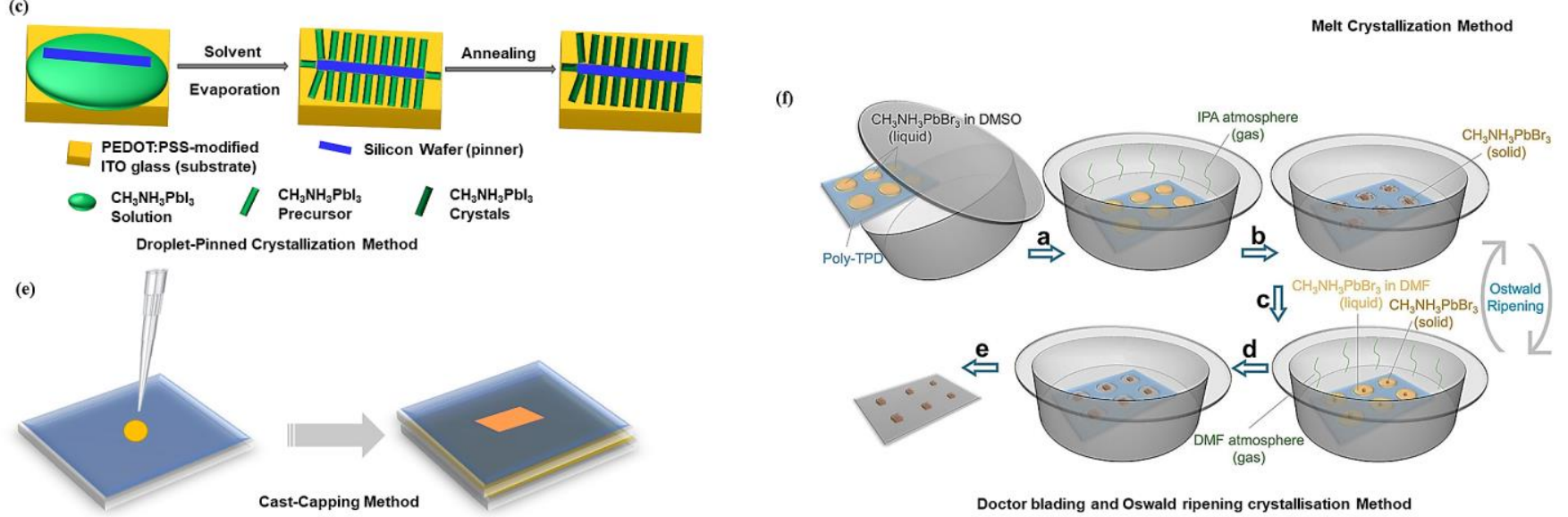

Figure 4. a) Schematic diagram of bottom seeded solution growth crystallization process. (Redrawn from ref. 5 copyright 2015 American Association for the Advancement of Science). b) Photograph of a batch of as-grown $\mathrm{MAPbBr}_{3}$ and $\mathrm{MAPbI}_{3}$ single-crystals produced within a week. (Reprinted with permission from ref. 5 copyright 2015 American Association for the Advancement of Science). c) Schematic of the growth process of $\mathrm{CH}_{3} \mathrm{NH}_{3} \mathrm{PbI}_{3}$ crystals. (Redrawn from ref. ${ }^{46}$ copyright 2016 The Royal Society of Chemistry). d) Schematic diagram of the melt crystallization method. (Redrawn from ref. ${ }^{47}$ copyright 2017 Springer). e) Schematic illustration of the cast-capping technique of growing single crystals. 
(Redrawn from ref. ${ }^{48}$ copyright 2017 Elsevier). f) Schematic of Oswald ripening crystallization method. (Reprinted with permission from ref. ${ }^{49}$ copyright 2018 American Chemical Society).

Dang et al. first reported the BSSG method by growing single-crystals of $\mathrm{MAPbI}_{3}{ }^{50}$ The crystals are produced by modifying the temperature conditions and selecting a high-quality seed crystal grown by the spontaneous crystallization method. In this method, the tray fixed with the seed crystal, as shown schematically in Fig. $3 \mathrm{~b}$ is rotated by using an electric motor, and the temperature of the saturated solution is cooled down from $65{ }^{\circ} \mathrm{C}$ to $40{ }^{\circ} \mathrm{C}$. As a result, single-crystals of $\mathrm{MAPbI}_{3}$ are produced. ${ }^{50}$ Consequently, an unreactive platinum wire was used to fix a seed crystal (Fig. 3b), to obtain a single-crystal, by lowering the temperature of the solution from $100{ }^{\circ} \mathrm{C}$ to $57^{\circ} \mathrm{C} .{ }^{35}$ With the above two methods, it is possible to grow large size single-crystals with high quality under controlled and stable conditions.

\subsection{Inverse Temperature Crystallization Method}

The inverse temperature method (ITC) is a technique used for the rapid growth of single crystals within minutes. ${ }^{78}$ Single-crystals were grown by ITC in appropriate solvents, producing high-quality and shapecontrolled single-crystals. ${ }^{13,36,51}$ This method involves the dissolution of $\mathrm{MAPbBr}_{3}$ in an appropriate solvent, that is, $\mathrm{N}, \mathrm{N}$-dimethylformamide (DMF), thus forming small $\mathrm{MAPbBr}_{3}$ perovskite precipitates under high-temperature conditions. The solubility of $\mathrm{MAPbBr}_{3}$ in the solvent DMF is controlled by varying the temperature from room temperature to $80 \mathrm{C}$. Such an unusual property was used for crystallization in a hot solution with rapid inverse solubility, as illustrated in Fig. 3c. The crystal growth of $\mathrm{MAPbBr}_{3}$ perovskites using the ITC method was recorded at various time intervals, as illustrated in Fig. 3d. Interestingly, the crystal formation of both $\mathrm{MAPbBr}_{3}$ and $\mathrm{MAPbI}_{3}$ is a reversible process, and the crystals disappear when left to cool at room temperature. ${ }^{13,36,51}$

Later, this method was implemented to grow mixed halide perovskites of $\left(\mathrm{CH}_{3} \mathrm{NH}_{3}\right) \mathrm{Pb}\left(\mathrm{Br}_{1-\mathrm{x}} \mathrm{Cl}_{\mathrm{x}}\right)_{3}$ single-crystals. ${ }^{52}$ Similarly, a modified ITC method was used to grow a 5-mm-sized $\mathrm{FAPbI}_{3}$ single-crystal from a $\mathrm{FAPbI}_{3}$ seed crystal using the cooling solution method, followed by placing the seed crystals in an 
ITC precursor to form large crystals. ${ }^{53}$ The ITC method is distinguished from the temperature lowering method, it is suitable for materials with high solubility at room temperature in an appropriate solvent, subject to the condition that the solubility decreases with increasing temperature.

SCPs have charge carrier diffusion lengths in the order tens of micrometer range. For widespread utilization of single-crystals, the thickness of the active layer should be less than its diffusion length. Therefore, the growth methods need to be redesigned primarily to control the thickness and orientation of as-grown single-crystalline thin films. Recent studies have revealed that single-crystalline perovskite films exhibit optoelectronic properties that are similar to those of SCPs. ${ }^{54-57}$ Being in this rergime, a onestep printing method to fabricate $\mathrm{CH}_{3} \mathrm{NH}_{3} \mathrm{PbI}_{3}$ single-crystal perovskite thin films on a wafer-scale substrate has been reported recently. ${ }^{58}$ The enhanced carrier mobility observed in the SCPs thin film was thought to be the driving force in enhancing the performance of optoelectronic devices. ${ }^{58}$ The propensity for SCPs thin films to grow on any substrate allows them to be obtained in proper lateral configurations, enabling the fabrication of flexible devices. ${ }^{58}$ To confine the thickness, single crystals were grown between two parallel glass slides, designed in a dynamic flow setup by using a peristaltic pump to grow $\mathrm{MAPbI}_{3}$ single crystals of lateral sizes up to $1 \mathrm{~cm}$ and thicknesses of $150 \mu \mathrm{m}$ (Fig. 3e). ${ }^{37}$ Recently, a modified setup is also used to grow ultra-thin free-standing single crystals of thickness $35 \mu \mathrm{m}$ (Fig. 3f). ${ }^{38}$ Realizing the advantage to grow the perovskite single crystals directly on the substrate, Chen designed a novel setup by clamping the two substrates together by a binder clip and vertically immersing in to the solution (Fig. 3g). ${ }^{39}$ These single crystals have low lateral sizes with tunable thickness from $13 \mathrm{~nm}$ to $4.5 \mu \mathrm{m}$ obtained by varying the pressure of the binder clips. Later an ingenious way to confine the single crystal by stacking a U- shaped PTFE frame between the substrates (Fig. 3h) has been proposed. The temperature across the frame aids crystal growth. The thickness was tuned by varying the thickness of PTFE frame. ${ }^{40}$ Notably, the lateral size of the crystal is governed by its nucleation energy barrier. ${ }^{23} \mathrm{~A}$ 
substrate-surface modification strategy is also used by adjusting the nucleation barrier to grow large single crystals. $^{14}$

\subsection{Antisolvent Vapor-Assisted Crystallization Method (AVC)}

AVC technique works based on the diffusion process, initially used for the growth of $\mathrm{MAPbX}_{3}$ crystals. $^{5}$ The central basis of this versatile method is choosing an appropriate antisolvent that diffuses into the crystal precursor solution, leading to the growth of high-quality crystals of $\mathrm{MAPbX}_{3}$, as illustrated in Fig. 4 (a, b). Highly soluble and moderately coordinated solvents (DMF) can be considered for MAX and $\mathrm{PbX}_{2}$, along with an antisolvent in which both precursors are entirely insoluble (dichloromethane - DCM). DCM is preferred because it does not form any hydrogen bonding with the precursors and due to its poor solubility, reduces the asymmetric interactions with the ions during the formation of the crystal. Moreover, DCM has a low boiling point, so it can evaporate at room temperature and diffuse easily into precursor DMF solution. Employing this method, high-quality $\mathrm{MAPbBr}_{3}$ and $\mathrm{MAPbI}_{3}$ single-crystals (mm sized) were grown. ${ }^{5,} 59$ This method can be adapted to grow small-sized single-crystals but not large-sized singlecrystals, thus constraining its effective utilization for producing optoelectronic devices.

\subsection{Melt Crystallization Growth Method}

This technique consists of the a) Czochralski and b) Bridgman methods. Usually, organic compounds are chemically unstable at their melting temperature and high vapor pressure. Therefore, the melt crystallization technique is suitable for organic-inorganic halide perovskite materials with a specific melting point. ${ }^{60-61}$ The Bridgman technique is a commonly used method for growing crystals in a sealed ampoule. ${ }^{60,62}$ In this process, a quartz ampoule packed with reactants is sealed under vacuum, and then, a temperature gradient is applied. Later, spontaneous nucleation is induced at the tip of the ampoule at a particular temperature; then, the crystallization front propagates to the molten material. In 2012, $\mathrm{CsSnI}_{3}$

polycrystalline ingots and $\mathrm{CsPbr}_{3}$ single-crystals were prepared using the Bridgman growth method. ${ }^{63}$ The advantages of the Bridgman method are that it is readily implementable, and its interface curvature 
can be adjusted by changing the temperature of the crucible, as illustrated in Fig. $4 \mathrm{~d} .{ }^{47}$ Due to the mechanical stresses inside the crucible induced by contact of the growing crystal, the defect density, and impurity levels may be increased, thus inhibiting the application of these crystals. ${ }^{64}$

\subsection{Droplet-Pinned Crystallization Method}

Ye et al. first reported the droplet-pinned crystallization (DPC) method by growing a $\mathrm{MAPbI}_{3}$ singlecrystal. ${ }^{46}$ In this method, ITO glass is modified with PEDOT: PSS and a smaller piece of the silicon wafer is placed on the modified glass. A precursor solution of $\mathrm{MAPbI}_{3}$ is dropped on the sample. $\mathrm{MAPbI}_{3}$ is dispersed via the evaporation of the solvent. Rectangular $\mathrm{MAPbI}_{3}$ single-crystals are formed upon annealing at $100{ }^{\circ} \mathrm{C}$ for 3 minutes. Employing this method, besides the microscale single-crystals, the single-crystalline thin films can also be produced, as illustrated in Fig. 4c. ${ }^{29}$ The application of thicker single-crystals (mm scale) in a device may lead to a severe charge recombination thereby leading to poor solar cell performance.

\subsection{Solvent evaporation crystallization}

Solvent evaporation is the most typical technique to grow a single crystal. Here crystallization occurs as the solvent slowly evaporates from the precursor solution which is placed in between the two substrates. In 2016, Nguyen et al. first showed the cast-capping method to synthesize $\mathrm{MAPbX}_{3}(\mathrm{X}=\mathrm{I}, \mathrm{Cl}, \mathrm{Br})$ single crystals (Fig. 4e). ${ }^{48}$ Here, the precursor was cast on a substrate at room temperature and capped with another substrate. The obtained single crystals have a lateral size of a few hundred micrometers and thickness on the micrometer scale. However, the formation time of the crystals is comparably higher than all the other techniques. Recently, growth of $\left(\mathrm{FAPbI}_{3}\right)_{0.85}\left(\mathrm{MAPbBr}_{3}\right)_{0.15}$ via the same technique at a higher temperature of $80{ }^{\circ} \mathrm{C}$ was demonstrated to achieve single crystals with lateral sizes of up to $2 \mathrm{~mm}$. ${ }^{11}$ The major challenge with the Huang's methodology is the formation of discrete tiny crystals with non-uniform sizes. Subsequently, a facile roll to roll technique was developed to fabricate inch scale single crystals. The precursor solution was transferred on to the hot substrate $\left(180^{\circ} \mathrm{C}\right)$ using the rolling mold, thereby 
forming the quick crystallization leading to inch scale single crystals ${ }^{65}$ In a similar process, single-crystal plates were also patterned on the charge transporting layers via doctor blading technique and Oswald ripening crystallization process (Fig. 4 f). ${ }^{49}$

\subsection{Vapor-phase epitaxial growth}

In the vapor phase epitaxy, the precursor ions transported to the monocrystalline substrate at a proper temperature, they react to form single crystals. This technique enables us to grow a single crystal as low as monolayers thin. However, the temperatures required for such a high phase pure crystal are usually high. In addition to the high temperatures, the expansion coefficient of the target material should match with the substrate making this technique practically non-viable. Single crystals of $\mathrm{CsPbBr}_{3}$ and $\mathrm{CsSnBr}_{3}$ on $\mathrm{NaCl}$ substrate have been synthesized with lateral dimensions of up to centimeters. ${ }^{66}$ Around the same time centimeter-sized $\mathrm{CsPBr}_{3}$ single crystal on strontium titanate (STO) substrate with good crystallinity and crystal orientation was grown. ${ }^{67}$ All these techniques open up new avenues in the SCPs for various optoelectronic applications.

\section{Ion Migration in Hybrid Perovskites}

(a)
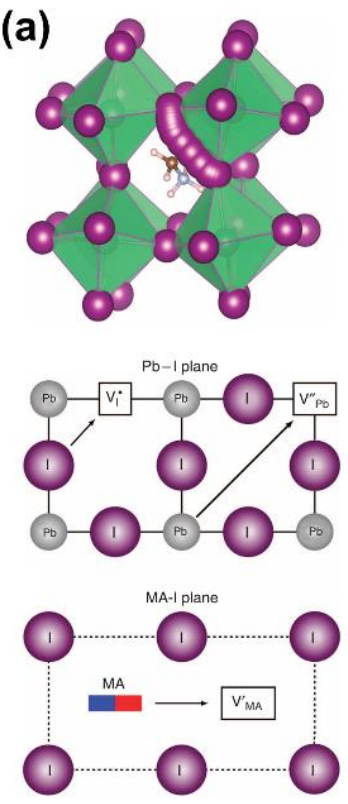

(b)
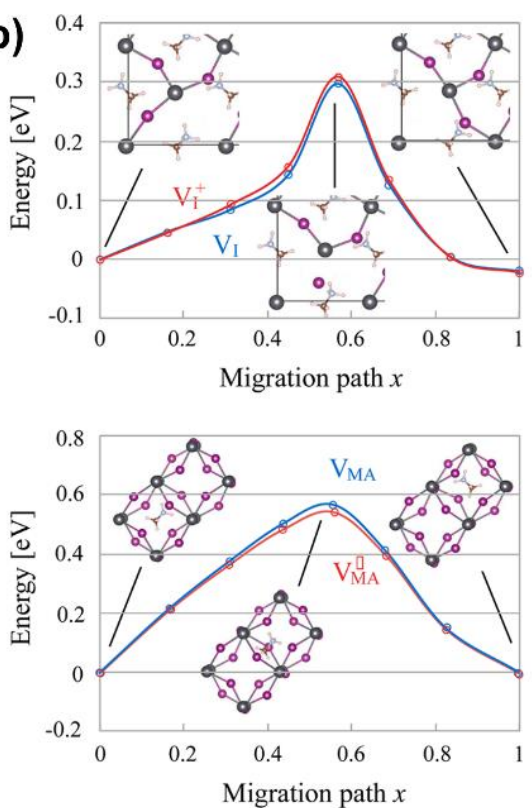

(c)
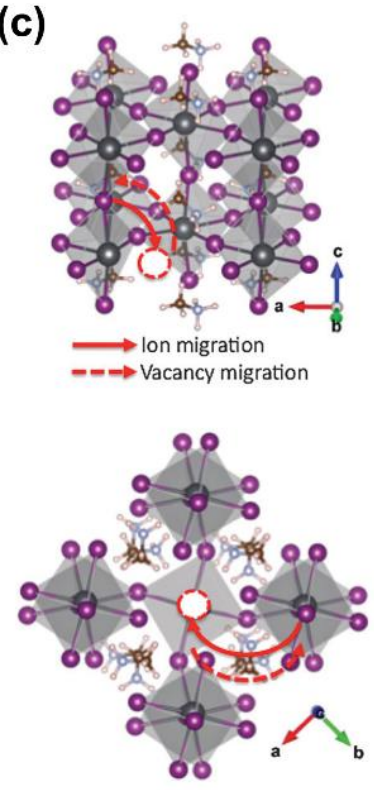
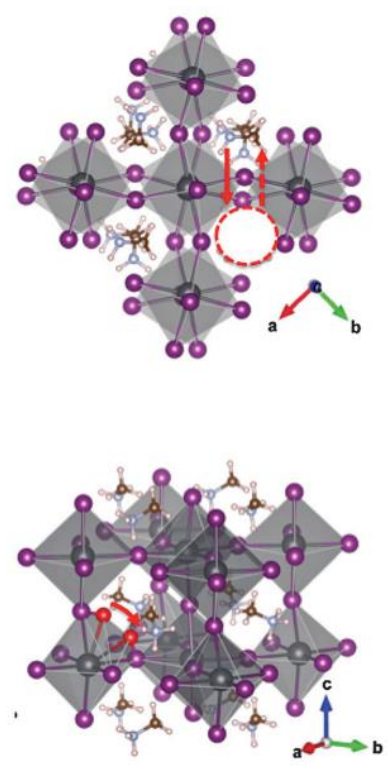

13 | P a g e 
Figure 5. a) Illustration of migration paths and ionic transport mechanisms for $\mathrm{I}^{-}, \mathrm{Pb}^{2+}$, and $\mathrm{MA}^{+}$in $\mathrm{MAPbI}_{3} ; \mathrm{b}$ ) energy profiles along the $\mathrm{V}_{\mathrm{I}}$ and $\mathrm{V}_{\mathrm{MA}}$ migration paths in $\mathrm{MAPbI}_{3}$; and c) diffusion paths for the $\mathrm{V}_{\mathrm{I}}, \mathrm{V}_{\mathrm{MA}}, \mathrm{V}_{\mathrm{Pb}}$ and $\mathrm{I}_{\mathrm{i}}$ defects in $\mathrm{MAPbI}_{3}$. (Reprinted with permission from refs. ${ }^{68-70}$ copyrights 2015 Nature Publishing Group, 2015 American Chemical Society, 2015 The Royal Society of Chemistry).

Recently, the formation energies of ionic defects and activation energies of ion migration for ideal perovskite structures have been theoretically examined based on density functional theory (DFT) and molecular dynamics (MD) calculations. ${ }^{68,69,70,71}$ As summarized in Table 1, Eames et al. obtained the lowest activation energy $E_{\mathrm{a}}$ of $0.58 \mathrm{eV}$ for $\mathrm{I}^{-}$vacancies, a higher $E_{\mathrm{a}}$ value $(0.84 \mathrm{eV})$ for $\mathrm{MA}^{+}$vacancies, and the highest $E_{\mathrm{a}}$ value $(2.31 \mathrm{eV})$ for Pb vacancies using the PBEsol level of theory (Fig. 5a). ${ }^{68}$ They suggested that the $\mathrm{I}^{-}$vacancy is the most mobile species, while $\mathrm{MA}^{+}$and $\mathrm{Pb}^{2+}$ vacancies are likely to be immobile, and such cation diffusion may control the crystal growth processes. They also concluded that the accumulation of $\mathrm{I}^{-}$ions and vacancies at the device interfaces could create hysteresis in the perovskite photovoltaic devices. Tateyama et al. found that I- vacancies can easily diffuse along different crystallographic axes in both $\mathrm{MAPbI}_{3}$ and $\mathrm{FAPbI}_{3}$, with small $E_{\mathrm{a}}$ values of 0.44 and $0.48 \mathrm{eV}$, respectively (see the energy profiles in Fig. 5b). ${ }^{69}$ They also found that $\mathrm{MA}^{+}$and $\mathrm{FA}^{+}$cations have rather low migration barriers, with $E_{\mathrm{a}}$ values of 0.57 and $0.61 \mathrm{eV}$, respectively, indicating that the organic cations can also migrate in the hybrid perovskite materials when applying an external electric field.

Meanwhile, Azpiroz et al. obtained much lower $E_{\mathrm{a}}$ values $(0.16 \mathrm{eV})$ for both I vacancies and interstitials, a significantly lower $E_{\mathrm{a}}$ value $(0.80 \mathrm{eV})$ for $\mathrm{Pb}^{2+}$ vacancies, but a comparable $E_{\mathrm{a}}$ value $(0.46)$ for $\mathrm{MA}^{+}$ vacancies at the PBE level of theory (see the migration paths shown in Fig. $5 \mathrm{c}){ }^{70}$ They concluded that $\mathrm{I}^{-}$ vacancies migrate on very short time scales (less than $1 \mu \mathrm{s}$ ), too fast to explain the slow response (several seconds) of PSCs, while $\mathrm{MA}^{+}$and $\mathrm{Pb}^{2+}$ vacancies should be responsible for the slow response inherent to 
perovskites. Subsequently, Delugas et al. also showed low $E_{\mathrm{a}}$ values for I- vacancy diffusion $(0.10 \mathrm{eV})$ and interstitial diffusion $(0.24 \mathrm{eV})$ using molecular dynamics (MD) simulations, indicating that $\mathrm{I}^{-}$vacancy diffusion is the preferred ion diffusion pathway. ${ }^{71}$

Yang et al. obtained $E_{\mathrm{a}}$ values for I-vacancies $(0.26 \mathrm{eV})$ and interstitials $(0.19 \mathrm{eV})$ as well as $E_{\mathrm{a}}$ values for $\mathrm{MA}^{+}$vacancies $(0.62 \mathrm{eV})$ and interstitials $(0.38 \mathrm{eV})$ suggesting favorable $\mathrm{I}^{-}$and $\mathrm{MA}^{+}$interstitial and vacancy movement in $\mathrm{MAPbI}_{3}{ }^{72}$ Recently, both Meloni et al. and Pazoki et al. found that both $\mathrm{MA}^{+}$and $\mathrm{Pb}^{2+}$ cation vacancies have much larger $E_{\mathrm{a}}$ values (by more than $1 \mathrm{eV}$ ) than I vacancies $(0.37-0.45 \mathrm{eV}) .^{73-}$ ${ }^{74}$ Very recently, we found that the transition energy barrier for $\mathrm{Br}^{-}$migration through vacancies within the bulk phase is lower in $\mathrm{MAPbBr}_{3}$ than in $\mathrm{FAPbBr}_{3}$ and $\mathrm{FAPbBr}$ has a much higher rotation barrier of the organic cation than $\mathrm{MAPbBr}_{3}$ due to the stronger hydrogen bonding with $\mathrm{Br}$ atoms in $\mathrm{FAPbBr}_{3}{ }^{75}$

Table 1. Summary of defect activation energies (in eV) of bulk $\mathrm{MAPbI}_{3}$ obtained by theoretical calculations.

\begin{tabular}{ccccccc}
\hline $\begin{array}{c}\text { Theoretical } \\
\text { Methods }\end{array}$ & $\begin{array}{c}\text { Theoretical } \\
\text { Code and Level }\end{array}$ & $\begin{array}{c}\text { I } \\
\text { Vacancy }\end{array}$ & $\begin{array}{c}\text { I } \\
\text { Interstitial }\end{array}$ & $\begin{array}{c}\text { MA } \\
\text { Vacancy }\end{array}$ & $\begin{array}{c}\text { Pb } \\
\text { Vacancy }\end{array}$ & Ref. \\
\hline DFT & VASP (PBEsol) & 0.58 & -- & 0.84 & 2.31 & 68 \\
\hline DFT & QE (PBE+vdW) & 0.44 & -- & 0.57 & -- & 69 \\
\hline DFT & QE (PBE) & 0.16 & 0.16 & 0.46 & 0.80 & 70 \\
\hline MD & DLPOLY & 0.10 & 0.24 & -- & -- & 71 \\
\hline DFT & VASP (PBE) & 0.26 & 0.19 & 0.62 & -- & 73 \\
\hline DFT & CPMD (PBE) & 0.45 & -- & 1.12 & 1.39 & 74 \\
\hline DFT & QE (PBE) & 0.37 & -- & 1.14 & 1.37 & 72 \\
\hline
\end{tabular}

Overall, the calculated $E_{\mathrm{a}}$ values are sensitive to the underlying theoretical methods but are within the range of 0.1-0.6 eV for I- vacancies and interstitials, the range of $0.5-1.2 \mathrm{eV}$ for $\mathrm{MA}^{+}$vacancies and 15 | P a g e 
interstitials and $>1 \mathrm{eV}$ for $\mathrm{Pb}^{2+}$ vacancies, suggesting that both the halide anion and the organic cation can migrate. It should be noted that in perovskite thin films, other factors, such as dynamical disorder and grain boundaries, can also affect the ion migration since hybrid perovskites can easily deviate from their ideal bulk structure. Even though the formation of defects can be largely suppressed in the perovskite single crystals, we cannot fully avoid ion migration processes in their solar cell devices. Since DFT calculations on the ion migrations were performed in the single-crystal structures of bulk hybrid perovskites, the obtained conclusion on the calculated activation energies can be used to understand the hysteresis phenomena in the perovskite single crystal-based devices, and the same computational methods can be used to understand the ion migrations of new hybrid perovskite single crystals.

\section{Chemical Stability of Perovskites}

Commercially viable PSCs technology suffers from two main challenges: achieving high PCE and achieving device stability. ${ }^{76}$ Currently, research has focused on improving the PCE of the devices by focusing on fabrication methods, device structures, and other various parameters. However, the application of PSCs is limited by the stability constraints, to overcome this hurdle, research has to be directed towards improving the stability of the devices for outdoor and industrial applications. The main factor that affects the stability of PSCs is the chemical stability, which varies under different atmospheric conditions. ${ }^{76}$ As a typical case, the chemical stability of a perovskite, methylammonium lead iodide, is shown in equation (1):

$$
\mathrm{PbI}_{2}(\mathrm{~s})+\mathrm{CH}_{3} \mathrm{NH}_{3} \mathrm{I}(\mathrm{aq}) \leftrightarrow \mathrm{CH}_{3} \mathrm{NH}_{3} \mathrm{PbI}_{3}(\mathrm{~s})(1)
$$

The synthetic process is indicated by the forward arrow, and the decomposition of the perovskite is illustrated by the backward arrow. Other perovskites, such as $\mathrm{CH}_{3} \mathrm{NH}_{3} \mathrm{PbBr}_{3}$ and $\mathrm{CH}_{3} \mathrm{NH}_{3} \mathrm{PbCl}_{3}$, exhibit similar reactions. Generally, nanostructures and thin films can be stabilized by surface ligand functionalization at the time of direct solution growth at room temperature. ${ }^{77}$ In sharp contrast, in the case of single crystals, these surface ligands cannot be incorporated to stabilize their surface. The perovskite 
single crystals solar cells are been intercepted from commercialization because of their sensitivity towards the following factors: oxygen and moisture, light, and thermal conditions.

\subsection{Oxygen and moisture}

The stability of perovskite single-crystal is severely affected by oxygen and moisture in the atmosphere. For instance, consider the reaction of the perovskite $\mathrm{CH}_{3} \mathrm{NH}_{3} \mathrm{PbI}_{3}$ with oxygen, which is shown below.

$$
\begin{aligned}
& \mathrm{CH}_{3} \mathrm{NH}_{3} \mathrm{I}(\mathrm{aq}) \leftrightarrow \mathrm{CH}_{3} \mathrm{NH}_{2}(\mathrm{aq})+\mathrm{HI}(\mathrm{aq})(2 \mathrm{~b}) \\
& 4 \mathrm{HI}(\mathrm{aq})+\mathrm{O}_{2}(\mathrm{~g}) \leftrightarrow 2 \mathrm{I}_{2}(\mathrm{~s})+2 \mathrm{H}_{2} \mathrm{O}(\mathrm{l})(2 \mathrm{c}) \\
& 2 \mathrm{HI}(\mathrm{aq}) \leftrightarrow \mathrm{H}_{2}(\mathrm{~g})+\mathrm{I}_{2}(\mathrm{~s})
\end{aligned}
$$

Upon perovskite exposure to moisture, $\mathrm{CH}_{3} \mathrm{NH}_{3} \mathrm{PbI}_{3}$ coordinates with $\mathrm{H}_{2} \mathrm{O}$ molecule to form an intermediate complex $\left[\left(\mathrm{CH}_{3} \mathrm{NH}^{3+}\right)_{\mathrm{n}-1}\left(\mathrm{CH}_{3} \mathrm{NH}_{2}\right)_{\mathrm{n}} \mathrm{PbI}_{3}\right]\left[\mathrm{H}_{3} \mathrm{O}\right]$ and subsequently degrades the perovskite. Importantly, $\mathrm{MAPbI}_{3}$ suffer serious degradation by the incorporation of water molecules into the crystal structure, where they form weak hydrogen bonds with the highly hygroscopic methylammonium cations, causing bond dissociations between the crystal constituents. ${ }^{67,78-80}$ Moreover the degradation can also be initiated by the deprotonation of the methylammonium cation of the perovskite by a photogenerated reactive oxygen species (superoxide, $\mathrm{O}^{2-}$ ) where the $\mathrm{O}^{2-}$ is generated by the reaction of photo-generated electrons in the perovskite and molecular oxygen. ${ }^{81}$ Until now, the application of $\mathrm{MAPbI}_{3}$ has focused on polycrystalline films; compared with SCPs, the high density of defects and grain boundaries in the thin films reduces the performance of the perovskites. ${ }^{82}$ The intriguing properties such as the low defect densities and absence of grain boundaries that act as recombination centers, makes single-crystal perovskites both superior moisture and thermal stability thereby preserving the chemical structure and properties in the air for a long time. ${ }^{67}$ Intriguingly, the component $\mathrm{CH}_{3} \mathrm{NH}_{3} \mathrm{~Pb}\left(\mathrm{I}_{1-\mathrm{x}} \mathrm{Br}_{\mathrm{x}}\right)_{3}$ showed stability when exposed to $55 \%$ humidity for almost 20 days and exhibited an excellent power conversion efficiency. ${ }^{83}$ Single-crystal $\mathrm{MAPbI}_{3}$-based PSCs, demonstrated almost no degradation in the open ambient at $30 \%$ humidity and $23{ }^{\circ} \mathrm{C}$ in the dark for a month, exhibiting superior stability than polycrystalline thin- 
film solar cells. ${ }^{84}$ Moreover, even after being aged in the dark air for 1000 hours the PSCs device manifested $93 \%$ PCE of the initial PCE. ${ }^{40}$

\subsection{Light}

The migration of ionic defects (such as vacancies or interstitials) is the most common process in

perovskite solar cells, which induces the experimental hysteresis and switchable photovoltaic effects. ${ }^{85-86}$

Fig. 5a illustrates several primary ion migration paths between neighboring positions in $\mathrm{MAPbI}_{3}$, including i) methylammonium $\left(\mathrm{MA}^{+}\right)$ions migrating to the vacant cage, ii) lead ions $\left(\mathrm{Pb}^{2+}\right)$ migrating along the diagonal (110) direction, and iii) iodine ions $\left(\mathrm{I}^{-}\right)$moving along an octahedron. ${ }^{68}$ The interactions between the organic cations and the inorganic framework act as a barrier for ionic migration, resulting in the variation of activation energy $\left(E_{\mathrm{a}}\right)$. Generally, ion migration is considerably improved under sun illumination in the polycrystalline films. ${ }^{25,87}$ In the case of $\mathrm{MAPbI}_{3}$ single crystal, a similar trend was observed where Ea of ion migration under illumination was declined to $0.33 \mathrm{eV}$ from $0.83 \mathrm{eV}$ in dark conditions. A constant slope with a Ea of $25 \pm 3 \mathrm{meV}$ obtained in quasi-2D $\mathrm{BA}_{2} \mathrm{MA}_{2} \mathrm{~Pb}_{3} \mathrm{I}_{10}$ single-crystal film screening that ion migration along the in-plane direction has been reduced. ${ }^{8}$ So, the reduction of vacancy defects and the absence of ion migration leads to the efficient and stabilized perovskite singlecrystal electronic devices.

\subsection{Temperature}

The operating temperature is crucial for perovskite device performance. In perovskites, thermally induced phase transitions are commonly observed. The optical and charge transport properties of perovskites are phase-dependent and hence the application of perovskite in the devices is challenging. Generally, at the grain boundaries decomposition occurs at low temperatures but elevated at higher temperatures because of the contaminants that are stored in the grain boundaries. It was recently reported that $\mathrm{FAPbI}_{3}$ single crystal and wafer are able to withstand higher temperatures compared to polycrystalline thin films counterparts. ${ }^{37,89}$ Although these single-crystals show good photoelectric properties, they have 
poorer thermal stability compared to completely inorganic perovskites ${ }^{82}$ due to the presence of volatile organic moieties. Therefore, highly thermostable optoelectronic properties are exhibited by the allinorganic SCPs.

\section{Surface and Interface in Hybrid Perovskites}

(a)

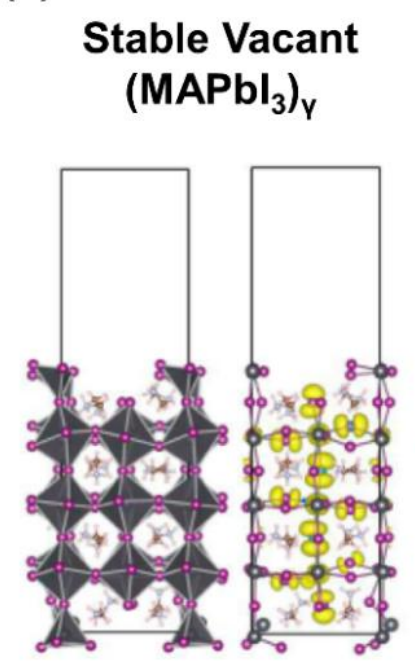

$\mathrm{Pbl}_{2}$-rich flat
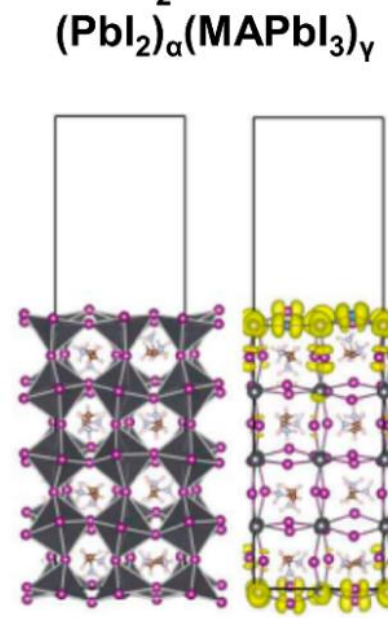

(b)

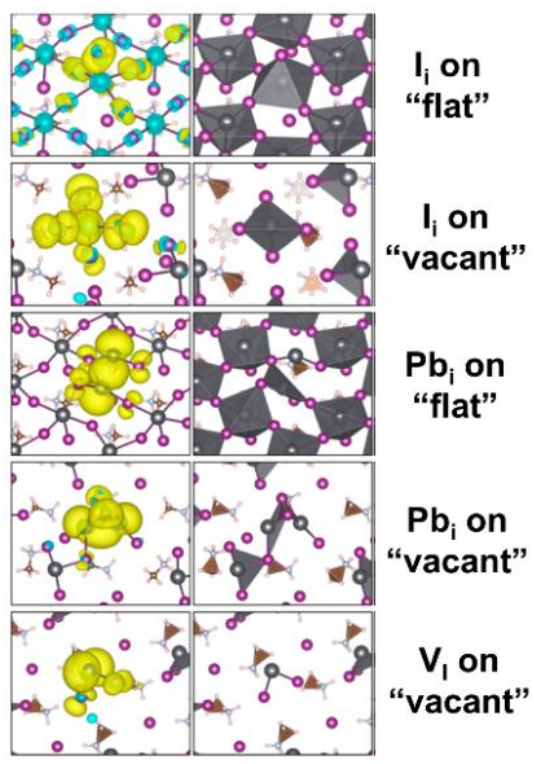

Figure 6. a) Charge density distribution for the valence band maximum of the $\mathrm{MAPbI}_{3}(001)$ surface with stable vacant and $\mathrm{PbI}_{2}$-rich terminations. b) Charge density distribution for an iodine interstitial $\left(\mathrm{I}_{\mathrm{i}}\right)$ on flat and vacant surfaces, a lead interstitial $\left(\mathrm{Pb}_{\mathrm{i}}\right)$ on flat and vacant surfaces, and an iodine vacancy $\left(\mathrm{V}_{\mathrm{I}}\right)$ on a vacant surface. (Reprinted with permission from refs. ${ }^{90-91}$ copyrights 2014, 2017 American Chemical Society).

In perovskite-based optoelectronic devices, although bulk electronic and optical properties of perovskites are a prerequisite for good photovoltaic performance, surface termination and passivation are also crucial for achieving efficient carrier transport and charge extraction. Haruyama et al. studied the structural stability and electronic states of the tetragonal-phase $\mathrm{MAPbI}_{3}$ (110), (001), (100), and (101) surfaces with different terminations using DFT calculations at the GGA/PBE level of theory (Fig. 6a). ${ }^{90}$ They found that both vacant and flat terminations can appear on the probable $\mathrm{MAPbI}_{3}(110)$ and (001) 
surfaces, and these two stable surfaces with vacant and $\mathrm{PbI}_{2}$-rich terminations can maintain the electronic features of bulk $\mathrm{MAPbI}_{3}$, leading to the long carrier lifetime observed in PSCs. Moreover, they found that the shallow surface states on the $\mathrm{MAPbI}_{3}(110)$ and (001) surfaces can become efficient intermediates for hole transfer. Later, Uratani et al. investigated the structural and electronic properties of various terminations (i.e., MAI, flat and vacant) of the tetragonal-phase $\mathrm{MAPbI}_{3}$ surfaces under different growth conditions using DFT calculations (Fig. 6b). ${ }^{91}$ They found that i) under I-rich conditions, the extra I atoms on flat and vacant surfaces can act as carrier trapping centers; ii) under Pb-rich conditions, I vacancies on vacant surfaces and excessive $\mathrm{Pb}$ atoms on both flat and vacant surfaces become carrier traps, under $\mathrm{Pb}$ rich conditions, the formation of carrier trapping surface defects is thermodynamically less favorable than under I rich conditions; and iii) under moderate conditions, no surface defects easily form due to their high formation energy. Based on these findings, they suggested that reducing the surface carrier trapping centers can improve the carrier lifetime and avoid hysteresis.

The surface properties of perovskite materials affect the electronic processes at the interfaces when they are combined with other charge-transporting semiconductors in optoelectronic devices. Precisely, the electronic band edge energies and their matching with hole/electron-transporting materials should be adjusted to promote efficient charge injection/extraction. Density functional theory (DFT) and molecular dynamics (MD) simulations have been applied to study the interfacial energy alignment and charge transfer properties at perovskite/organic interfaces. Mosconi et al. studied the effect of surface chlorine atoms on the morphology and electronic structure of perovskite (110) and (001) surfaces at the interface with anatase $\mathrm{TiO}_{2}$ using DFT calculations (Fig. 7a-b). ${ }^{92}$ They found that i) both $\mathrm{MAPbI}_{3}$ and $\mathrm{MAPbI}_{3-\mathrm{x}} \mathrm{Cl}_{\mathrm{x}}$ (110) surfaces tend to grow on $\mathrm{TiO}_{2}$ with higher stability than (100) surfaces due to the better structural matching between the surface $\mathrm{I} / \mathrm{Cl}$ atoms of the perovskites and $\mathrm{Ti}$ atoms of $\mathrm{TiO}_{2}$; ii) interfacial $\mathrm{Cl}$ atoms can increase the binding energy of the $\mathrm{MAPbI}_{3-\mathrm{x}} \mathrm{Cl}_{\mathrm{x}}$ (110) surface to $\mathrm{TiO}_{2}$ compared to the case of $\mathrm{MAPbI}_{3}$, contributing to enhanced temporal stability of the solar cell devices; and iii) the interaction of 
the $\mathrm{MAPbI}_{3-\mathrm{x}} \mathrm{Cl}_{\mathrm{x}}$ perovskite with $\mathrm{TiO}_{2}$ modifies the interface electronic structure, leading to a stronger interfacial coupling between the $d$-band of $\mathrm{Ti}$ atoms and $p$-band of $\mathrm{Pb}$ atoms, thus favoring efficient electron injection. The theoretical results by Yin et al. showed that both hole interfacial transfer and electron interfacial transfer depend strongly on the $\mathrm{MAPbI}_{3}$ surface orientation: the nonpolar $\mathrm{MAPbI}_{3}$ (001) and (110) surfaces tend to favor hole injection into Spiro-OMeTAD and the polar MAPbI 3 (100) surface tends to facilitate electron transfer to PCBM due to the largely delocalized surface states and orbital coupling (Fig. 7c).

(a)

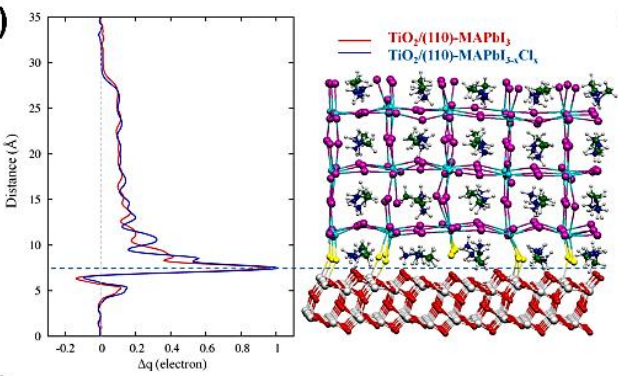

(b)
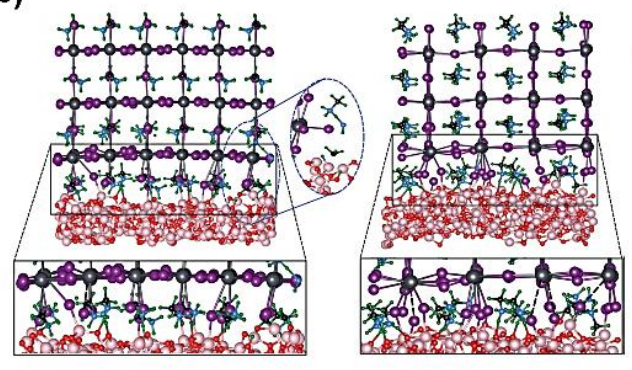

(c)

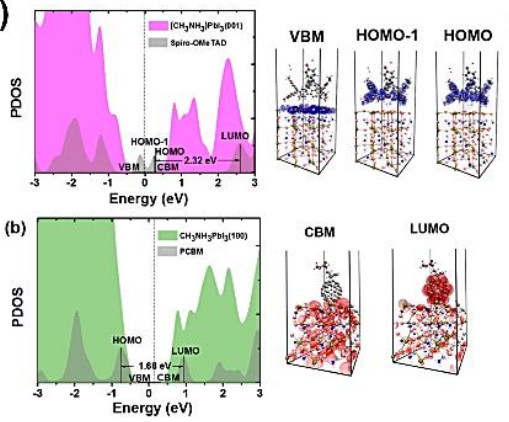

(d)

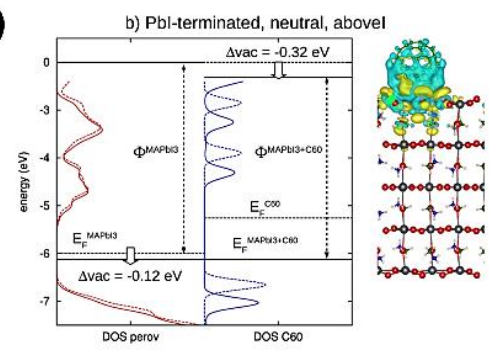

(e)
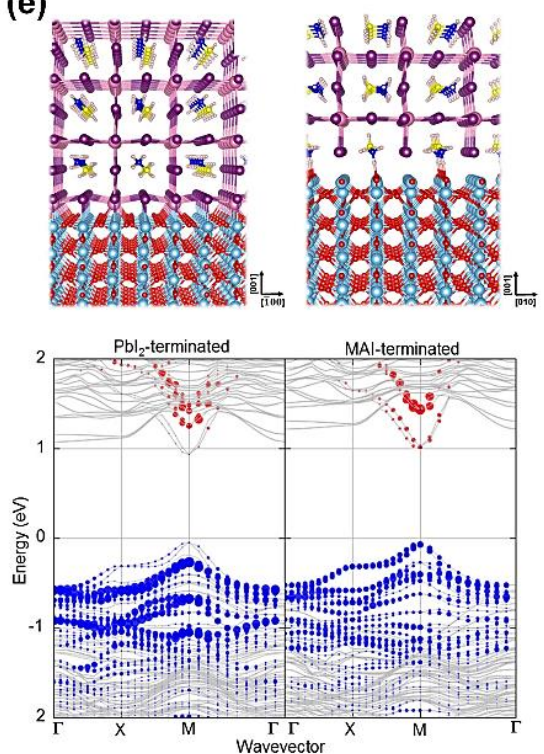

Figure 7. a) Interfacial structure and charge displacement of a $\mathrm{TiO}_{2} /$ perovskite interface. b) Optimized structures of the $\mathrm{MAPbI}_{3}$ (001) and (110) surfaces on amorphous alumina. c) The density of states and charge density of a Spiro-OMeTAD molecule on the $\mathrm{MAPbI}_{3}(001)$ surface and a PCBM molecule on the $\mathrm{MAPbI}_{3}$ (100) surface. d) The density of states, electronic levels and electronic density of MAI-terminated $\mathrm{MAPbI}_{3} / \mathrm{C}_{60}$. e) Interfacial structures and band structures of $\mathrm{PbI}_{2}$ - and $\mathrm{MAI}$-terminated $\mathrm{MAPbI}_{3}(001)$ and $\mathrm{TiO}_{2}$. (Reprinted with permission from refs. ${ }^{92-96}$ copyrights $2014,2015,2017,2018$ American Chemical Society, 2017 The Royal Society of Chemistry). 
Claudio et al. reported a DFT study of the energetics and electronic properties of $\mathrm{MAPbI}_{3}$ surfaces and clarified the dependence of the valence band and conduction band energies on both the MA cation orientations and surface terminations (i.e., $\mathrm{PbI}_{2}$ and MAI terminations, as given in Fig. $7 \mathrm{~d}$ ). ${ }^{95}$ They demonstrated that $\mathrm{MAPbI}_{3}$ with exposed MAI-rich layers is more thermodynamically stable than $\mathrm{PbI}_{2}-$ terminated surfaces and features a more favorable energy level alignment for electron extraction using fullerene electron-transporting materials. Recently, Myung et al. studied two inorganic/organic perovskite solar cell interfaces, $\mathrm{Gr} / \mathrm{CsPbI}$ and $\mathrm{TiO}_{2} / \mathrm{MAPbI}_{3}$ (Fig. 7e). ${ }^{96}$ They showed that a $\mathrm{PbI}_{2} / \mathrm{MAI}$-terminated perovskite interfaced with graphene or $\mathrm{TiO}_{2}$ exhibits sizable/robust Rashba-Dresselhaus (RD) effects using DFT and ab initio molecular dynamics (AIMD) simulations. They also suggested that robust RD effects at the interface, even at high temperatures, can change the direct-type band to an indirect-type band to suppress the recombination of electrons and holes, which makes the accumulated carriers overcome the potential barrier between the single crystal perovskite and charge-transfer materials.

Therefore, the DFT calculations on the interfacial structures suggest that controlling perovskite crystallization and surface orientation should be considered in designing the active layer formed by the perovskite single crystals and other charge transporting materials. Based on this, we propose that the surface terminations of perovskite single crystals with different functional organic groups could provide additional routes to optimize the photovoltaic performance of perovskite single crystal-based solar cells. From experimental point of view, more efforts are demanded in achieving the perovskite single crystals with sole crystal orientation by using solution-processed crystal growing method; and from theoretical point of view, the modified interfacial crystal models and advanced DFT methods $(e . g .$, the combination of spin-orbit coupling and hybrid functionals) are needed to understand the charge transfer processes between perovskite single crystal and other novel charge transporting materials.

\section{Charge Carrier Dynamics of Perovskite Single-crystals}


It is crucial to consider the carrier lifetime of a device before designing it. The recombination of free electrons and holes occurs after the material is excited by photons to an excited state. ${ }^{97}$ There are two types of recombination: radiative recombination and nonradiative recombination. In radiative recombination, the electron and hole recombine to emit a photon, whereas, in nonradiative recombination, photon emission does not occur, as the trap will induce carrier recombination. ${ }^{97}$ The carrier lifetime can be expressed as

$$
1 / \tau=1 / \tau_{\mathrm{r}}+1 / \tau_{\mathrm{nr}}
$$

Where $\tau$ is the carrier lifetime, $\tau_{\mathrm{r}}$ is the radiative lifetime and $\tau_{\mathrm{nr}}$ is the nonradiative lifetime. ${ }^{98}$
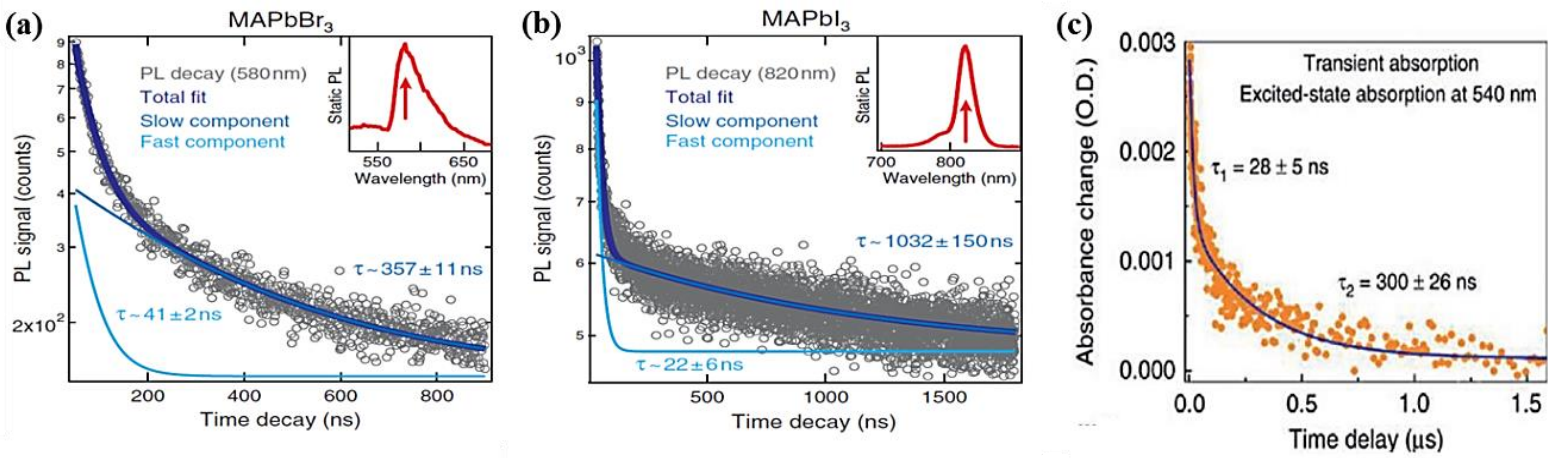

(d)

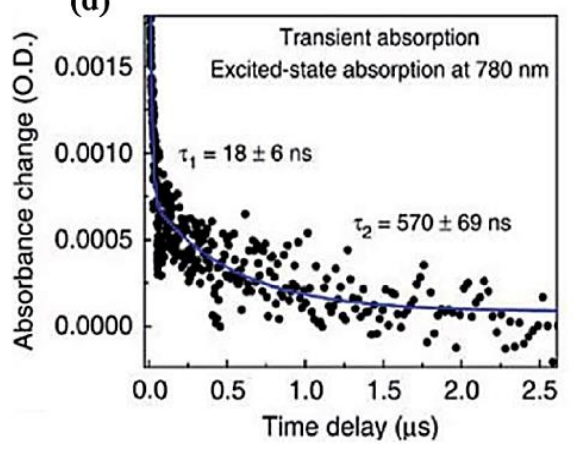

(e)

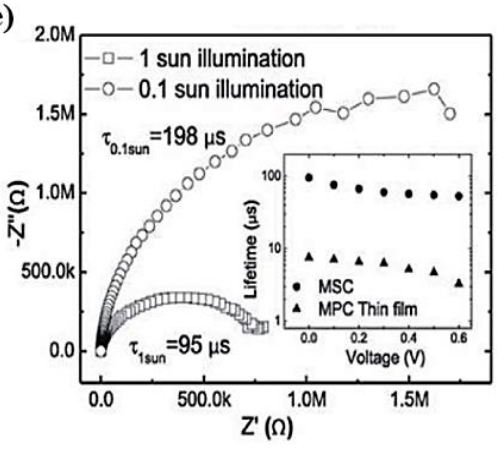

(f)

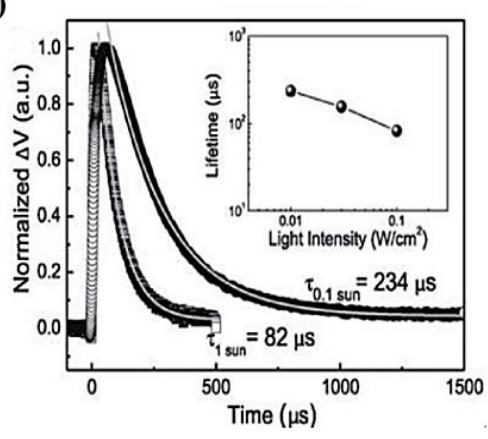

Figure 8. Different ways to determine the carrier mobility and carrier diffusion length of perovskite single-crystals. (a, b) Photoluminescence decay. (Reprinted with permission from ref. 5 copyright 2015 American Association for the Advancement of Science). (c, d) transient absorption. (Reprinted with permission from ref. 4 copyright 2015 Nature Publishing Group). (e, f) Impedance and transient photovoltage decay curve ref. 4. (Reprinted with permission from ref. ${ }^{6}$ copyright 2015 American Association for the Advancement of Science). 
As shown in Fig. 8 (a-e), photo decay, absorption, luminescence transient decay, transient photovoltage, and impedance curves have been measured in single-crystalline perovskites. ${ }^{4-5,36}$ For a single-crystal, fewer trap states exist when it has a long carrier lifetime. ${ }^{99-101}$

$$
L_{D}=\sqrt{k T} \mu \tau / q
$$

The above equation indicates that the carrier diffusion length is determined by the carrier lifetime and carrier mobility, ${ }^{78,101,50}$ where $k$ is the Boltzmann constant, $\mathrm{T}$ is the absolute temperature, and $q$ is the elementary charge. The carrier diffusion length in solar cells was calculated by the Huang et al. as 175 $\mu \mathrm{m}$ for $\mathrm{MAPbI}_{3}$ single-crystals with the help of impedance and transient photovoltaic measurements under 1 sun illumination. ${ }^{50}$ However, acute charge accumulation occurs in typical bulk SCPs unlike thin-film SCPs having a thickness in the order of diffusion length of the carriers.

Table 2. Optoelectronic parameters of single-crystalline perovskites reported in the literature. ${ }^{102}$ 


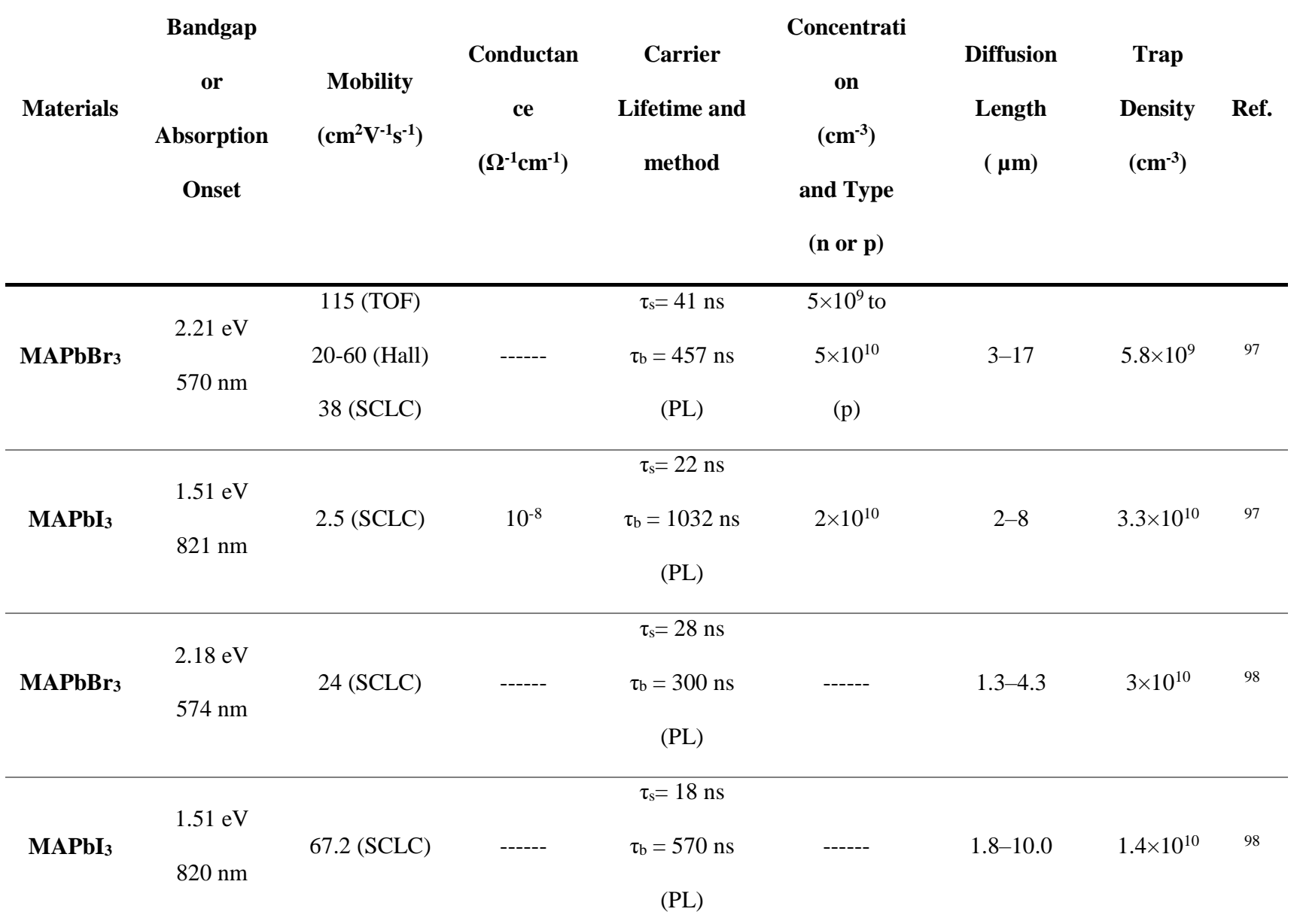

$164 \pm 25$

hole mobility

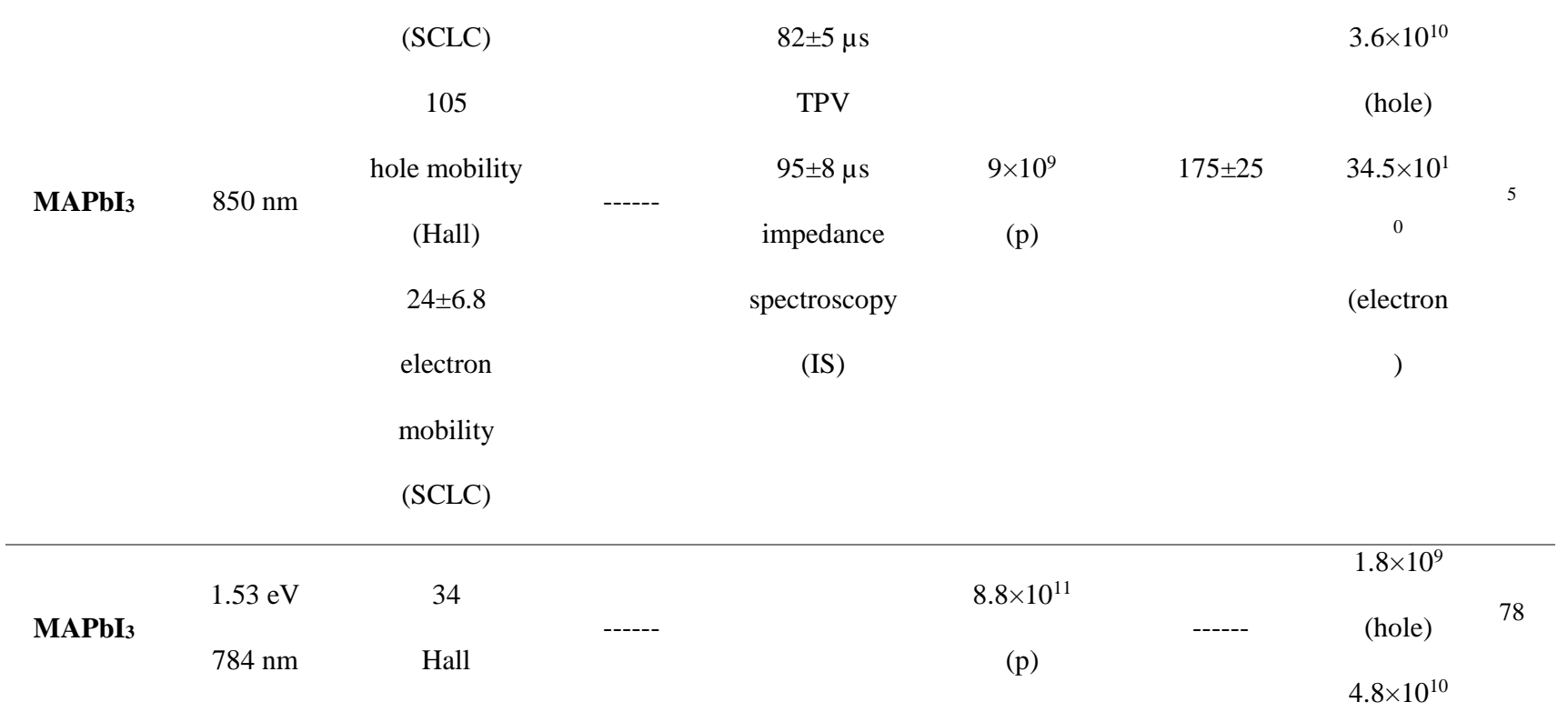




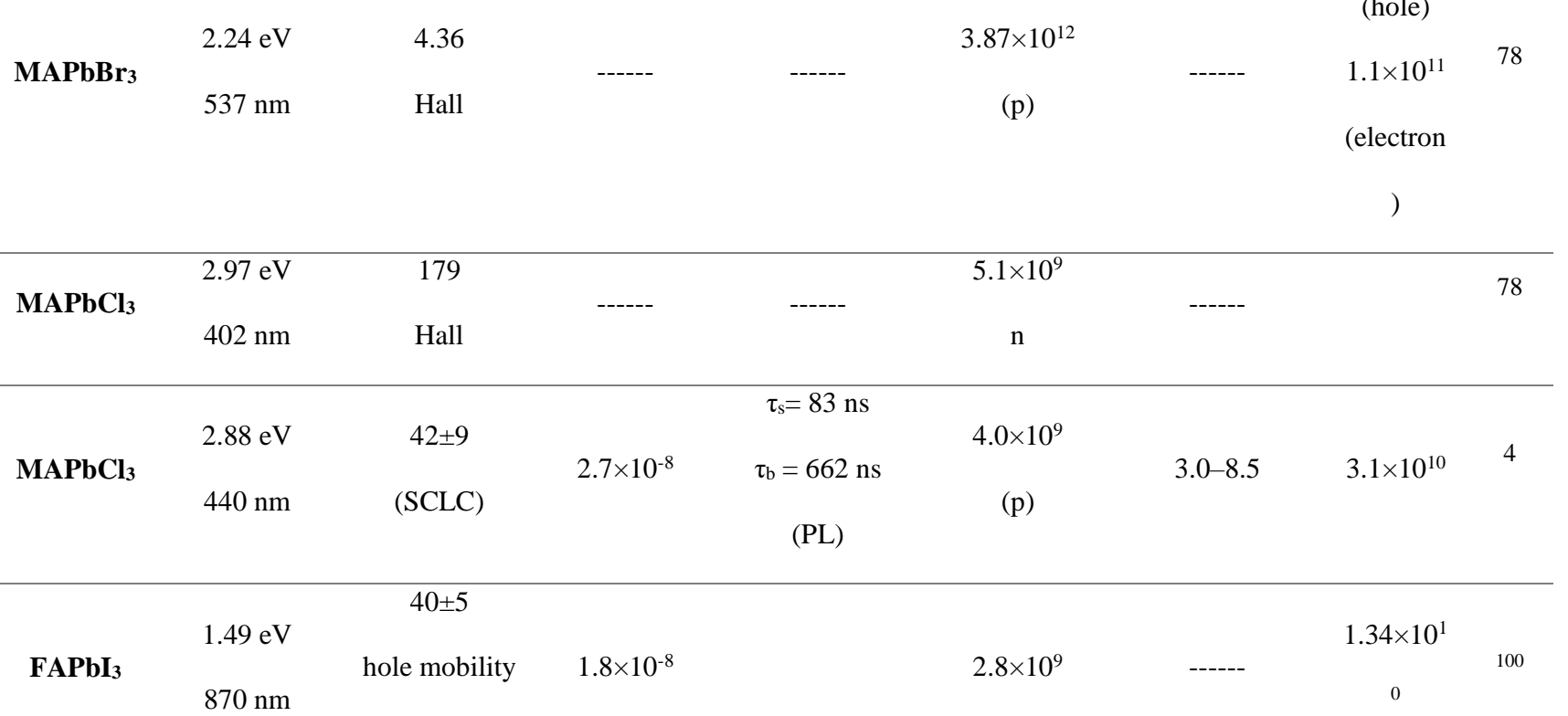

(SCLC)

In summary, to achieve an efficient PSCs that reaches the Shockley-Queisser limit, there is a need to manifest a clear idea about the factors that explicitly influence the potential of the material to be used for fabrication. It is crucial to consider the charge carrier's diffusion length, lifetime and mobility in a material.

The single-crystal perovskite endows long diffusion length of charge carriers which depends on the film morphology and crystallinity. Moreover, the long-range ordered patterned in perovskite single crystal lattice unlike polycrystalline thin fim considerably decrease surface defects and charge carrier trapping. Since there are no grain boundaries on the other hand, present in the single-crystal unlike extensively disordered polycrystalline perovskite, charge recombination loss of these devices will be minimum.

\section{Light Emitting Devices based on Perovskite Single Crystals}

The first single-crystal $\mathrm{MAPbBr}_{3}$ micro platelet-based LED with device configuration ITO/PVK/Au, supported a continuous operation for $54 \mathrm{~h}$ at $\sim 5000 \mathrm{~cd} \mathrm{~m}^{-2}$ without degradation of brightness, by quenching the ionic movement at a low temperature. ${ }^{103}$ By tuning the halide composition in solution- 
processed organometal halide perovskites, the LEDs with high-brightness are accomplished. ${ }^{21}$ Expanding on this study, light-emitting electrochemical cells (LECs) are developed using $\mathrm{CH}_{3} \mathrm{NH}_{3} \mathrm{Br}_{3}$ single crystals, are exhibited a stable luminance. ${ }^{104}$ The LED device based large area $(\mathrm{cm}$-scale) 2D layered $\mathrm{Pb}$-free $\left(\mathrm{CH}_{3} \mathrm{NH}_{3}\right)_{2} \mathrm{MnCl}_{4}$ single crystals, exhibited good red-light luminescence properties, with a $\mathrm{QE}$ of $2.4 \%$ upon excitation at $417 \mathrm{~nm}$ and are proposed to be used for white light lighting. ${ }^{105}$

The random orientations in polycrystalline perovskite films hinder the coherent light emission. To overcome the drawback of polycrystalline film, single-crystal perovskite has been introduced in the fabrication of electroluminescent devices. Recently, highly stable inorganic single-crystalline perovskite nanoplatelets $\mathrm{CsPbX}_{3}\left(\mathrm{X}=\mathrm{Cl}^{-}, \mathrm{Br}^{-}, \mathrm{I}^{-}\right)$synthesized by chemical vapor deposition were demonstrated for the tunable high-quality laser covering entire visible regime at the room temperature. ${ }^{106}$ The wavelength-tunable lasing at room-temperature with very low lasing thresholds $\left(220 \mathrm{~nJ} \mathrm{~cm}{ }^{-2}\right)$ and highquality factors $(Q \sim 3,600)$ was demonstrated from single-crystal lead halide perovskite nanowires. ${ }^{107}$ In the hybrid MHPs, the perovskites with formamidinium have shown superior properties over the methyl ammonium ones, for the development of continuous-wave lasers and light-emitting diodes. ${ }^{108}$ Single crystalline nanowires of $\mathrm{CsPbr}_{3}$ showed the robust and stable lasing emission with no visible degradation after at least $8 \mathrm{~h}$ or $7.2 \times 10^{9}$ laser shots under continuous illumination. ${ }^{109}$

The $\mathrm{CH}_{3} \mathrm{NH}_{3} \mathrm{PbI}_{3}$ layers processed via solution-casting in ambient atmosphere onto nano-imprinted second-order Bragg gratings initially exhibited highly polarized surface-emitted lasing at room temperature with a linewidth of less than $0.2 \mathrm{~nm}$ and a laser threshold of $120 \mathrm{~kW} / \mathrm{cm} .{ }^{2,110}$ Later numerous groups also have reported striking ultra-stable amplified lasing applications at various temperatures using single crystal thin film perovskites. ${ }^{111-112}$

\section{Photodetector Applications}

Photodetectors are one of the widely known applications of MHPs, which primarily convert light signals into electrical signals and have found many potential applications in various fields. ${ }^{113-116}$ SCP 
Photodetectors owing to their striking optoelectronic properties have more advantages compared to their counterparts, i.e., polycrystalline films, leading to worldwide interest in single-crystal MHP-based photodetectors. $^{4,117-118}$

Photodetectors have been divided into various types of devices based on their layer composition, as illustrated in Fig. 9, including into two-terminal and three-terminal devices referred to as photodiodes, photoconductors, and phototransistors with source, drain and gate electrodes. ${ }^{119-120}$

In recent years, perovskites have exhibited exemplary performances as photodetectors. ${ }^{77,121-122}$ The faster photo responsive photodetectors were fabricated using single-crystalline perovskites grown by various methods. ${ }^{44,123,117}$ The $\mathrm{MAPbI}_{3}$ film-based solution-processed photodetector was shown to exhibit the broad photoresponse in the range from $310 \mathrm{~nm}$ to $780 \mathrm{~nm} \cdot{ }^{124-125}$ Moreover, the $\mathrm{MAPbI}_{3}$ single-crystal thin films were also used in the high energy X-ray detectors that could detect X-rays with high sensitivity and responsivity. ${ }^{126}$ Comparative studies were carried out on the scintillation properties of threedimensional (3D) $\mathrm{MAPbI}_{3}$ and $\mathrm{MAPbBr}_{3}$ and two-dimensional (2D) (EDBE) $\mathrm{PbCl}_{4}$ low-bandgap perovskite single-crystal using the X-ray excited thermoluminescence measurements. ${ }^{127}$

These devices can be compared by considering their properties and photo responsive behavior (Table 3). The two main parameters of photodetectors governing the device performance are the responsivity (R) and external quantum efficiency (EQE). ${ }^{47,}{ }^{128-129}$ In photodiodes, an absorbed photon generates an electron-hole pair with EQE not more than 100\%, which requires noninjecting metal-semiconductor contacts. Although the responsivity enhancement induced by the introduction of an interface layer (holeor electron-blocking layer) is unclear, this layer can reduce the dark current under reverse bias to obtain a high detectivity. Compared to photodiodes and vertical photoconductors, lateral photoconductors have a short carrier transit length and a small electrode spacing that together provide a fast response and a low driving voltage. 

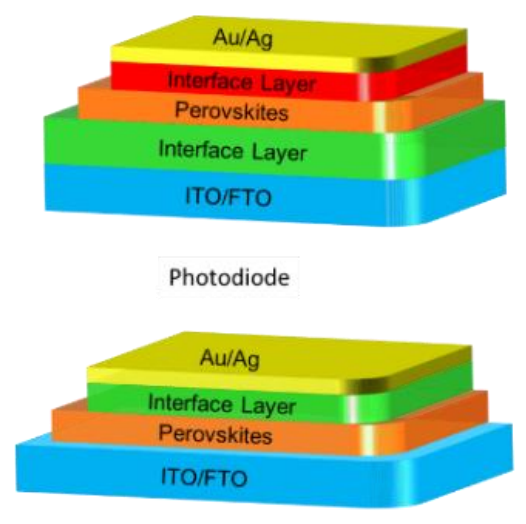

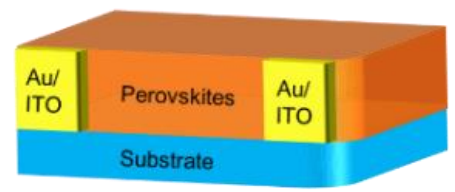

Phototransistor

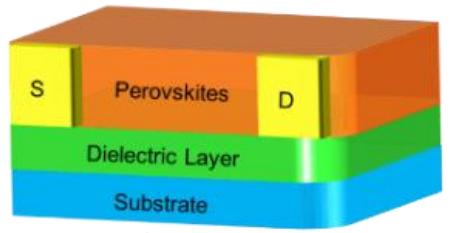

Photoconductor ( Metal Semiconductor Contact)

Figure 9. Schematic representation of various perovskite-based photodetector architectures. (Redrawn from ref. ${ }^{119}$ copyright 2017 The Royal Society of Chemistry).

$\mathrm{MAPbI}_{3}$ single crystal's (100) facet has been used to fabricate high performing photodetector. In single crystals, low trap density attributes to high carrier mobility and long carrier diffusion length, results in achieving highly sensitive $\mathrm{MAPbI}_{3}$ photodetectors. ${ }^{35}$ The halide perovskite single-crystals were shown to demonstrate narrowband photodetection with a very narrow spectral response and a full-width at halfmaximum of $<20 \mathrm{~nm}$ by modulating the response spectrum in the visible range through changing the halide composition in the single crystals. ${ }^{130-131}$ Furthermore, an efficient visible-blind UV photodetector was devised using high quality, suitable bandgap $\mathrm{MAPbCl}_{3}$ single-crystal grown by retrograde solubility behavior of hybrid perovskites. ${ }^{117}$ The first self-powered single-crystal perovskite photodetector, driven by a triboelectric nanogenerator (TENG) with a large responsivity of $196 \mathrm{~V}\left(\mathrm{mWcm}^{-2}\right)^{-1}$ operated without an external electric field was fabricated on the (100) facet of a bulk $\mathrm{CH}_{3} \mathrm{NH}_{3} \mathrm{PbI}_{3}$ perovskite single crystal. ${ }^{132}$ A self-powered broadband photodetector ranging from $375 \mathrm{~nm}$ to $808 \mathrm{~nm}$, based on a $\mathrm{MAPbI}_{3}$ single-crystal with $\mathrm{Au}-\mathrm{Al}$ asymmetric electrodes showed a responsivity of $0.24 \mathrm{AW}^{-1}$, at the low incident power density of $1 \times 10^{-8} \mathrm{~W} \mathrm{~cm}^{-2}$ and a response time of $71 \mu$ s under zero bias. The critical issue of metalsemiconductor contacts, forming the Schottky junction was resolved by setting the channel length to 30 $\mu \mathrm{m}$ for sufficient electron-hole pair separation and transportation. ${ }^{133}$ Unlike one component photodetector, 
a facile two-step approach was used to fabricate a core-shell heterojunction self-powered photodetector based on a $\mathrm{CH}_{3} \mathrm{NH}_{3} \mathrm{PbBr}_{3}$ single-crystal showing the responsivity up to $11.5 \mathrm{mAW}^{-1}$ under $450 \mathrm{~nm}$ irradiation at zero bias. ${ }^{134}$ A self-biased photodetector with an AVC-grown $\mathrm{MAPbBr} 3$ single-crystal that utilized Pt-Au electrodes to make a Schottky junction showed a photodetectivity of $1.4 \times 10^{10}$ Jones at zero bias. ${ }^{118}$ A geometry-regulated dynamic-flow reaction system was used to achieve the thinness-controlled perovskite wafers. The large-sized $\mathrm{FAPbI}_{3}$ and $\mathrm{MAPbI}_{3}$ perovskite single-crystal wafers reported the mass production of integrated photodetectors by simple deposition of $300 \mathrm{~nm}$ interdigital Au electrodes through a vacuum evaporation method. ${ }^{37}$

\subsection{Photodiodes}

A photodiode is a type of photodetector that has a configuration analogous to solar cell devices. It has a p-n junction operated with an applied reverse biased voltage . Single-crystal perovskite photodiodes are used in the detection of ultraviolet, visible, and near-infrared X-rays and gamma rays. These photodiodes are classified as spectrally broadband or narrowband based on the width of their spectral response window. ${ }^{135}$ The photodetection performance of perovskite photodiodes is discussed based on the spectral sensitivity to panchromatic or specific wavelengths.

Table 3. Comparison of the recently reported single-crystal-based photodetector.

\begin{tabular}{|c|c|c|c|c|c|}
\hline S. & Device Configuration & Photodetect & Respon & Responsivity AW ${ }^{-1} @$ the & Ref. \\
\hline \multirow[t]{5}{*}{ No } & & or & se & applied bias & \\
\hline & & and Light & Speed & & \\
\hline & & Source & (rise & & \\
\hline & & & time/fal & & \\
\hline & & & I time) & & \\
\hline
\end{tabular}




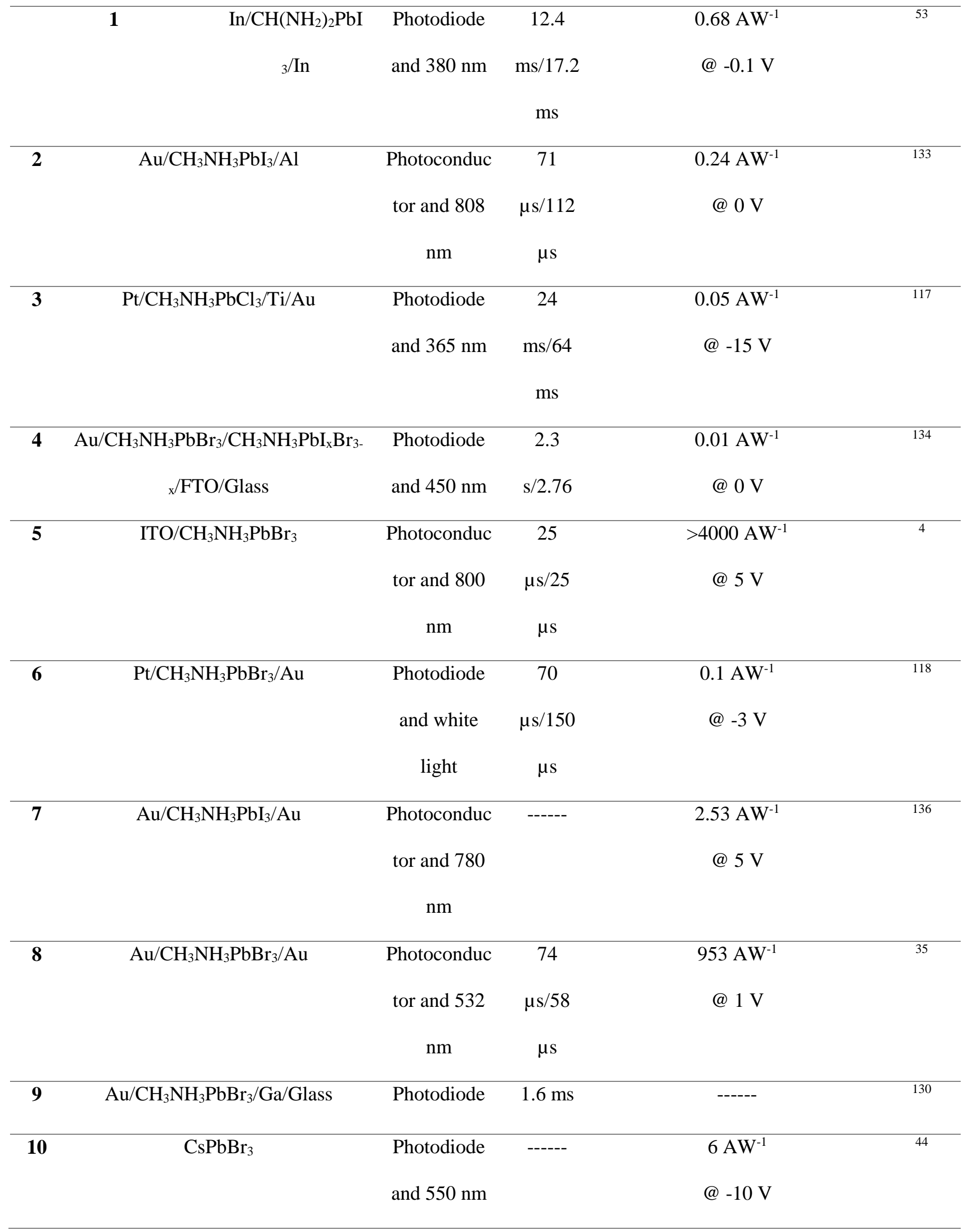




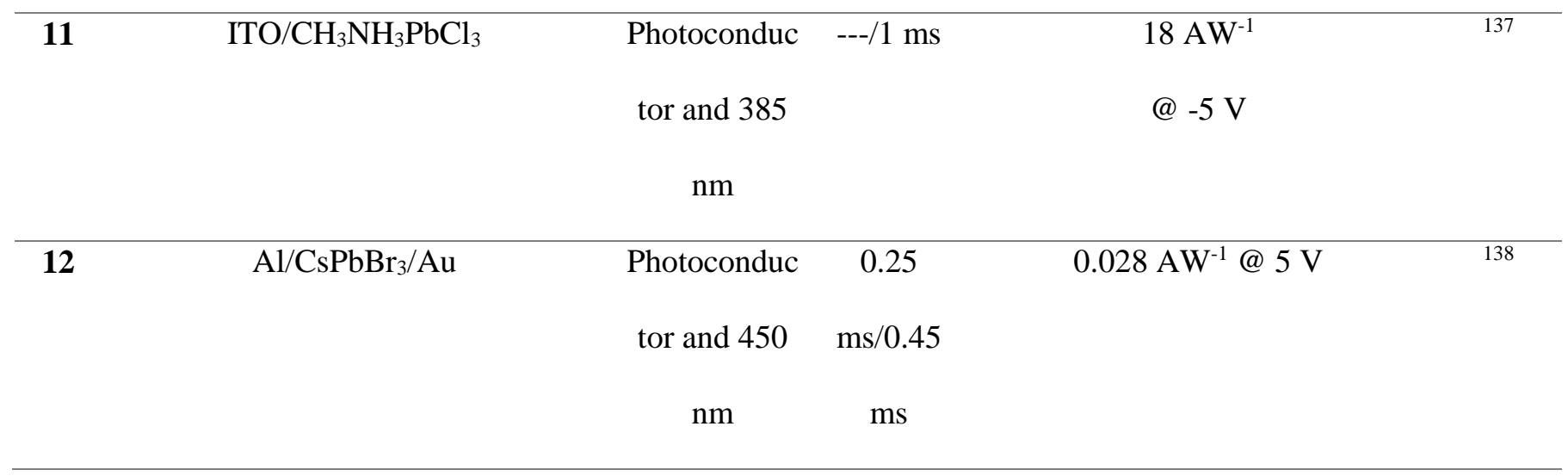

A MHP low-noise photodiode was fabricated with a performance equivalent to that of commercial inorganic semiconductor devices. ${ }^{35}$ Perovskite photodetectors with an excellent capability for weak lightsensing can potentially replace commercial silicon photodiodes in defense, communication, and imaging applications. Sensing from the UV-Vis to NIR is appealing for both scientific and industrial applications. Thanks to perovskites, as they can selectively absorb photons only in the UV/Vis/NIR regions due to their bandgap tunability. Au nanowire networks with high conductivity and stability were patterned as transparent electrodes in flexible $\mathrm{CH}_{3} \mathrm{NH}_{3} \mathrm{PbI}_{3}$ photodiodes, they perform comparable to ITO transparent electrode based devices. ${ }^{139}$ Similarly, exploiting the optoelectronic properties of $\mathrm{MAPbCl}_{3}$ crystal, UVphotodetector was fabricated. This $\mathrm{MAPbCl}_{3}$ single crystal-based UV-photodetector screened high ONOFF ratio and detectivity. ${ }^{117}$ The device architecture is shown in Fig. 10a .The band energy diagram of the device is illustrated in Fig. 10b. The current-voltage characteristics were measured in the dark and under illumination, as shown in Fig. 10c. The $O N$ and $O F F$ photo responsive cycles were measured at 15 V, as shown in Fig. 10d.

\subsection{Photoconductors}

Photoconductors based on perovskites with vertical or lateral device architectures can exhibit a high responsivity. Generally, difference between photoconductors and photovoltaic detectors is: photoconductive detectors use the increase in electrical conductivity resulting from increases in the number of free carriers generated when photons are absorbed (generation of current), whereas 
photovoltaic current is generated as a result of the absorption of photons of a voltage difference across a p-n junction (generation of voltage). In general, photoconductive detectors have a higher frequency response; however they also have a higher signal to noise ratio. Hence, it is recommended using photoconductive detectors if a high-powered laser is used. The term photoconductive gain corresponds to the ratio between the charge recombination time $\left(t_{r}\right)$ and the charge transit time $\left(t_{t}\right)$. The high sensitivity of photodetectors due to a high gain can provide promising applications in high-speed optical communication and high-resolution imaging. ${ }^{140}$ Regarding the vertical-structure photoconductors, a small electrode spacing, and a high gain can be obtained at a low working voltage, which is associated with the high charge carrier mobility of perovskites. Recently, perovskite film devices with the vertical structure were fabricated, which exhibited a high responsivity of $4200 \mathrm{AW}^{-1}$ at low bias. ${ }^{5,141-142}$ Regarding the lateral structure devices using high-quality perovskite films with a large electrode spacing, a relatively high working voltage is required to maintain a high gain. ${ }^{124}$, 143-151 Single-crystal perovskite-based photoconductors with low trap density showed ultrahigh responsivities exceeding $103 \mathrm{AW}^{-1}$. 4, 35, 152

The critical components for forming a Schottky junction with asymmetric electrodes are illustrated in Fig. 11a. ${ }^{133}$ The device was fabricated through the deposition of $\mathrm{Au}$ and $\mathrm{Al}$ on the surface of the perovskite single-crystal. The suitable metals $\mathrm{Al}$ and $\mathrm{Au}$ were chosen to form high- and low-energy barriers, respectively, as shown in Fig. $11 \mathrm{~b} .^{133}$ The photo responsive $O N$ and $O F F$ characteristics of the device under various laser illuminations (Fig. $11 \mathrm{c}, \mathrm{d}$ ) showed no response for light illumination beyond $830 \mathrm{~nm}$, as the band edge of perovskite is at $830 \mathrm{~nm}$. Therefore, the minimal photon energy that can be absorbed is at $830 \mathrm{~nm}$ and hence the spectral response of the device under the identical conditions exhibited different photo responsive efficiencies at different incident light wavelengths. ${ }^{133}$

A large area photodetector was fabricated using a crystalline film made of large single- crystals. Because of the comparable diffusion length and mobility of the single-crystal,it exhibited high 
gain and high gain-bandwidth product. ${ }^{4}$ Similarly, a transparent visible-blind UV photodetector was fabricated using substrate-integrated $\mathrm{CH}_{3} \mathrm{NH}_{3} \mathrm{PbCl}_{3}$ based single-crystals. ${ }^{137}$

Phototransistors have a three-terminal configuration similar to that off field-effect transistors. For phototransistors, the channel conductance is controlled by the implementation of light absorption. Phototransistors based on perovskite materials show superior carrier transport properties with ambipolar characteristics. The performance can be improved through hybridization with 2D layered materials. The phototransistors exhibited an ultrafast photoresponse speed of less than $10 \mathrm{~ms}$. Orientationally pure crystalline $\mathrm{CH}_{3} \mathrm{NH}_{3} \mathrm{PbI}_{3}$ film with a periodic microarray was produced using a thermal-gradient-assisted directional crystallization method. ${ }^{15}$ The phototransistors based on the films with different crystal orientations and a low trap density exhibited significant charge transport anisotropy, providing conclusive information for the material optimization of the crystalline morphology and the future development of novel optoelectronic devices. ${ }^{15}$

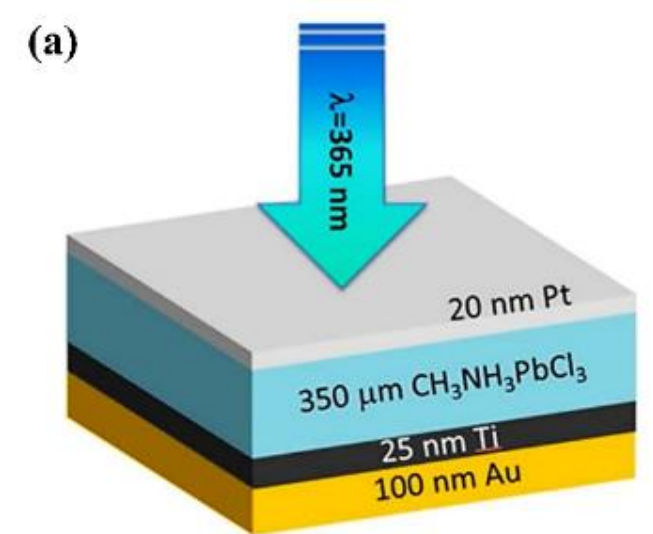

(c)

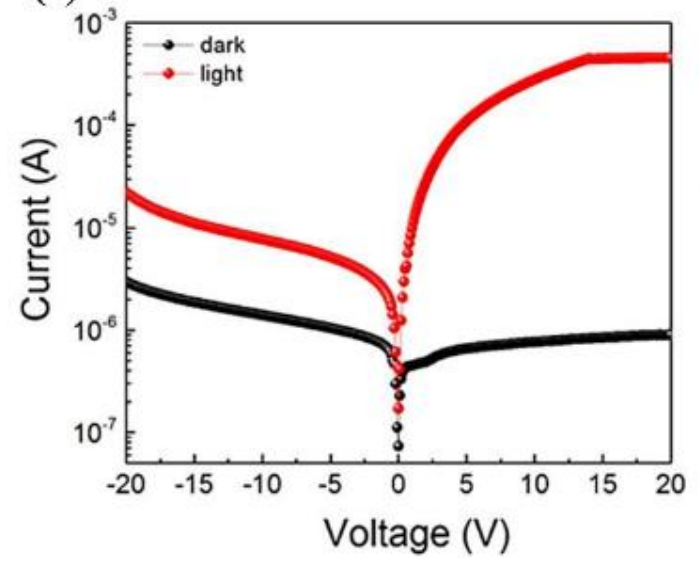

(b)

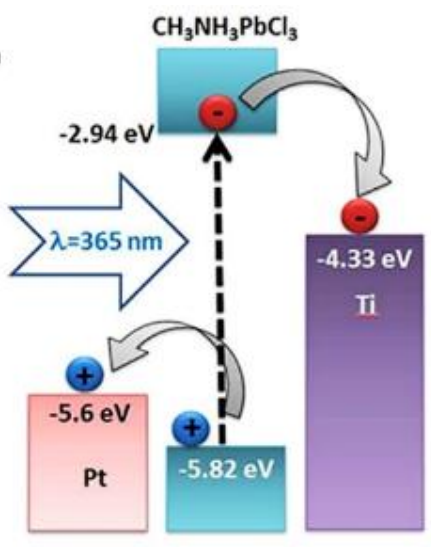

(d)

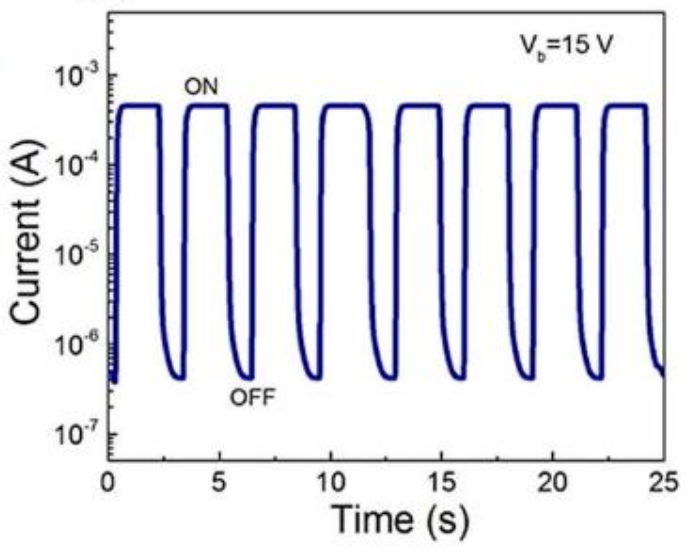


Figure 10. a) Device architecture of a $\mathrm{MAPbCl}_{3}$ single-crystal-based photodetector. b) Energy band diagram. c) Current-voltage ( $I-V)$ curves of the photodetector under illumination with solar-blind UV light $(\lambda=365 \mathrm{~nm})$ and under dark conditions. d) $O N-O F F$ photoresponse at a bias voltage of $15 \mathrm{~V}$ under modulated UV illumination. (Reprinted with permission from ref. ${ }^{117}$ copyright 2015 American Chemical Society).

(a)

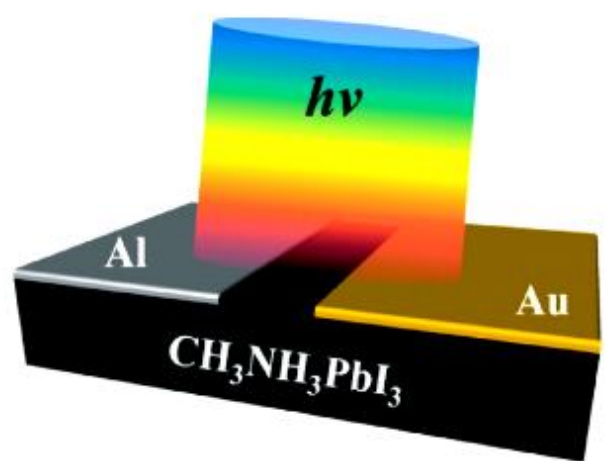

(c)

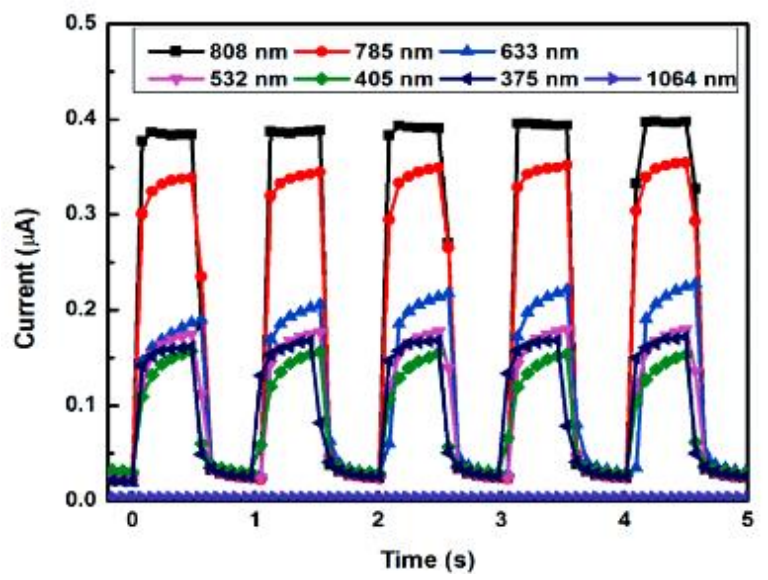

(b)
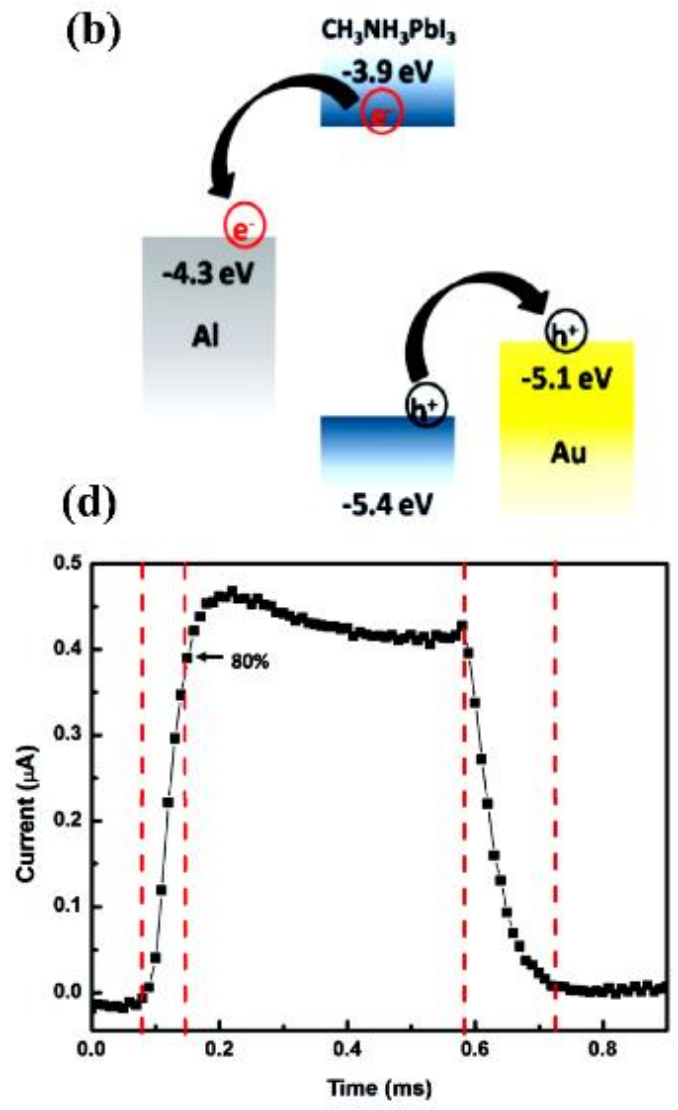

Figure 11. Structure of a self-powered photodetector. a) Schematic illustration of Au-Al electrodes separated by $30 \mu \mathrm{m}$ on a $\mathrm{MAPbI}_{3}$ single-crystal. b) Schematic illustration of the working mechanism of a Schottky junction based on asymmetric electrodes. c) Photo response characteristics, i.e., photocurrent signals, for different incident light wavelengths. d) Photo responsive ON and OFF cycle under $1.8 \mathrm{~mW}$ $\mathrm{cm}^{-2}$ light illumination under $532 \mathrm{~nm}$ at a bias of $0 \mathrm{~V}$. (Reprinted from ref. 149, copyright 2016 The Royal Society of Chemistry). 
Perovskite photodetectors do face many challenges that perovskite solar cells face to get commercialized; those challenges are related to stability, high responsivity, good external quantum yield, and toxicity. They have to compete with the technologies which are already established. Till date the best figure-of-merit parameters achieved by perovskite photodetectors are high responsivity more than $10^{4} \mathrm{~A}$ $\mathrm{W}^{-1},{ }^{153-154}$ short response time of $<1 \mathrm{~ns}^{155-156}$ detectivity nearly equal to $10^{14}$ Jones, ${ }^{7,} 157$ large linear dynamic range of $>150 \mathrm{~dB}^{154,158}$ and small $\mathrm{NEP}$ of $<50 \mathrm{fW} \mathrm{Hz}{ }^{-1 / 2},{ }^{156,159}$ showed their outstanding potential compared to commercial silicon-based. The long term stability of the perovskite is the main issue when compared to highly stable inorganic semiconductors. Many research groups are working on morphology manipulation of perovskite, ${ }^{160}$ interfacial engineering using buffer layers, ${ }^{161}$ passivations of surface defects ${ }^{159}$ and different device architectures, ${ }^{162}$ to amplify the operating stability and responsivity of the photodetectors. The present status of the developed perovskite detectors is poor towards NIR light. To enhance the absorption in NIR region, $\mathrm{PbS}$ QDs or narrow bandgap conjugated polymers were incorporated in the perovskites. ${ }^{163}$ It was observed that responsivity and detectivity for red light have improved by incorporating AuNRs into the polymer photodetectors. ${ }^{164}$ In a similar way by taking it as a testimonial through achieving the aspect ratios of AuNRs, to obtain the plasmon resonant wavelength located in the NIR region, we anticipate to achieve high performing photodetectors with amplified NIR responsivity.

\section{Single-crystalline Thin Film Solar Cells}

The first single-crystalline PSC with configuration ITO/PEDOT: PSS/single-crystalline perovskite /PCBM/ZnO/Al showed a power conversion efficiency of $1.73 \% .^{46}$ The MHPs with their wide absorption range, high carrier mobility, long carrier diffusion length, and high quantum efficiency have spurred photovoltaic applications. ${ }^{77,121-122,165-168}$ The performance of perovskite photodiodes has been enhanced by introducing ion-doped hole-transporting materials (HTMs) that improved the morphology and the energy level matching between the different layers. ${ }^{169-176}$ Although high-performance devices have been 
achieved with polycrystalline thin-film perovskites, the SCPs can surpass their polycrystalline counterparts due to their excellent optoelectronic properties. The hole mobility and diffusion length of SCPs were reported $164 \pm 25 \mathrm{~cm}^{2} \mathrm{~V}^{-1} \mathrm{~S}^{-1}$ and $175 \pm 25 \mu \mathrm{m}$, respectively. ${ }^{6}$ The detailed optoelectronic parameters such as carrier mobilities, conductivity, diffusion lengths, lifetimes etc., of single-crystalline perovskites are reported elsewhere. ${ }^{97}$

The optical absorption is paramount to the photovoltaic performance. A powerful tool to engineer the band structure in an $\mathrm{ABX}_{3}$ perovskite is element substitution, which impacts the optical properties. Achieving high output from perovskite solar cells is possible by controlling the carrier dynamics and the choice of charge transport materials. ${ }^{177}$ The necessary condition to obtain the maximum output from a perovskite photodiode is matching of the electronic energy levels of the perovskite absorbers and the adjacent charge transport materials, with a minimum energy loss and reduced carrier recombination. ${ }^{169}$

Detailed information about the types of heterostructures that can form in perovskite-based photonic devices has been described elsewhere. ${ }^{178}$ Briefly, this process is illustrated in Fig. 12. As shown in Fig. 12 (type 1), a staggered gap heterointerface is formed. 

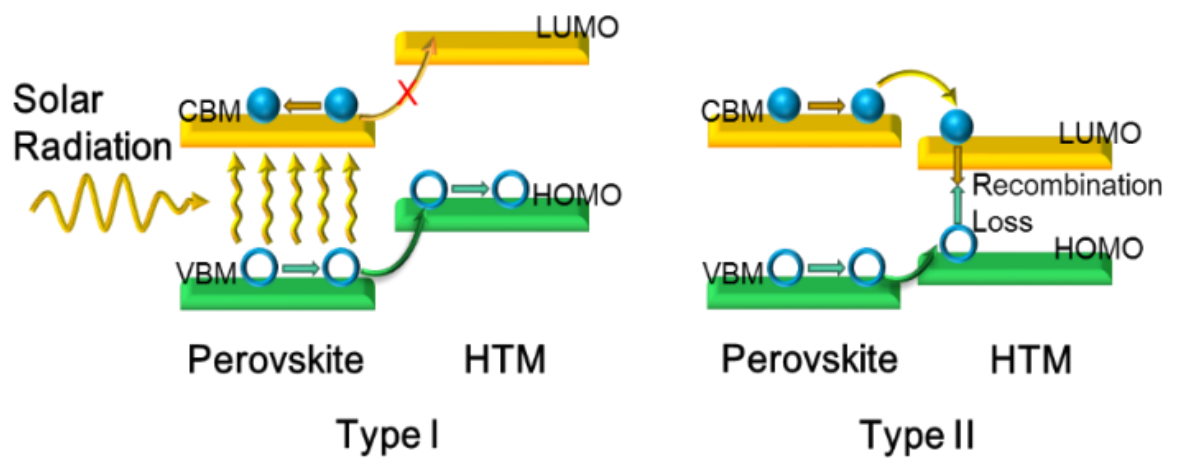

Perovskite HTM

Type I

Type II
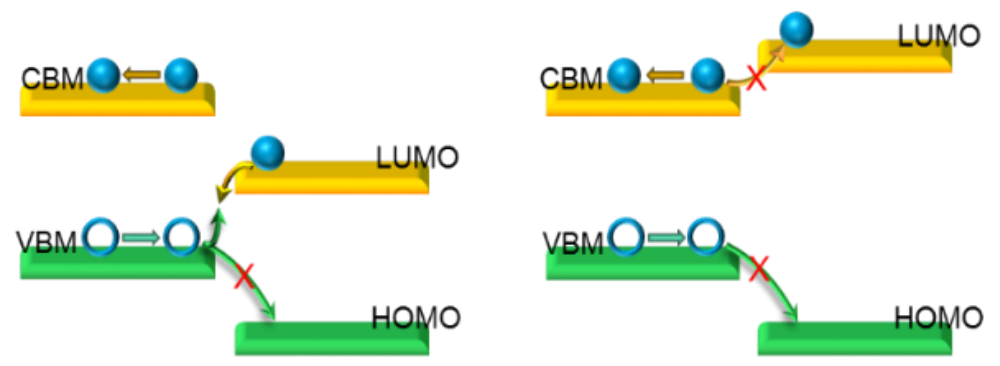

Perovskite HTM

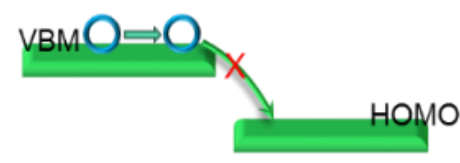

Perovskite HTM

Type III

Type IV

Figure 12. Schematic representation of band energy level alignments at the perovskites/HTMs interfaces.

a) Type I: staggered-gap type heterointerface; perovskite in contact with an HTMs of a high-lying HOMO level. b) Type II: straddling-gap type heterointerface possible between perovskite and HTMs of a small energy gap. c) Type III: reverse staggered-gap type heterointerface possible between perovskites and HTMs of a deep-lying HOMO level. d) Type IV: reverse straddling-gap type heterointerface possible between perovskite and HTMs of a large energy gap. (Redrawn from ref. ${ }^{178}$ copyright 2015 Wiley).

The highest occupied molecular orbital (HOMO) and lowest unoccupied molecular orbital (LUMO) of HTMs are proportional to the valence band maximum (VBM) and conduction band minimum (CBM) respectively, which would lead to a lack of a barrier for hole extraction and blocking of electron extraction. Considering the type II alignment in Fig. 12, we can determine that there is electron-hole recombination loss in the HTMs due to the lack of an electron barrier. ${ }^{179}$ Considering the case of type III alignment in Fig. 12, due the deep-lying HOMO of the HTMs, extraction of holes from the perovskite VBM to the HTMs HOMO energy level ensues, and recombination between the holes and electrons of the VBM and 
HTMs LUMO, respectively, may occur. ${ }^{179}$ It is clear from the type IV alignment diagram (Fig. 12) that when an HTMs comes in contact with a reverse straddling-gap heterointerface, the heterointerface is not suitable for charge separation due to the wide energy gap.
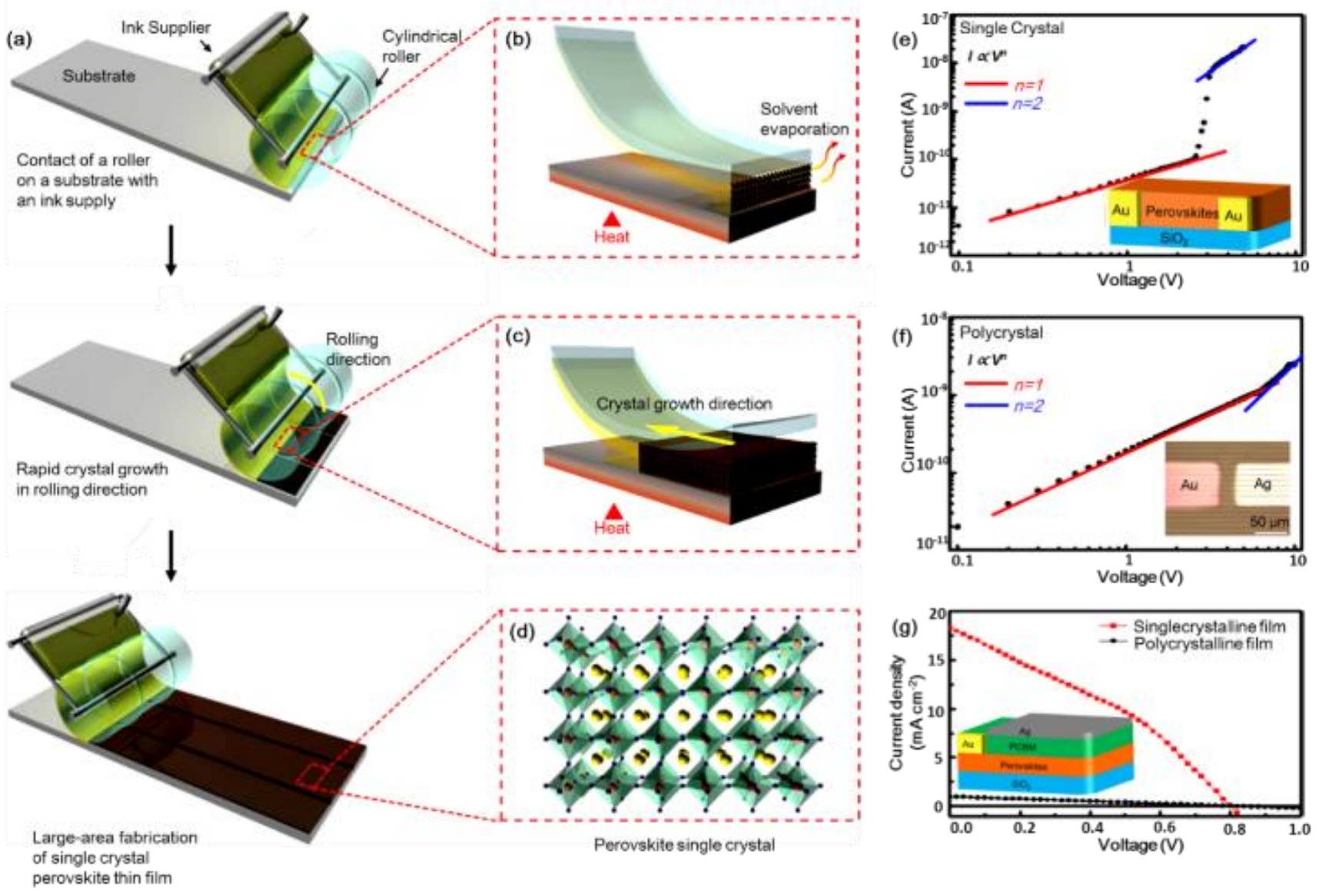

Figure 13. a) Schematic illustration of pattering the single-crystal perovskite thin films. a) The standard procedure followed in the GC-LCG with a rolling mold. b) Rapid solvent evaporation happening at the open end of the channel, and c) Geometrical confinement of the crystal growth along the channels of the mold. d) Crystal structure of the single-crystalline $\mathrm{CH}_{3} \mathrm{NH}_{3} \mathrm{PbI}_{3}$ films (red sphere: $\mathrm{Pb}^{2+}$, yellow sphere: $\mathrm{CH}_{3} \mathrm{NH}_{3}{ }^{+}$, violet sphere: $\mathrm{I}^{-}$). e) $\mathrm{I}-\mathrm{V}$ characteristics obtained from a 200 -nm-thick single-crystal perovskite patterned thin film. The inset shows a schematic device used for SCLC measurements. f) Current-voltage $(I-V)$ characteristics obtained from a 200-nm-thick spin-coated polycrystalline perovskite thin film. g) $J-$ $V$ curves obtained from the single-crystalline (red) and polycrystalline (black) perovskite thin-film lateral 
solar cells. The inset shows a schematic device used to perform the measurements. (Redrawn and reprinted from ref. ${ }^{58}$ copyright 2017 Nature Publishing Group).

Highly efficient PSCs have been built with polycrystalline perovskite absorbers based on various device strategies. ${ }^{58,173,180-185}$ The severe instabilities and the long-term stability issues arising due to the structural defects, especially dislocations and grain boundaries, impede the viable commercialization of the aforementioned devices. ${ }^{58}$ Therefore, research is focused on employing single-crystalline films of these materials. Due to the larger grains and lower grain boundary density, perovskite monocrystalline thin films resemble SCPs in terms of their optoelectronic properties. ${ }^{54-55,180}$ Recent report has manifested a direct dependence of the grain size on the temperature during the preparation of high-quality singlecrystals using the hot-casting technique. ${ }^{22,186-187}$ Expanding on the above method, a novel one-step printing method has been developed to fabricate single-crystal $\mathrm{CH}_{3} \mathrm{NH}_{3} \mathrm{PbI}_{3}$ perovskite thin films on a wafer-scale substrate. ${ }^{58}$ Briefly, in this method, a perovskite ink solution is transferred to a heated substrate through a channel-patterned rolling mould to induce lateral crystal growth and instant crystallization that results in the formation of highly aligned patterned thin films of SCPs. ${ }^{58}$ Such an approach is based on the geometrically confined lateral crystal growth (GC-LCG) method. ${ }^{58}$ The fabrication of patterned thin films of a single-crystal perovskite is illustrated in Fig. 13, where a poly (dimethylsiloxane) mould is wrapped around a cylindrical metal roller mounted with an ink supplier filled with the $\mathrm{CH}_{3} \mathrm{NH}_{3} \mathrm{PbI}_{3}$ perovskite precursor solution and is put into contact with a preheated $\mathrm{SiO}_{2}$ substrate at $180{ }^{\circ} \mathrm{C}$ (Fig. 13a). The solvent evaporates due to the hot substrate, resulting in perovskite ink solution crystallization at the open end of the channels (Fig. 13b). The crystal growth from the perovskite ink solution in the GC-LCG method utilizing a rolling mould is depicted in Fig. $13 c{ }^{58}$ By employing the GCLCG process, a single-crystal $\mathrm{CH}_{3} \mathrm{NH}_{3} \mathrm{PbI}_{3}$ perovskite thin film with a tetragonal crystal structure was successfully grown (Fig. 13d). An advantage of such a method is the ability to control the direction of the crystal growth due to the instant crystallization and geometrical confinement that can be implemented in $40 \mid \mathrm{P}$ a g e 
the roll-printing process. A gap-type device was fabricated using 200-nm-thick single-crystal $\mathrm{CH}_{3} \mathrm{NH}_{3} \mathrm{PbI}_{3}$ along with to $100 \mathrm{~mm}$-gap $\mathrm{Au}$ electrodes for the SCLC measurements of the thin film semiconductor, as illustrated in Fig. 13e. ${ }^{188-189}$ The single-crystalline thin film is optimal for improving the performance of optoelectronic devices owing to its high carrier mobility. Hole mobility of $45.64 \mathrm{~cm}^{2} \mathrm{~V}^{-}$ ${ }^{1} \mathrm{~S}^{-1}$ was reported for the single-crystal perovskite film, which is comparable to the values previously reported for bulk SCPs. ${ }^{5-6,58,190}$ The SCLC regime was also observed for the polycrystalline perovskite thin film, with mobility of $0.2512 \mathrm{~cm}^{2} \mathrm{~V}^{-1} \mathrm{~s}^{-1}$, as illustrated in Fig. 13f. A perovskite solar cell fabricated with a lateral configuration (Fig. 13g) was subjected to an external potential field to induce ion migration within the perovskite layer. Single-crystal devices demonstrated a PCE of $4.83 \%$, a short-circuit current density $\left(J_{\mathrm{sc}}\right)$ of $18.33 \mathrm{~mA} \mathrm{~cm}^{-2}$, an open-circuit voltage $\left(V_{\mathrm{oc}}\right)$ of $0.801 \mathrm{~V}$ and a fill factor $(F F)$ of 0.329 (Fig. 13g). From 100 solar cell devices with a narrow distribution of efficiencies, an average efficiency of $4.14 \%$ was recorded, compared to the maximum efficiency of $0.194 \%$ with a $J_{\mathrm{sc}}$ of $0.974 \mathrm{mAcm}^{-2}, \mathrm{a}$ $V_{\mathrm{OC}}$ of $0.803 \mathrm{~V}$ and an $F F$ of 0.248 reported for the lateral perovskite solar cell using a polycrystalline perovskite film shown in Fig. $13 \mathrm{~g}$ (dark line). ${ }^{58}$ 

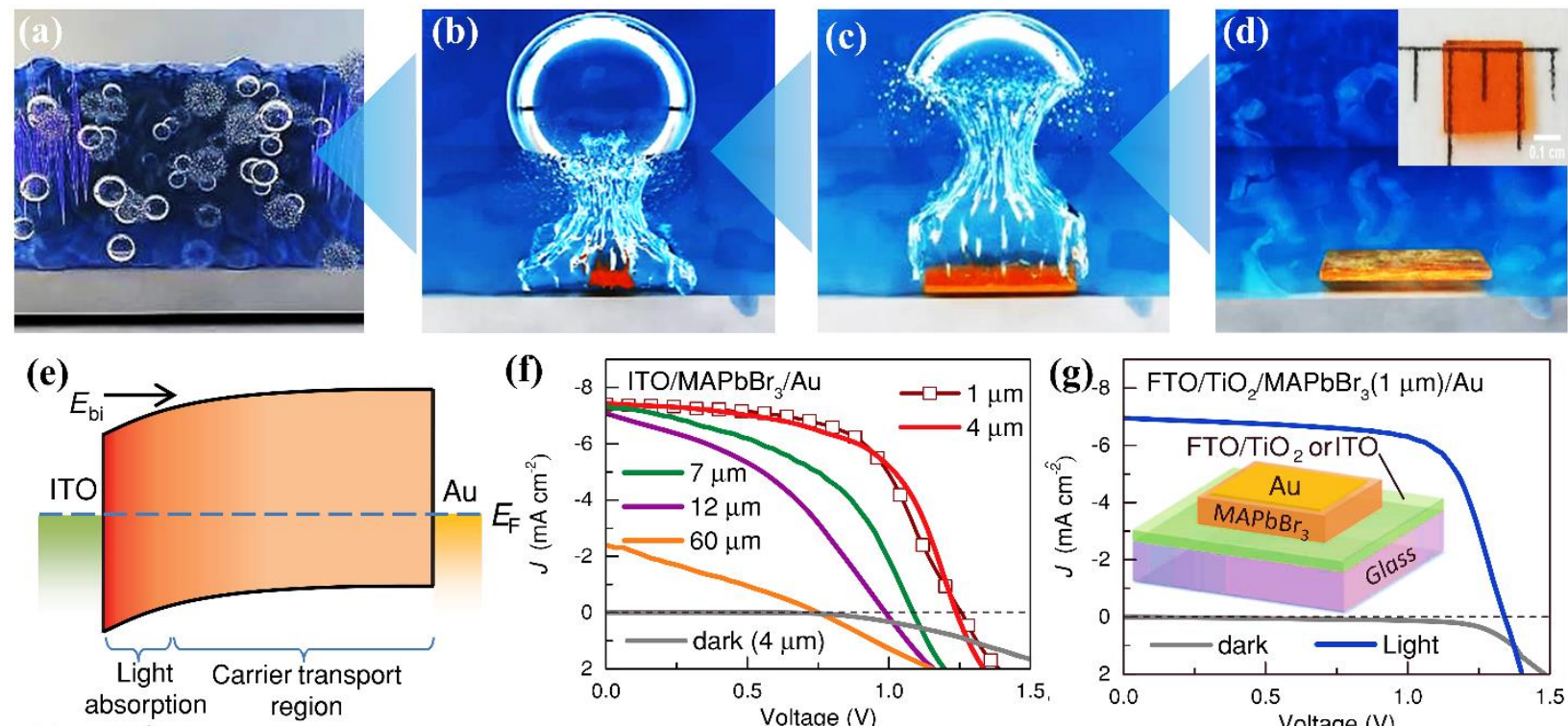

(h) region
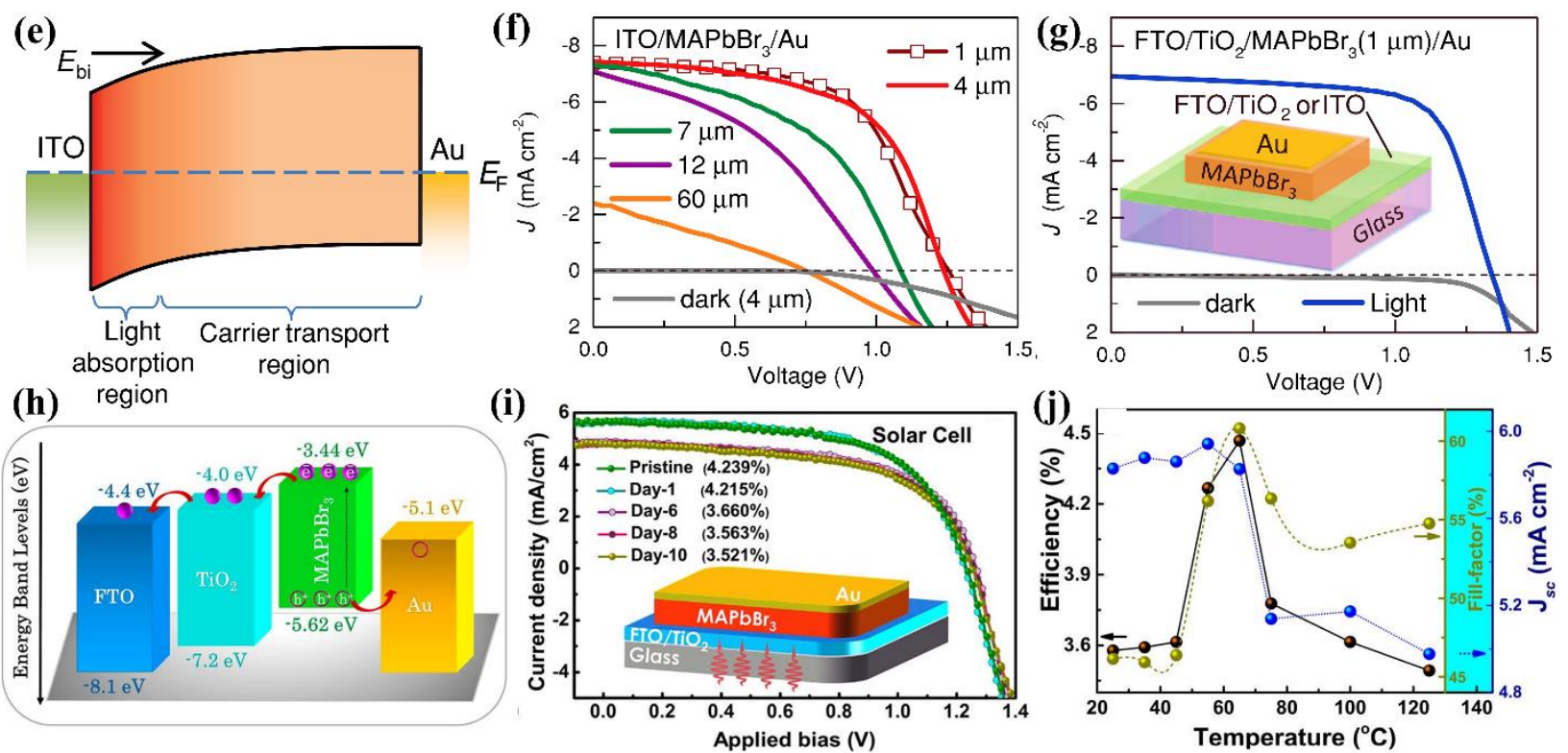

Figure 14. a-d) Schematic illustrations of the monocrystalline films by CTAC process on a microscopic scale. c) Cavitation induced by an ultrasonic pulse in the perovskite solution. b-d) The cavitation triggered bubble collapsing in the neighborhood of a substrate is asymmetric and results in a high-speed jet towards the substrate, which is the origin of initial stage preferential lateral crystallization. e, f) $J$ - $V$ characteristics of $\mathrm{FTO} / \mathrm{TiO}_{2}$ based monocrystalline solar cells. (Redrawn from ref. ${ }^{191}$ copyright 2016 Wiley). g) Schematic band energy level alignment. h) Schematic of the band alignment energy levels. (i, j) $J-V$ characteristics and solar cell parameter variation as a function of temperature respectively. (Redrawn from ref. ${ }^{192-193}$ copyright 2016 American Chemical Society).

Recently, a new versatile technique was developed to synthesize hybrid perovskite monocrystalline films on substrates by exploiting the propensity of perovskites to crystallize in solution. ${ }^{191}$ Such a new growth method for crystallization was designed based on a CTAC strategy that promotes heterogeneous 
nucleation by contributing enough energy to overcome the nucleation barrier. ${ }^{191}$ Briefly, when the solution attains a low supersaturation level through the use of the antisolvent vapor diffusion technique, upon the introduction of a very short ultrasonic pulse, monocrystalline films of $\mathrm{MAPbBr}_{3}$ are grown onto different substrates within several hours of the ultrasonic pulse application. The cavitation process is supported by the release of transient ultrahigh energy and is expected to induce nucleation by overcoming the nucleation barrier through rapid local cooling. ${ }^{194}$ The micro-jetting observed upon the collapse of cavities is asymmetric near a solid surface, and high-speed fluid jets are produced towards the surface ${ }^{195}$ Fig. 14 (ad) illustrates the CTAC process. It has also been established that when an ultrasonic pulse is introduced at high supersaturation levels, cavitation triggers excessive nucleation events. ${ }^{191}$ The film thickness can be limited within the range of the carrier diffusion length by monitoring the rate and time of crystal nucleation and growth. ${ }^{5}$ Monocrystalline thin-film solar cells grown by the CTAC route ${ }^{191}$ showed a large Schottky barrier at the ITO/perovskite junction based on the estimation of the work function of approximately $4.6 \mathrm{eV}$ for ITO (Fig. 14e). The built-in potential of approximately $1.2 \mathrm{~V}$, as observed in the Mott-Schottky plot, fairly matched the $\mathrm{V}_{\mathrm{oc}}$ of the device. Most of the devices showed a PCE of 5.00\% $\pm 0.2 \%$, without the use of any hole or electron transport layers (Fig. 14f).

Further investigations on enhancing the performance of monocrystalline film-based devices were focused on the $\mathrm{FTO} / \mathrm{TiO}_{2} / \mathrm{MAPbBr}_{3} / \mathrm{Au}$ device configuration, where the $\mathrm{TiO}_{2}$ film acts as an electron transporting layer (ETL). The $\mathrm{TiO}_{2} / \mathrm{MAPbBr}_{3}$ interface formed a p-n junction as substantiated by the clear current rectification in the $J-V$ curve of the cell. The PCE was enhanced to $6.53 \%$, with a $V_{\text {OC }}$ of $1.36 \mathrm{~V}$, a $J_{\mathrm{sc}}$ of $6.96 \mathrm{mAcm}^{-2}$, and a fill factor of 0.69 (Fig. $14 \mathrm{~g}$ ). ${ }^{191}$ It has also been reported that $\mathrm{MAPbBr}_{3}$ solar cells without an HTL have the highest $V_{\mathrm{OC}}{ }^{79,} 196$ The device without the ETL layer showed hysteresis compared to the device with the ETL layer, which can be explained based on various theories related to the origin of hysteresis in PSCs. ${ }^{197-200}$ The $\mathrm{TiO}_{2}$ interlayer could have reduced the traps in the perovskite 
bottom surface, resulting in less hysteresis, which was further corroborated by the faster stabilization of the transient photocurrent.

The substantial effect of temperature on the performance of SCPs and their optoelectronic properties, such as charge separation and charge recombination dynamics were investigated. ${ }^{192}$ Interestingly, excitation properties were obtained at $65^{\circ} \mathrm{C}$, attributed to the relaxed crystal structure. Devices exhibited high PCE, $J_{\mathrm{sc}}$ and $V_{\mathrm{oc}}$ at $65{ }^{\circ} \mathrm{C}$ (Fig. 14i) due to the low transport resistance coupled with the high recombination resistance and high carrier mobilities, further validating the claim for better performance at $60 \pm 5^{\circ} \mathrm{C}$. Importantly, it was observed that the energy barrier for the perovskite HOMO was reduced at $65{ }^{\circ} \mathrm{C}$, and hence, the Au electrode could provide efficient hole collection (Fig. 14h) Therefore, such study in single-crystal-based devices is believed to unveil the exact mechanisms to realizing the ideal device operation. The effect of surface restructuring in humid conditions, which is crucial to understanding the interfaces in solar cells was examined to identify the critical variables governing the performance of single-crystal devices and thereby fabricate high-surface-quality single-crystals. In a typical study, the devices built with pristine single-crystal surfaces showed a gradual decrease in PCE (from $4.24 \%$ on the first day to $3.52 \%$ on the tenth day) with time due to the slow surface modulation in the open air (Fig. 14i). A comprehensive investigation was carried out to examine the uncharacteristic behavior of the device in ambient air. Surprisingly, upon cleaving the single-crystal in ultrahigh vacuum (UHV), the pristine surface of the single-crystal exhibited different optical, morphological and electrical properties compared with an aged crystal. The single-crystal was found to become strained in the humid ambient $(\mathrm{RH} \geq 55 \%)$ due to the formation of perovskite hydrate on the surfaces of the single-crystal, which eventually led to the release of the strain via the formation of grain boundaries, as probed by scanning tunneling microscopy. Their study has opened up new avenues of scientific inquiry for engineering the surfaces of SCPs that are consequential to augmenting the anticipated stability and improving the photovoltaic and optoelectronic devices. 
A high-quality single-crystalline perovskite, $\mathrm{CH}_{3} \mathrm{NH}_{3} \mathrm{PbI}_{3}$, self-grown on an $\mathrm{FTO} / \mathrm{TiO}_{2}$ substrate was reported (Fig. 15a). ${ }^{39,84}$ Morphological investigations with atomic force microscopy (AFM) demonstrated that the topography of the device exhibited a smooth surface with a root mean square roughness of approximately $3.36 \mathrm{~nm}$ (Fig. 15b). ${ }^{84,201}$ Cross-sectional images (SEM images) of the n-ip-type solar cell device with the $\mathrm{FTO} / \mathrm{TiO}_{2} / \mathrm{CH}_{3} \mathrm{NH}_{3} \mathrm{PbI}_{3} /$ Spiro-OMeTAD/Ag configuration indicated tight packing between the $\mathrm{CH}_{3} \mathrm{NH}_{3} \mathrm{PbI}_{3}$ and $\mathrm{FTO} / \mathrm{TiO}_{2}$ integrated interfaces (Fig. 15c). ${ }^{33}$

To understand the growth mechanism of $\mathrm{CH}_{3} \mathrm{NH}_{3} \mathrm{PbI}_{3}$ single-crystals, X-ray diffraction studies were performed over a large area (micron scale). The selected profiles of the two measured reflections are presented in psuedocubic setting (as illustrated in Fig. 15d, e). The 002 C-type reflections observed suggested that the vertical growth of $\mathrm{CH}_{3} \mathrm{NH}_{3} \mathrm{PbI}_{3}$ along the [001] $\mathrm{C}$ reflection is dominant rather than low-symmetry structure twinning.

The HRTEM image (Fig. 15f) shows the well-ordered crystalline lattice of the single-crystal, and the fast Fourier transform (FFT) pattern corresponds to a tetragonal phase with viewing direction along the [2 10 0] zone axis (Fig. 15g). The single-crystalline characteristic of $\mathrm{CH}_{3} \mathrm{NH}_{3} \mathrm{PbI}_{3}$ on $\mathrm{FTO} / \mathrm{TiO}_{2}$ is further confirmed by the high-resolution TEM image (Fig. 15f) and selected area electron diffraction (SAED) pattern (Fig. 15g). With the help of TRPL, the exciton diffusion was studied by comparing the carrier lifetimes in polycrystalline $\mathrm{CH}_{3} \mathrm{NH}_{3} \mathrm{PbI}_{3}$ on $\mathrm{FTO}$ and single-crystalline $\mathrm{CH}_{3} \mathrm{NH}_{3} \mathrm{PbI}_{3}$ on FTO as well as on $\mathrm{FTO} / \mathrm{TiO}_{2}$ monitored at the wavelength of $400 \mathrm{~nm}$ (Fig. 15h). ${ }^{33}$ 


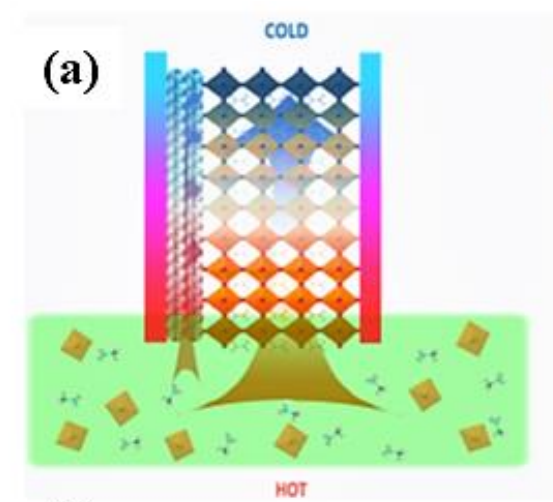

(e)

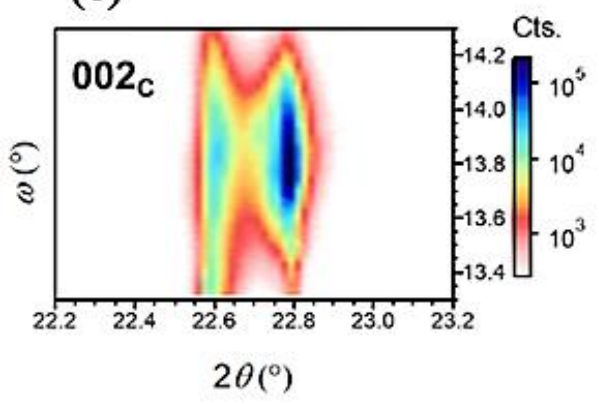

(d)

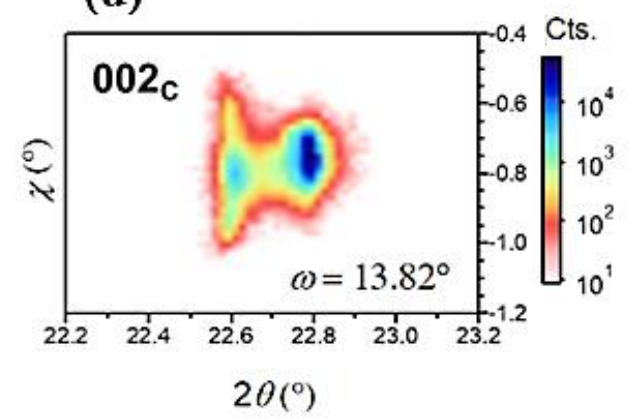

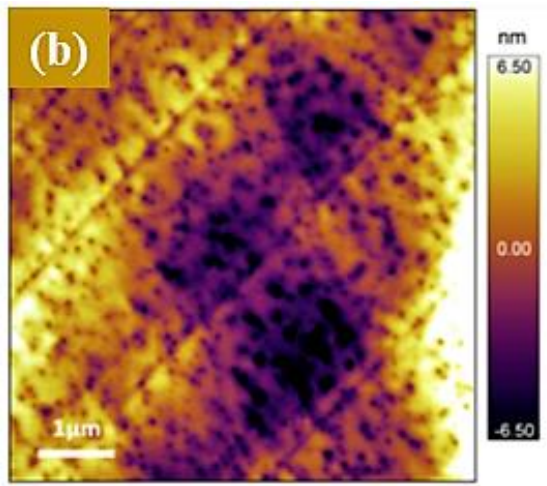
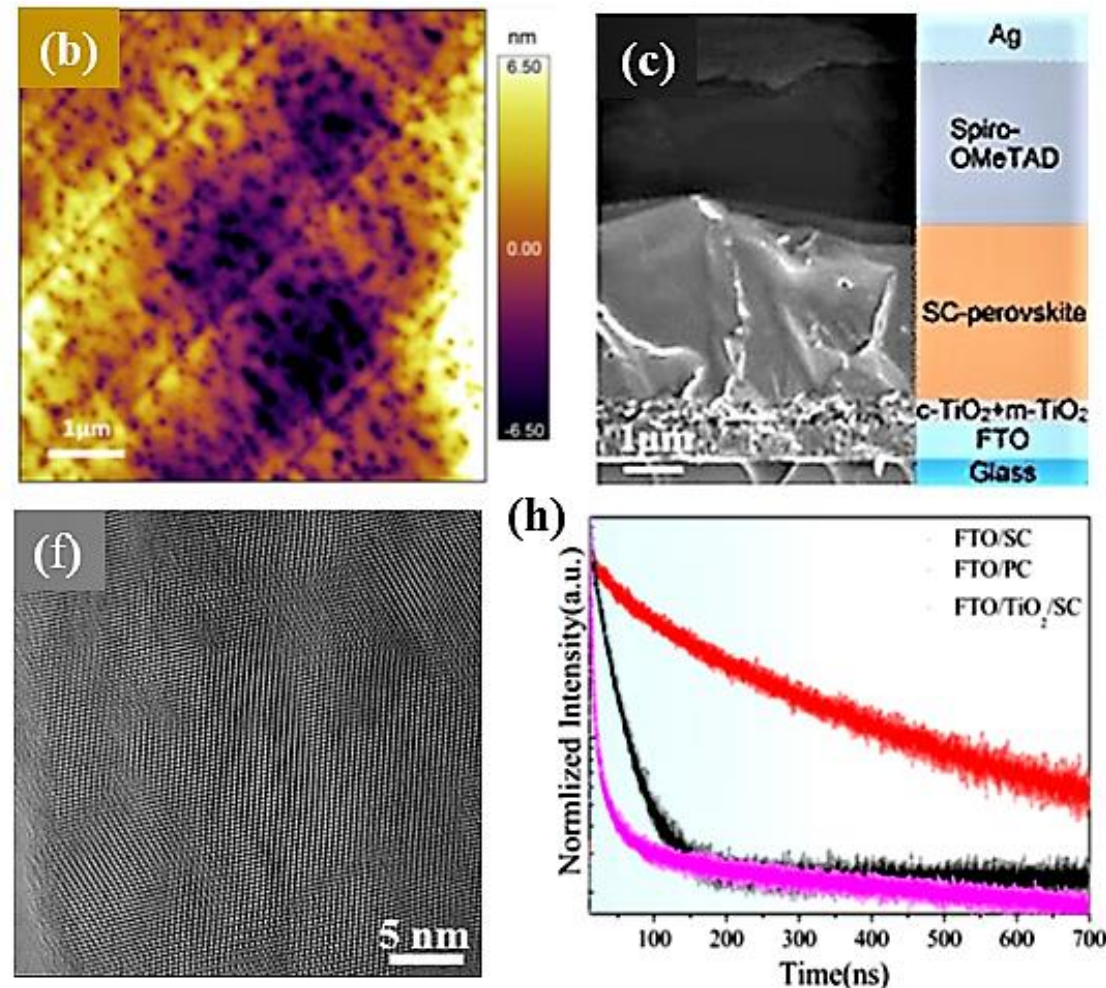

(h)
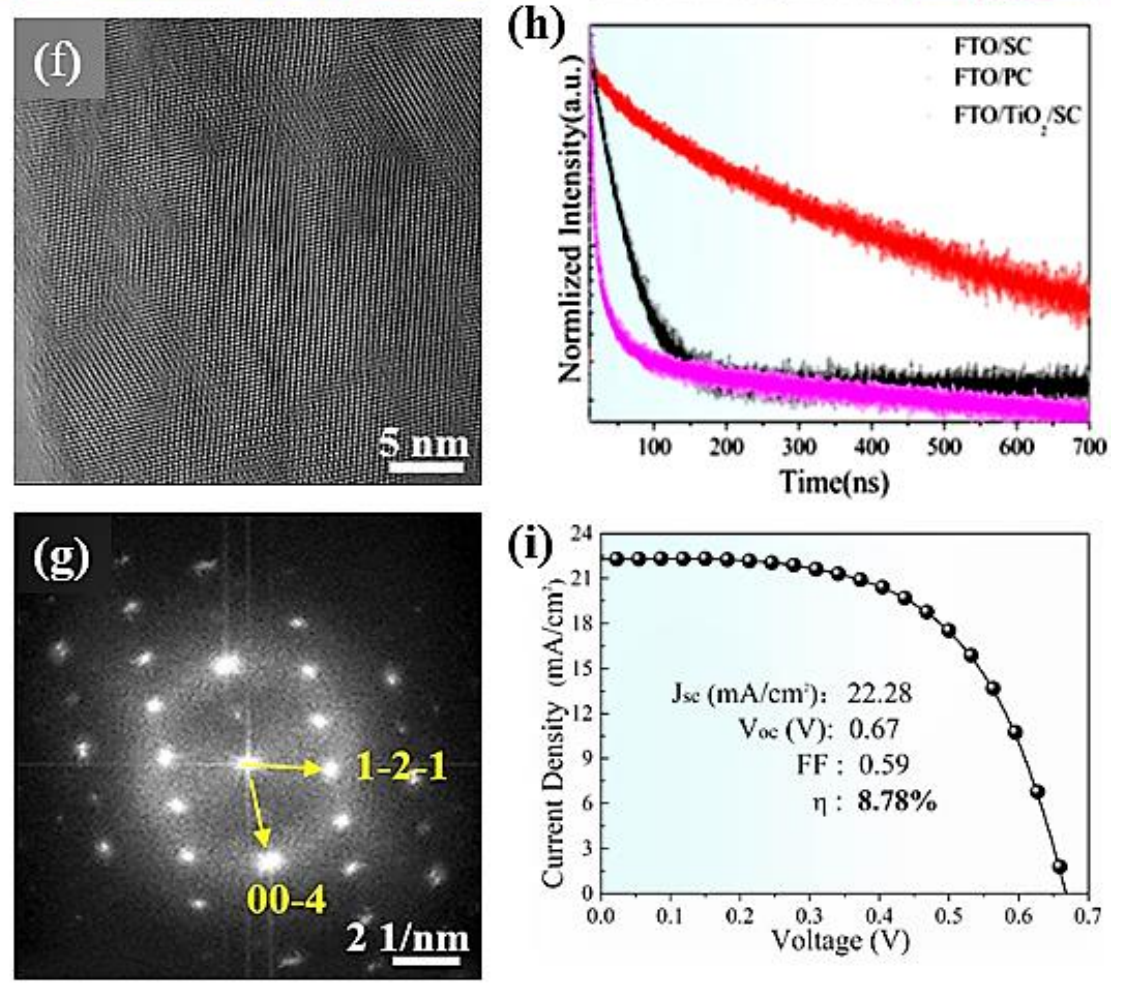

Figure 15. Schematic showing self-grown single-crystalline $\mathrm{CH}_{3} \mathrm{NH}_{3} \mathrm{PbI}_{3}$ film via a temperature gradient and the capillary effect. b) Topographical mapping of as grown perovskite films. c) Cross-sectional SEM micrograph glass/FTO/TiO $/$ Perovskite/ Spiro-OMeTAD/Ag solar cell device. d), e) Selected profiles of the reflections presented in pseudocubic setting, measured from $\mathrm{CH}_{3} \mathrm{NH}_{3} \mathrm{PbI}_{3}$ on an $\mathrm{FTO} / \mathrm{TiO}_{2}$ substrate. f), g) HRTEM micrograph of single-crystalline $\mathrm{CH}_{3} \mathrm{NH}_{3} \mathrm{PbI}_{3}$ and corresponding FFT pattern showing the well-ordered crystalline lattice. h) TRPL of single-crystalline and polycrystalline $\mathrm{CH}_{3} \mathrm{NH}_{3} \mathrm{PbI}_{3}$ on various substrates i) $J-V$ curves of the champion glass/FTO/TiO $2 /$ Perovskite/ Spiro-OMeTAD/Ag solar cell device. (Reprinted from ref.120 copyright 2017 Elsevier). 
Table 4. Comparison of single-crystal-based solar cells

\begin{tabular}{|c|c|c|c|c|c|c|c|}
\hline $\begin{array}{l}\text { S. } \\
\text { No }\end{array}$ & Device Configuration & $\begin{array}{l}\text { Thickness } \\
(\mu \mathrm{m})\end{array}$ & $\begin{array}{l}\mathrm{JSC} \\
\left(\mathrm{mA} \mathrm{cm} \mathrm{cm}^{-2}\right)\end{array}$ & $\begin{array}{l}\text { VoC } \\
(\mathrm{V})\end{array}$ & $\begin{array}{l}\text { FF } \\
(\%)\end{array}$ & $\begin{array}{l}\text { PCE } \\
(\%)\end{array}$ & Ref. \\
\hline 1. & FTO/PVK/Au & 16 & 7.77 & 0.65 & 0.39 & 1.98 & 202 \\
\hline 2. & $\mathrm{FTO} / \mathrm{TiO}_{2} / \mathrm{PVK} / \mathrm{Au}$ & 16 & 8.35 & 0.91 & 0.53 & 4.08 & 202 \\
\hline 3. & $\mathrm{FTO} / \mathrm{TiO}_{2} / \mathrm{PVK} / \mathrm{HTM} / \mathrm{Au}$ & 16 & 8.77 & 1.31 & 0.62 & 7.11 & 202 \\
\hline 4. & $\begin{array}{l}\mathrm{FTO} / \mathrm{TiO}_{2} / \mathrm{CH}_{3} \mathrm{NH}_{3} \mathrm{PbI}_{3} / \text { Spiro-OMe } \\
\text { TAD/ Ag }\end{array}$ & ------ & 22.283 & 0.668 & 0.59 & 8.78 & 84 \\
\hline 5. & ITO/MAPbBr $3 / \mathrm{Au}$ & 1 & 7.39 & 1.25 & 0.59 & 5.49 & 31 \\
\hline 6. & $\mathrm{FTO} / \mathrm{TiO}_{2} / \mathrm{MAPbBr}_{3} / \mathrm{Au}$ & 1 & 6.96 & 1.36 & 0.69 & 6.53 & 31 \\
\hline 7. & $\mathrm{Au} / \mathrm{SiO}_{2} / \mathrm{MAPbI} 3 / \mathrm{Au}$ & 33 & 18.33 & 0.801 & 0.329 & 4.83 & 203 \\
\hline 8. & $\mathrm{Au} / \mathrm{SiO}_{2} / \mathrm{MAPbI}_{3} / \mathrm{PCBM} / \mathrm{Ag}$ & ------- & 0.974 & 0.803 & 0.248 & 0.194 & 203 \\
\hline
\end{tabular}

From the TRPL measurements, it was observed that the average carrier lifetime of $206.2 \mathrm{~ns}$ for the single-crystalline perovskite is 25.5 times longer than that for its polycrystalline counterpart (8.1 ns), which is attributed to the exciton lifetime in the polycrystalline form being deteriorated by grain boundaries and defects, which contribute to increased electron transport resistance and bimolecular recombination. Conversely, for the $\mathrm{FTO} / \mathrm{TiO}_{2}$ case, the carrier lifetime (11.2 ns) for the single-crystal is considerably reduced due to the efficient carrier extraction at the $\mathrm{TiO}_{2} /$ perovskite interface.

The devices fabricated with n-i-p-type PSCs (Fig. 15i) with the $\mathrm{FTO} / \mathrm{TiO}_{2} / \mathrm{CH}_{3} \mathrm{NH}_{3} \mathrm{PbI}_{3} / \mathrm{Sp}_{\text {iro- }}$ OMeTAD/Ag configuration were characterized in the forward and reverse scan directions. Under the reverse-bias scan, these PSCs exhibited an open-circuit voltage $\left(\mathrm{V}_{\mathrm{oc}}\right)$ of $0.668 \mathrm{~V}$, a $J_{\mathrm{sc}}$ of $22.283 \mathrm{~mA} / \mathrm{cm}^{2}$, and an $F F$ of 0.590 , thus yielding a PCE of $8.78 \%$, whereas under the forward scan, they showed a $V_{\text {oc }}$ of $0.649 \mathrm{~V}$, a $J_{\mathrm{sc}}$ of $22.143 \mathrm{~mA} / \mathrm{cm}^{2}$, and an $F F$ of 0.572 , resulting in a slightly smaller efficiency of $8.22 \%$. 
The slight decrease in the efficiency is attributed to the thin film coverage issue, and hence, the singlecrystalline PSCs are expected to improve with full coverage such that they rival their polycrystalline counterparts. In summary, a narrower bandgap, a higher exciton concentration with less recombination, and highly efficient electron extraction are crucial factors for highly efficient single-crystalline PSCs.
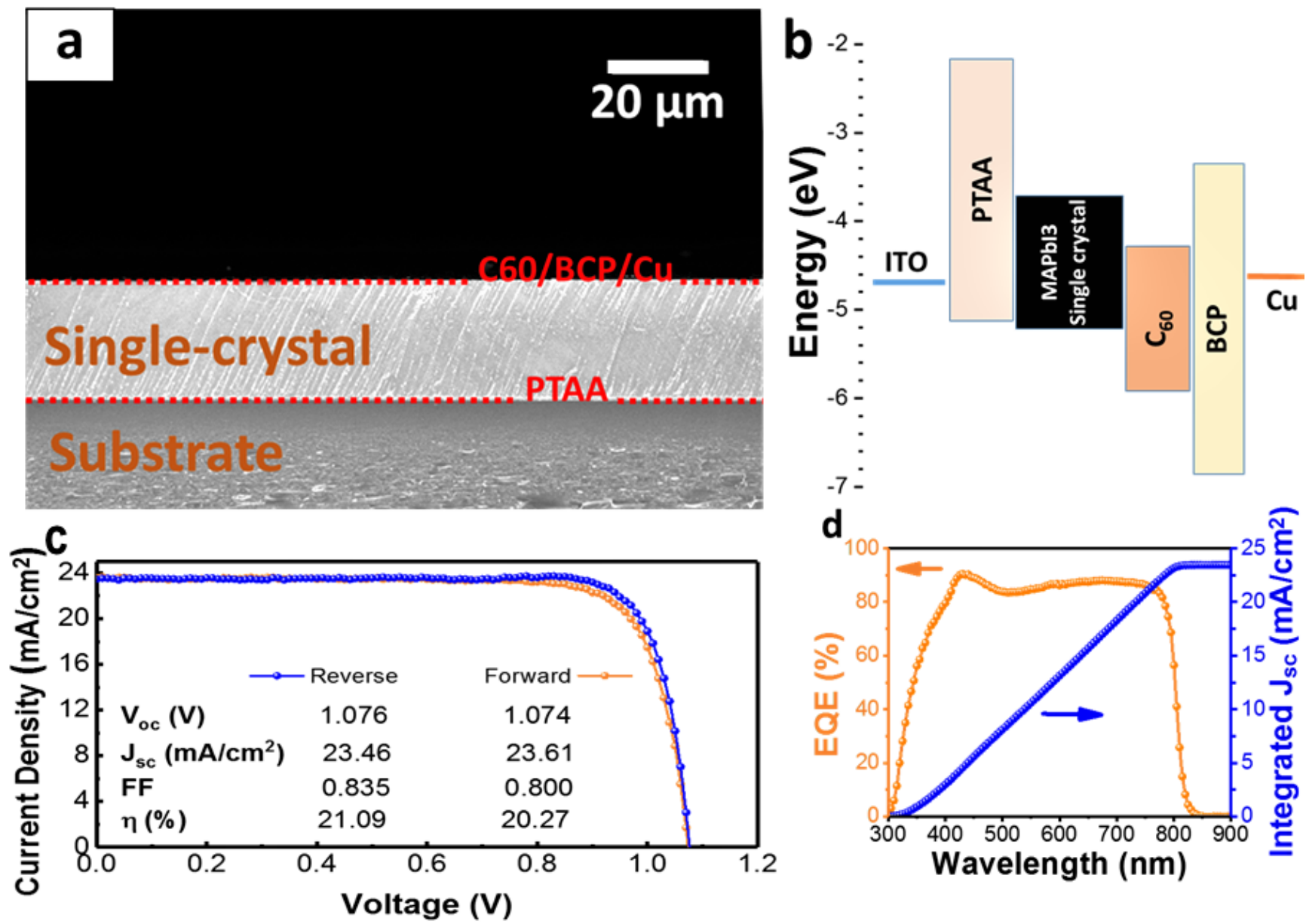

Figure 16. a) Cross-sectional image of the solar cell device, b) Schematic band alignment c) $J-V$ solar cell characteristics. d) (EQE) and integrated JSC of the champion device respectively. (Reprinted with permission from ref. ${ }^{204}$ copyright 2019 American Chemical Society).

There are two approaches to realizing these factors: i) utilizing a p-i-n architecture with the device configuration of ITO/PEDOT:PSS/perovskite/PCBM (spray)/silver paste or/Al and (ii) using polymer bezel in an n-i-p architecture of FTO/PCBM/perovskite/Spiro-OMeTAD/Au or silver paste/PCBM/perovskite/Spiro-OMeTAD/Au, which is a substrate-free architecture. ${ }^{102}$ 
The below-bandgap absorption is found to narrow down the effective optical bandgap in perovskite single crystals when employed in devices exhibited a high PCE of $17.8 \% .^{205}$ In augmentation, recently a record efficiency of $21.09 \%$ and FFs of up to $84.3 \%$ was accomplished using $\sim 20 \mu \mathrm{m}$ thick $\mathrm{MAPbI}_{3}$ single-crystal absorber layer in an inverted p-i-n architecture. The device architecture, energy landscape, current-voltage characteristics, corresponding external quantum efficiency (EQE) and integrated $J_{\mathrm{SC}}$ of the champion device are shown in Fig.16 (a-d) respectively. ${ }^{204}$

\section{Chemistry on the surface of the crystal}

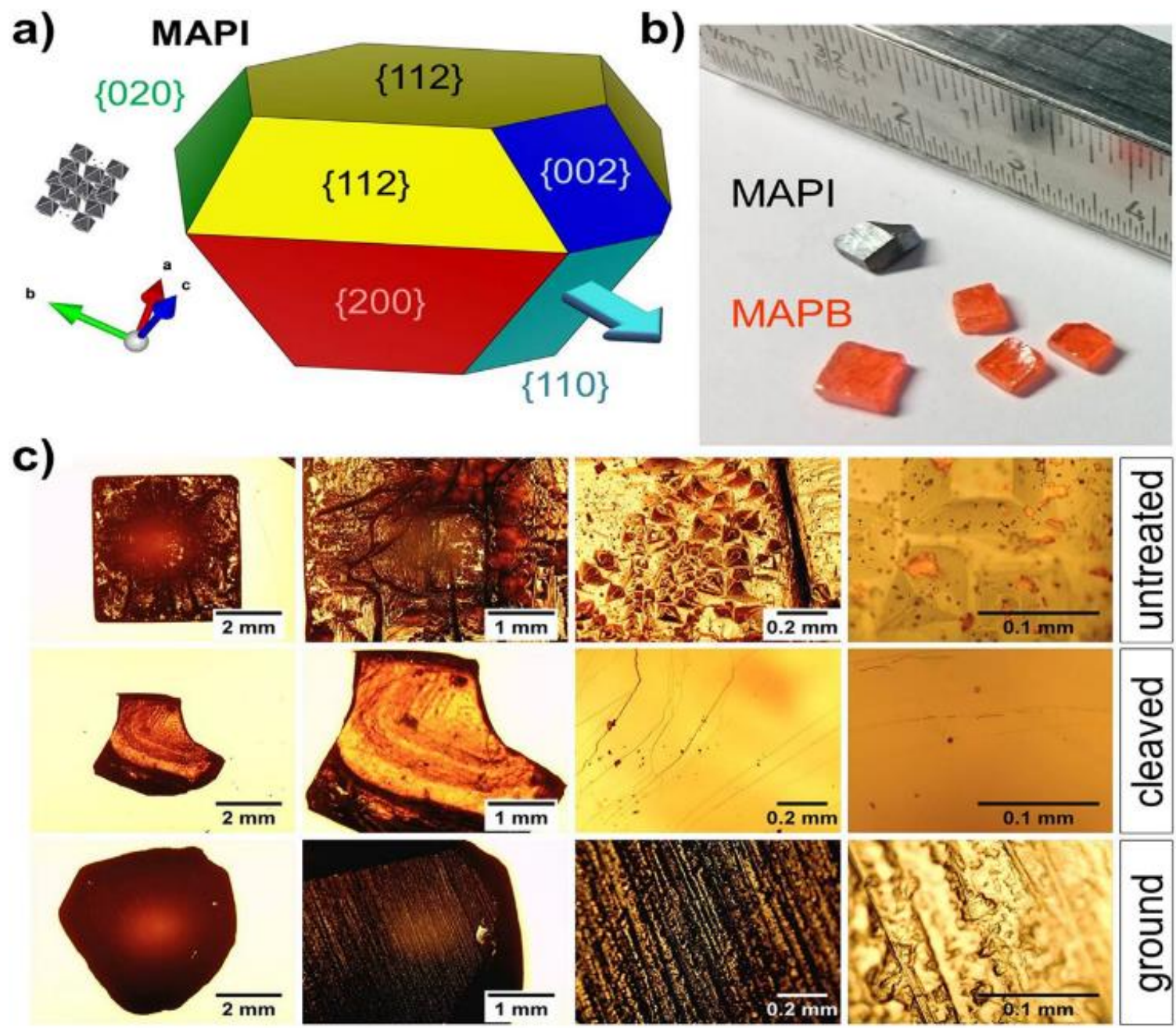

Figure 17. a) Preferred crystal geometry of single-crystal $\mathrm{MAPbI}_{3}$ represented by color coding and the turquoise arrow pointing in the preferred growth direction parallel to the $\langle 110\rangle$ lattice vectors as indicated. b) Polyhedral $\mathrm{MAPbI}_{3}$ and cuboidal $\mathrm{MAPbBr}_{3}$ (MAPB) single-crystals. c) Optical microscopic 
images of an untreated $\mathrm{MAPbBr}_{3}$ crystal (top row), a cleaved $\mathrm{MAPbBr}_{3}$ crystal (middle) and a sandpaper ground $\mathrm{MAPbI}_{3}$ crystal (bottom) at different magnifications. (Reprinted with permission from ref. 102 copyright 2018 Nature Publishing Group).

The as-grown crystals of $\mathrm{MAPbBr}_{3}$ exhibit a cuboidal shape, whereas $\mathrm{MAPbI}_{3}$ crystals exhibit a polyhedral shape, and the preferential growth direction for tetragonal $\mathrm{MAPbI}_{3}$ is along the $<110>$ crystallographic direction, as shown in Fig. 17a. In Fig. 17b, single-crystals of both $\mathrm{MAPbI}_{3}$ and $\mathrm{MAPbBr}_{3}$ are presented. The optical microscopy images presented in Fig. 17c are of an aged $\mathrm{MAPbBr}_{3}$ crystal at different magnifications. It has also been documented that there is an increase in the crystal surface roughness when dipping the crystals into the solvent from which they were synthesized. ${ }^{102}$ With the help of nitrogen gas drying of crystals, recrystallization occurs through the dissolution of material on the surface of the crystal, which leads to the surface treatment called cleaving, represented in the middle row of Fig. 17. Based on the surface treatments, the $\mathrm{MAPbI}_{3}$ crystals are expected to be more brittle than $\mathrm{MAPbBr}_{3}$ crystals. ${ }^{102}$

The density of surface traps plays a crucial role in the degradation of device performance. Surface recombination leads to the loss of carriers and frequently plays the primary role in determining the optoelectronic properties of semiconductors; in addition, the interface materials also play a significant role in the function of the device. To approach the thermodynamic efficiency limits of solar cells and other optoelectronic devices, a low surface recombination rate is vital. Hence, restraining the recombination of the carriers at the surface of perovskite crystals is crucial for designing devices. The interaction of MHPs with the environment has a significant impact on the morphology, photostability and optoelectronic properties of perovskites. ${ }^{206-209}$ It has already been reported that moisture and possibly oxygen molecules can affect the perovskite lattice strain, with a resultant shift in the photoluminescence (PL) spectrum. ${ }^{210}$ The PL results indicated a yield improvement in an oxygen atmosphere, which is $50 \mid \mathrm{P}$ a g e 
associated with the photochemical reaction occurring at the surface of bulk $\mathrm{MAPbI}_{3} .{ }^{208}$. Furthermore, water infiltration into $\mathrm{MAPbI}_{3}$ films can enhance the ionic conductivity. ${ }^{209}$ Comparing polycrystalline thin films and single-crystals, the intrinsic response and optoelectronic properties of devices may be limited by the microstructure quality and non-crystalline domains in thin films, whereas this issue is overcome in single-crystals, making them the ideal platform to investigate the intrinsic material properties as well as surface recombination. The single (1p) and two-photon (2p) excitation in the $\mathrm{MAPbBr}_{3}$ singlecrystals demonstrated an unusually low surface recombination velocity of $4 \mathrm{~cm} / \mathrm{s}$ attributing to the physisorption of $\mathrm{O}_{2}$ and $\mathrm{H}_{2} \mathrm{O}$ molecules.

(a)
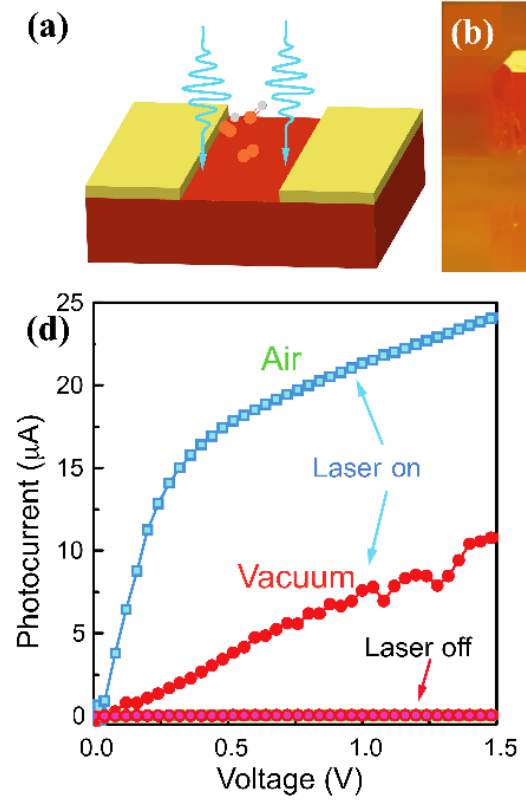
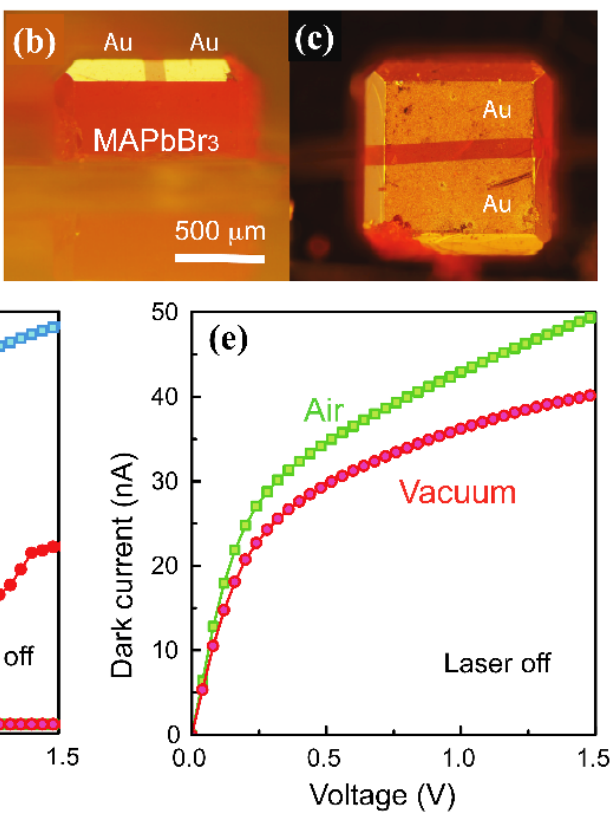

(f)

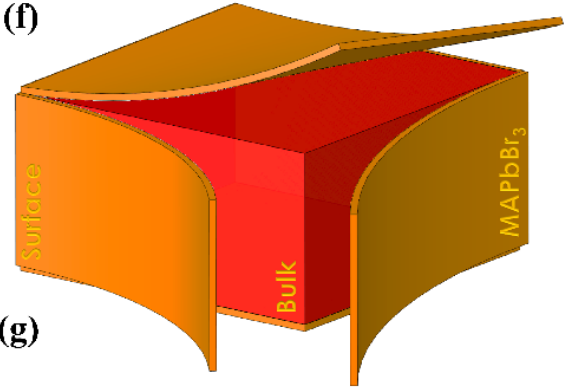

(g)

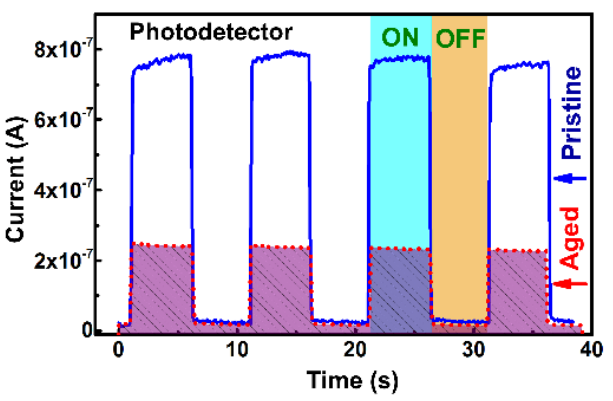

Figure 18. a) Schematic device architecture, $(b, c)$ cross-sectional view and top view of the planar singlecrystal device used for $I-V$ measurements. d) Laser-illumination-dependent $I-V$ characteristics. e) Dark $I$ $V$ characteristics in air and under vacuum. (Reprinted with permission from ref. ${ }^{211}$ copyright 2016 American Association for the Advancement of Science). f) Schematic showing the aged surface and the cleaved pristine surface used for photodetector measurements. g) $O N$ and $O F F$ response cycles of aged and pristine surfaces under AM 1.5G illumination. (Reprinted with permission from ref. ${ }^{212}$ copyright 2017 American Chemical Society). 
The photophysical and charge transport properties of $\mathrm{MAPbBr}_{3}$ single-crystals are ultrasensitive to the environment and areare entirely and quantitatively reversible. This can be considered as the basis for improving the sensitivity of $\mathrm{MAPbBr}_{3}$-based gas detectors. Fang et al. investigated the charge transfer properties of $\mathrm{MAPbBr}_{3}$ devices in both vacuum and air with and without laser illuminations, as illustrated in Fig. 18(a-e). Significant change in the photocurrent is observed compared to the dark current. The photocurrent is sensitive to the incoming beam light, ambient and the surface trap sites. The trapping sites in $\mathrm{MAPbBr}_{3}$ can be deactivated by a photochemical reaction involving oxygen that causes nonreversible PL enhancement. ${ }^{213}$ The PL modulation is fast and reversible in $\mathrm{MAPbBr}_{3}$ single-crystals due to the physical processes (reversible physisorption of $\mathrm{O}_{2}$ and $\mathrm{H}_{2} \mathrm{O}$ ), rather than the photochemical reactions and hence the $\mathrm{MAPbBr}_{3}$ crystals exhibit high photostability under ambient conditions compared to $\mathrm{MAPbI}_{3}$. $^{214}$

In the advancement of surface studies, the single-crystals were cleaved under ultrahigh vacuum to probe into the intrinsic structural and optoelectronic properties for both pristinely cleaved and aged surfaces. (Fig. 18f). ${ }^{193}$ It was conclusively established that surface restructuring on aged surfaces leads to changes in the optical properties, composition, bandgap, charge carrier dynamics, photocurrent, and performance of photovoltaic devices.
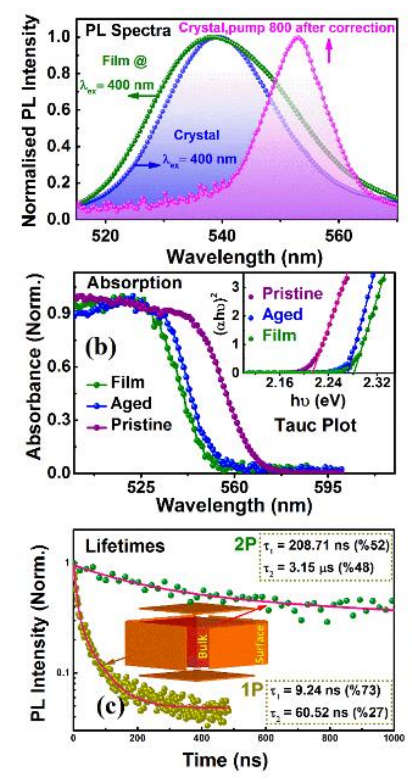
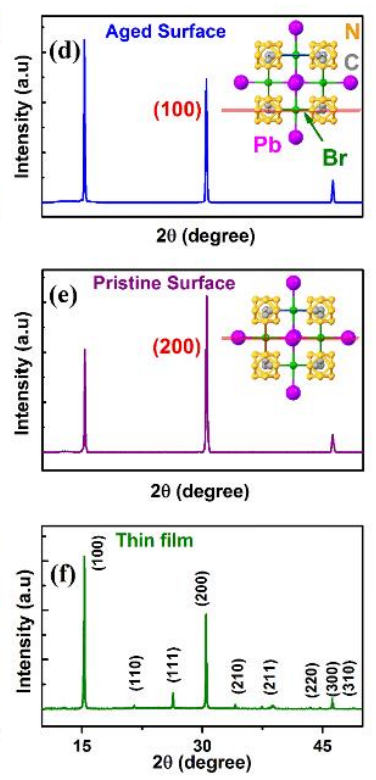
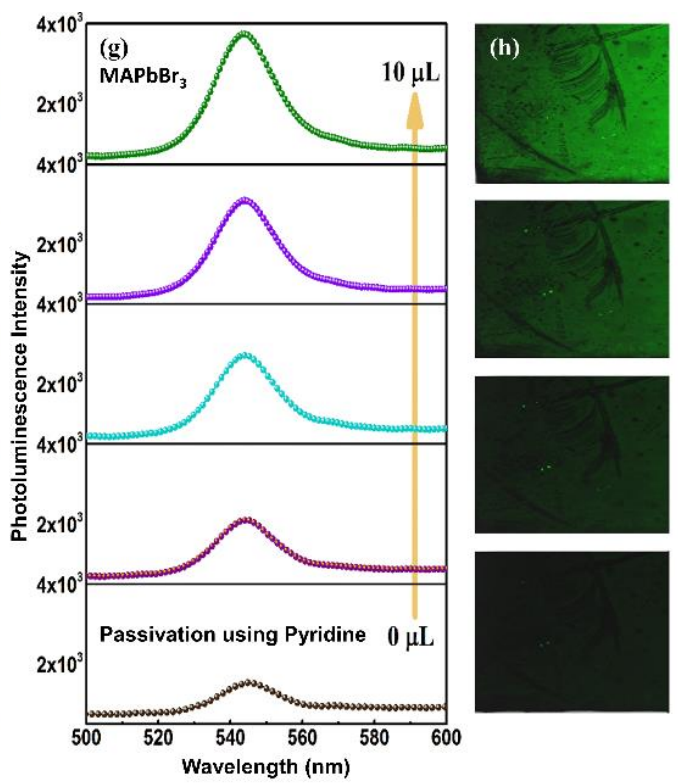
Figure 19. Optical properties of $\mathrm{MAPbBr}_{3}$ single-crystal: a) Normalized PL spectra at various excitation wavelengths as indicated. b) Absorption spectra recorded from a $\mathrm{MAPbBr}_{3}$ thin film, aged and pristine surfaces of $\mathrm{MAPbBr}_{3}$ single-crystal. Inset showing the Tauc plot and calculated bandgaps. c) Carrier lifetimes of $\mathrm{MAPbBr}_{3}$.XRD pattern for the d) aged, e) pristine surfaces and f) thin film. (Reprinted with permission from ref. ${ }^{193}$ copyright 2016 American Chemical Society). g) PL enhancement and h) Confocal scanning micrographs upon passivating the surface with pyridine. (Reprinted with permission from ref. 212 copyright 2017 American Chemical Society)

In general, the crystal surfaces are prone to hydration in the open ambient and suffer from surface degradation. $^{215}$ The relative humidity $(\mathrm{RH}) \geq 55 \%$ are shown to affect the crystallization process and deteriorate the device performance. ${ }^{216-218}$ It is important to note that the single-crystals are sensitive to exposure to different environments of moist and dry gases. ${ }^{219,193}$ Interestingly, pristine surfaces are prone to hydration and convert into polycrystalline surfaces when placed under ambient conditions over an extended period. ${ }^{193}$ To validate this phenomenon, a simple photodetector was fabricated with the $\mathrm{Au} / \mathrm{MAPbBr}_{3} / \mathrm{Au}$ configuration, which showed a higher photocurrent for the pristine surface and a lower photocurrent for the aged surface (Fig. 18g). ${ }^{193}$ These experiments demonstrated that the surface of the single-crystal transforms to polycrystalline due to perovskite hydrate formation through the intake of $\mathrm{H}_{2} \mathrm{O} .{ }^{193}$

Steady-state absorption and time-resolved photoluminescence studies of single-crystals of $\mathrm{MAPbBr}_{3}$ upon $1 \mathrm{p}$ and $2 \mathrm{p}$ excitation further confirmed the different behaviors, in terms of the absorption spectra, optical bandgap, and transient absorption, of the aged surface and the pristine surface (Fig. 19 (a-c)). ${ }^{218 \text {, }}$ 220, 221 As illustrated in Fig. 19a, the PL peaks of $1 \mathrm{p}$ and $2 \mathrm{p}$ excitation appeared at 540 and $580 \mathrm{~nm}$, respectively. The reabsorption of light occurs due to the large penetration depth, so the peak appears at $580 \mathrm{~nm}$; however, upon correction using the diffusion length and absorption coefficient, the peak more prominently appears at $555 \mathrm{~nm}$ (inset of Fig. 19b). ${ }^{36,222}$ Herein, the aged surface and the film were having 
the band gap $2.27 \mathrm{eV}$ and $2.28 \mathrm{eV}$, respectively, and the pristine surface has $2.22 \mathrm{eV}$, indicating that the aged surface resembles the polycrystalline film. ${ }^{193}$ Based on these observations on the surface transformation of a single-crystal, it is very necessary to optimize the surface quality and stability of the perovskite single-crystals for further improvement of optoelectronic and photovoltaic devices. ${ }^{193}$

Additionally, to probe the structural abnormalities in these pristine and aged surfaces, X-ray diffraction measurements were carried out, showing two characteristic orientations along the (100) and (200) planes (Fig. 19(d-f)). ${ }^{193,223,224}$ X-ray photoelectron spectroscopy (as shown in the image) revealed excess oxygen present on the aged surface of the crystal and completely absent in the case of the pristine surface, further confirming that perovskite hydrate is formed on the single-crystal due to water absorption. ${ }^{127}$ Recently, studies have focused on modulating surface traps and recombination velocities by passivating the surface of a single-crystal using small molecules. In a typical study, a PL enhancement (Fig. 19g) combined with a clear contrast between the confocal laser micrographs (Fig. 19h) of samples with and without the addition of pyridine, related to the single-crystal thickness, was observed, suggesting surface passivation of single crystals. ${ }^{212}$ 

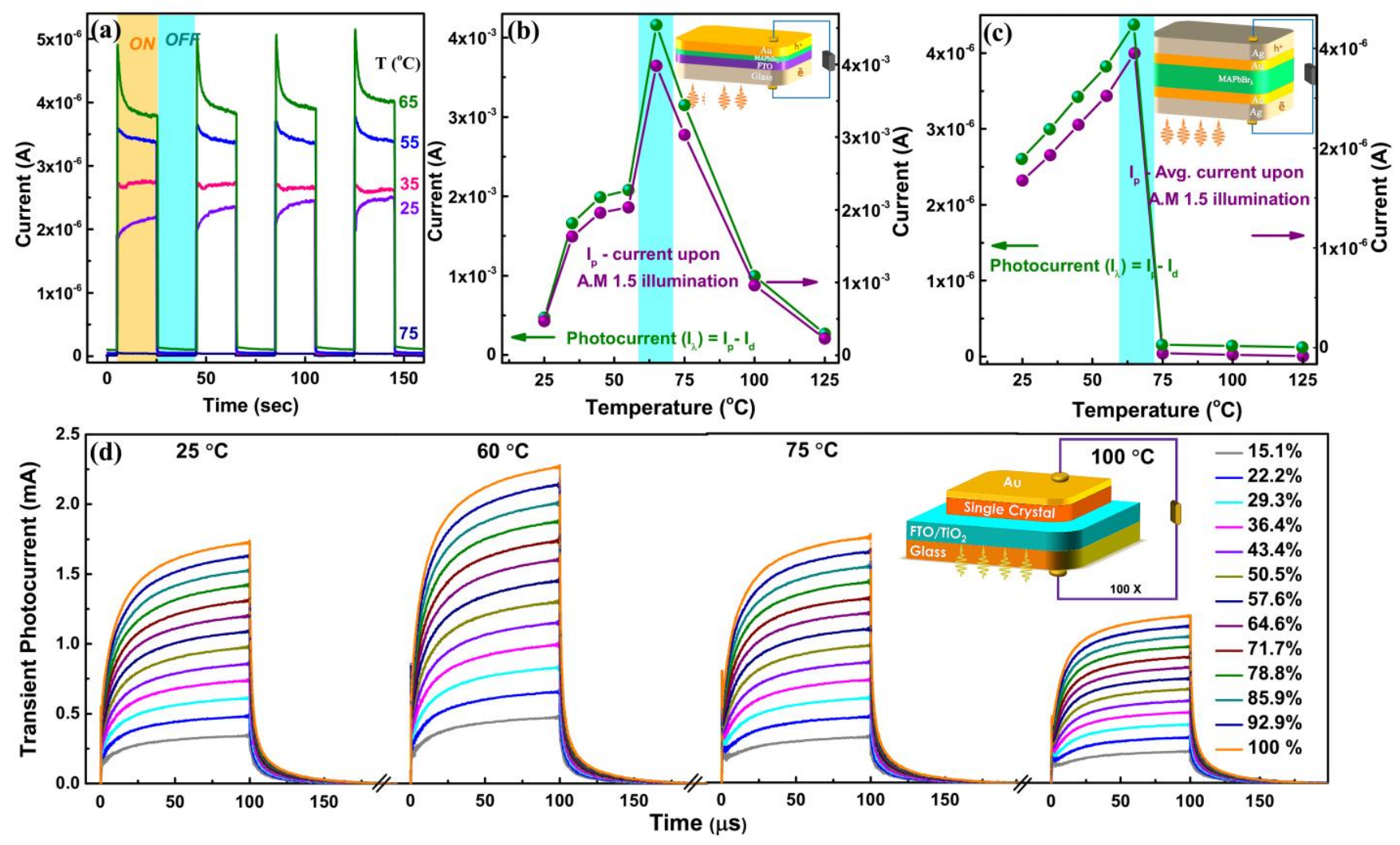

Figure 20. a) Steady-state photo responsive $O N$ and $O F F$ cycles obtained under AM $1.5 \mathrm{G} 1$ sun illumination. b, c) Photocurrents obtained from the devices (shown in the insets) at various temperatures for thick single-crystal and monocrystalline $\mathrm{MAPbBr}_{3}$ thin-film respectively. d) Solar light intensitydependent transient photocurrent traces obtained at various temperatures from the device shown in the inset. (Reprinted with permission from ref. ${ }^{166}$ copyright 2017 American Chemical Society)

One of the critical challenges impeding the efficient utilization of single-crystal devices is suitable operation conditions. The direct correlations between the annealing temperature and the structural, optical, electrical and electronic properties, charge carrier dynamics, and device performance of perovskite singlecrystals was recently established. ${ }^{166}$ As shown in Fig. 20, definite enhancements in the performances of both steady-state photodetectors $\left(\mathrm{Au} / \mathrm{MAPbBr}_{3} / \mathrm{FTO}, \mathrm{Au} / \mathrm{MAPbBr} 3 / \mathrm{Au}\right)$ and a transient photoresponse photodetector $\left(\mathrm{Au} / \mathrm{MAPbBr}_{3} / \mathrm{TiO}_{2} / \mathrm{FTO}\right)$ were observed at $60 \pm 5{ }^{\circ} \mathrm{C}$. It was also shown that the singlecrystal at $60 \pm 5^{\circ} \mathrm{C}$ exhibits a relaxed cubic crystal structure. Therefore, after careful investigation of the 
carrier mobilities, carrier lifetimes, photodetector and solar cell performances, the ideal operational window is established as $60 \pm 5^{\circ} \mathrm{C}$.

The single-crystal counterparts of these perovskites grown successfully by various crystal growth techniques, depending on the desired dimensions of the single-crystals utilized for multiple applications, are discussed in detail. Growing thinner single-crystals (few microns) of larger sizes with orientation control to realize practical photodetectors or solar cell applications of perovskites is challenging. Hence, innovative strategies are urgently needed for attaining a significantly large area of monocrystalline thin films.

Another consequential challenge is the surface restructuring of perovskites under relatively high humidity levels. A severe instability is anticipated when a photodetector is built based on hydrated surfaces due to the high resistances arising at the metal/semiconductor interfaces. Due to such surface deterioration, a strain is induced in the crystal lattice, which affects the optoelectronic behavior of the perovskite. Recently, some preliminary studies have focused on passivating the surface of single-crystals using amine-based solvents. ${ }^{225}$ A recent study showed that reacting the single-crystal surfaces with waterinsoluble lead (II) oxysalt improved the stability of devices and maintained $96.8 \%$ of their initial efficiency under constant irradiation of 1 Sun for $1200 \mathrm{hr}$ at $65^{\circ} \mathrm{C} .{ }^{226}$ It is also reported that the existence triiodide ions can act as hole-trapping centers that can deteriorate the device performance and by carefully controlling the crystal growth by reduction treatments can improve the photocurrent by few orders of magnitude. ${ }^{227}$

\section{Conclusions and perspectives}

Undoubtedly the perovskite single crystals have captivated the research interests of perovskite community due to their remarkable optical properties and potential optoelectronic applications. Herein, this review describes advancements in the growth methods of the single crystal 
perovskites, chemical stability, ion migration, surface and interface of the PSCs, and the applications of the single crystal perovskite in different device fabrications.

The perovskite with an ideal optimised bandgap can harvest more solar radiation and is paramount for efficient device fabrication. Various innovative approaches and strategies are recently being developed to enhance the performance and improved thermal, photo-, and structural stability of PSCs by utilizing the template-based and solution-processed perovskite films to accomplish highest efficiencies of $20.56 \% .^{228-229}$ There are few challenges that need to be addressed to achieve high-efficiency single-crystal solar cells: i) confining the vertical thickness of the perovskite single crystal in the order of tens of micron-scale to minimize the recombination of the charge carriers. The complexity in growing large area films with lateral dimensions up to a few tens of square millimeters needs to be addressed. The hydrophobic interface-confined lateral growth method, is believed to yield large-area films. Although the space confined methods are broadly used in growing the thin single crystalline films, the reproducibility is subject to various laboratory growth conditions. Therefore, seeding the substrate subsequent to the solution injection can be a viable solution, however efforts are to be directed to passivate the surface nonradiative recombination and enhance the carrier collection to push the efficiency towards theoretical limit; ii) increasing the carrier concentration in thick perovskite single crystals films through doping, so the ohmic loss can be reduced during the charge carrier collection. Albeit the fact that doping can tune the bandgap and increase the conductivity of perovskite single crystals, at very high doping levels, semiconductor may behave as a metal, so care has to be taken to introduce optimal doping of metal ions into perovskite lattice; iii) new device architectures have to be designed such as lateral device architecture auxiliary to the material optimization. Attention is needed to minimize the lattice mismatch to avoid interfacial losses. Importantly the ideality factor of the photodiode 
needs to at unity to avoid recombination losses, and iv) special care has to be taken to establish effective electronic contacts between the interfaces to minimize the defects and traps.

The interdependence of structure-property correlations in the single-crystalline perovskite films is yet to be established to enrich the high-speed photon detection applications. Researchers should focus on improving the preparation to control the orientation, thickness, and high-quality largearea single-crystalline films. Atomically thin 2D SCPs can also be excellent candidates for perovskite emitters in LEDs owing to their structural relaxations, bandgap tunability and increased PL intensity. Device stability can be improved by the introduction of the quasi 2D perovskites and surface treatments using the Lewis base treatments. Efforts also need to be focused on synthesizing the environmentally stable mixed combinations of $2 \mathrm{D} / 3 \mathrm{D}$ perovskites and employing them in the single junction or tandem cell for cost-effective, stable and efficient devices. Strategies need to be developed and challenges to be addressed in replacing unstable MA cation and toxic lead, to yield lead-free all-inorganic perovskites, that can pave a way for ambient stable devices.

We envisage that this perovskite technology may hold great promise to addressing our energy needs, however collective research efforts from multidisciplinary fields are highly encouraged to solve the challenges and make a synergetic effort. Perovskites single crystals have not limited their application to optoelectronics, such as solar cells, LEDs, transistors, photodetectors, and lasers however they have extended their use in the grounds of photoelectrochemical applications, carbon dioxide reduction and photocatalytic water splitting and set forth its journey to get explored in different fields of the science and technology.

\section{AUTHOR INFORMATION}

\section{Corresponding Author}


*E-mail: murali.banavoth@uohyd.ac.in

*E-mail: omar.abdelsaboor@kaust.edu.sa

Phone: +91402313 4828, +96628084491

\section{Notes}

The authors declare no competing financial interest.

\section{ACKNOWLEDGMENT}

This work was supported by the King Abdullah University of Science and Technology (KAUST) and School of Chemistry, University of Hyderabad. RK and HKK acknowledges Council of Scientific and Industrial Research (CSIR) and DST Inspire for Junior Research Fellowship (JRF) respectively. BM acknowledge the Department of Science and Technology (DST), Indo-Korea grant (No. INT/Korea/P-40) and (EEQ/2017/000304), Science \& Engineering Research Board (SERB).

\section{REFERENCES}

(1) Weber, D. $\mathrm{CH}_{3} \mathrm{NH}_{3} \mathrm{SnBr}_{\mathrm{X}} \mathrm{I}_{3-\mathrm{X}}(\mathrm{X}=0$-3), Ein $\mathrm{Sn}(\mathrm{II})-$ System Mit Kubischer Perowskitstruktur / $\mathrm{CH}_{3} \mathrm{NH}_{3} \mathrm{SnBr}_{\mathrm{X}} \mathrm{I}_{3-\mathrm{X}}(\mathrm{X}=0-3)$, A Sn(II)-System With Cubic Perovskite Structure, Zeitschrift für Naturforschung B 1978, 33, 862-865.

(2) Kojima, A.; Teshima, K.; Shirai, Y.; Miyasaka, T. Organometal Halide Perovskites as VisibleLight Sensitizers For Photovoltaic Cells. J. Am. Chem. Soc. 2009, 131, 6050-6051.

(3) Dar, M. I.; Jacopin, G.; Hezam, M.; Arora, N.; Zakeeruddin, S. M.; Deveaud, B.; Nazeeruddin, M. K.; Grätzel, M. Asymmetric Cathodoluminescence Emission In $\mathrm{CH}_{3} \mathrm{NH}_{3} \mathrm{PbI}_{3-\mathrm{X}} \mathrm{Br}_{\mathrm{X}}$ Perovskite Single Crystals. ACS Photonics 2016, 3, 947-952.

(4) Saidaminov, M. I.; Adinolfi, V.; Comin, R.; Abdelhady, A. L.; Peng, W.; Dursun, I.; Yuan, M.; Hoogland, S.; Sargent, E. H.; Bakr, O. M. Planar-Integrated Single-Crystalline Perovskite Photodetectors. Nat. Commun. 2015, 6, 8724.

(5) Shi, D.; Adinolfi, V.; Comin, R.; Yuan, M.; Alarousu, E.; Buin, A.; Chen, Y.; Hoogland, S.; Rothenberger, A.; Katsiev, K.; Losovyj, Y.; Zhang, X.; Dowben, P. A.; Mohammed, O. F.; Sargent, E. H.; Bakr, O. M. Low Trap-State Density and Long Carrier Diffusion in Organolead Trihalide Perovskite Single Crystals. Science 2015, 347, 519. 
(6) Dong, Q.; Fang, Y.; Shao, Y.; Mulligan, P.; Qiu, J.; Cao, L.; Huang, J. Electron-Hole Diffusion Lengths $>175 \mu \mathrm{m}$ in Solution-Grown $\mathrm{CH}_{3} \mathrm{NH}_{3} \mathrm{PbI}_{3}$ Single Crystals. Science 2015, 347, 967-970.

(7) Dou, L.; Yang, Y.; You, J.; Hong, Z.; Chang, W.-H.; Li, G.; Yang, Y. Solution-Processed Hybrid Perovskite Photodetectors with High Detectivity. Nat. Commun. 2014, 5, 5404.

https://www.nature.com/articles/ncomms6404\#Supplementary-Information.

(8) Lahnsteiner, J.; Jinnouchi, R.; Bokdam, M. Long-Range Order Imposed by Short-Range Interactions in Methylammonium Lead Iodide: Comparing Point-Dipole Models to MachineLearning Force Fields. Phys. Rev. B 2019, 100, 094106.

(9) Stoumpos, C. C.; Malliakas, C. D.; Kanatzidis, M. G. Semiconducting Tin and Lead Iodide Perovskites with Organic Cations: Phase Transitions, High Mobilities, and Near-Infrared Photoluminescent Properties. Inorg. Chem. 2013, 52, 9019-9038.

(10) Hodes, G. Perovskite-Based Solar Cells. Science 2013, 342, 317-318.

(11) Huang, Y.; Zhang, Y.; Sun, J.; Wang, X.; Sun, J.; Chen, Q.; Pan, C.; Zhou, H. The Exploration of Carrier Behavior in the Inverted Mixed Perovskite Single-Crystal Solar Cells. Adv. Mater. 2018, $5,1800224$.

(12) Alarousu, E.; El-Zohry, A. M., Jin, Zhumekenov, A.A., Yang, C., Elhabshi, E., Gereige, I., AlSaggaf, A., Malko, A.V.; Bakr, O., Mohammed, O. F. Ultralong Radiative States in Hybrid Perovskite Crystals: Compositions for Sub-Millimeter Diffusion Lengths. J. Phys. Chem. Lett. 2017, 8, 4386-4390.

(13) Abdelhady, A. L.; Saidaminov, M. I.; Murali, B.; Adinolfi, V.; Voznyy, O.; Katsiev, K.; Alarousu, E.; Comin, R.; Dursun, I.; Sinatra, L.; Sargent, E. H.; Mohammed, O. F.; Bakr, O. M. Heterovalent Dopant Incorporation for Bandgap and Type Engineering of Perovskite Crystals. $J$. Phys. Chem. Lett. 2016, 7, 295-301.

(14) Bao, C.; Yang, J.; Bai, S.; Xu, W.; Yan, Z.; Xu, Q.; Liu, J.; Zhang, W.; Gao, F. High Performance and Stable All-Inorganic Metal Halide Perovskite-Based Photodetectors for Optical Communication Applications. Adv. Mater. 2018, 30, 1803422.

https://www.osa-opn.org/home/newsroom/2018/october/perovskite_photodetectors_for_lifi/ (15) Cho, N.; Li, F.; Turedi, B.; Sinatra, L.; Sarmah, S. P.; Parida, M. R.; Saidaminov, M. I.; Murali, B.; Burlakov, V. M.; Goriely, A.; Mohammed, O. F.; Wu, T.; Bakr, O. M., Pure Crystal Orientation and Anisotropic Charge Transport in Large-Area Hybrid Perovskite Films. Nat. Commun. 2016, 7, 13407.

(16) Ning, W.; Wang, F.; Wu, B.; Lu, J.; Yan, Z.; Liu, X.; Tao, Y.; Liu, J.-M.; Huang, W.; Fahlman, M.; Hultman, L.; Sum, T. C.; Gao, F., Long Electron-Hole Diffusion Length in HighQuality Lead-Free Double Perovskite Films. Adv. Mater. 2018, 30, 1706246.

https://liu.se/en/news-item/dubbla-perovskiter-i-framtidens-miljovanliga-solceller.

(17) Kanemitsu, Y. Luminescence Spectroscopy Of Lead-Halide Perovskites: Materials Properties And Application As Photovoltaic Devices. J. Mater. Chem. C 2017, 5, 3427-3437.

(18) Dursun, I.; Shen, C.; Parida, M. R.; Pan, J.; Sarmah, S. P.; Priante, D.; Alyami, N.; Liu, J.; Saidaminov, M. I.; Alias, M. S.; Abdelhady, A. L.; Ng, T. K.; Mohammed, O. F.; Ooi, B. S.; Bakr, O. M., Perovskite Nanocrystals as a Color Converter for Visible Light Communication. ACS. Photonics 2016, 3, 1150-1156. 
(19) Chen, Q.; Wu, J.; Ou, X.; Huang, B.; Almutlaq, J.; Zhumekenov, A. A.; Guan, X.; Han, S.; Liang, L.; Yi, Z.; Li, J.; Xie, X.; Wang, Y.; Li, Y.; Fan, D.; Teh, D. B. L.; All, A. H.; Mohammed, O. F.; Bakr, O. M.; Wu, T.; Bettinelli, M.; Yang, H.; Huang, W.; Liu, X. All-Inorganic Perovskite Nanocrystal Scintillators. Nature 2018, 561, 88-93.

(20) Zhang, Q.; Su, R.; Liu, X.; Xing, J.; Sum, T. C.; Xiong, Q., High-Quality Whispering-GalleryMode Lasing from Cesium Lead Halide Perovskite Nanoplatelets. Adv. Funct. Mater. 2016, 26, 6238-6245.

(21) Tan, Z.-K.; Moghaddam, R. S.; Lai, M. L.; Docampo, P.; Higler, R.; Deschler, F.; Price, M.; Sadhanala, A.; Pazos, L. M.; Credgington, D.; Hanusch, F.; Bein, T.; Snaith, H. J.; Friend, R. H. Bright Light-Emitting Diodes Based on Organometal Halide Perovskite. Nat. Nanotechnol. 2014, 9, 687.

https://ceramics.org/ceramic-tech-today/perovskite-materials-lead-to-better-leds-

possiblyadvance-flat-panel-displays.

(22) Nie, W.; Tsai, H.; Asadpour, R.; Blancon, J.-C.; Neukirch, A. J.; Gupta, G.; Crochet, J. J.; Chhowalla, M.; Tretiak, S.; Alam, M. A. High-Efficiency Solution-Processed Perovskite Solar Cells with Millimeter-Scale Grains. Science 2015, 347, 522-525.

(23) Wang, X.-D.; Li, W.-G.; Liao, J.-F.; Kuang, D.-B., Recent Advances in Halide Perovskite Single-Crystal Thin Films: Fabrication Methods and Optoelectronic Applications. Solar RRL 2019, 3, 1800294.

(24) Wang, K.; Yang, D.; Wu, C.; Shapter, J.; Priya, S., Mono-crystalline Perovskite Photovoltaics toward Ultrahigh Efficiency? Joule 2019, 3, 311-316.

(25) Xing, J.; Wang, Q.; Dong, Q.; Yuan, Y.; Fang, Y.; Huang, J. Ultrafast Ion Migration In Hybrid Perovskite Polycrystalline Thin Films Under Light and Suppression in Single Crystals. Phys. Chem. Chem. Phys. 2016, 18, 30484-30490.

(26) Halide Perovskite Phase Transitions Observations Using Temperature Dependent Photoluminescence Spectroscopy. https://www.edinst.com/phase-transitions-halide-perovskite/ (accessed Oct 10, 2019)

(27) Fan, Z.; Sun, K.; Wang, J., Perovskites for Photovoltaics: A Combined Review of OrganicInorganic Halide Perovskites and Ferroelectric Oxide Perovskites. J. Mater. Chem. A 2015, 3, 18809-18828.

(28) Hoefler, S. F.; Trimmel, G.; Rath, T. Progress on lead-free metal halide perovskites for photovoltaic applications: a review. Monatshefte für Chemie - Chemical Monthly 2017, 148, 795826.

(29) Dang, Y.; Ju, D.; Wang, L.; Tao, X. Recent Progress in the Synthesis of Hybrid Halide Perovskite Single Crystals. Cryst. Eng. Comm. 2016, 18, 4476-4484.

(30) Schuck, G.; Többens, D. M.; Koch-Müller, M.; Efthimiopoulos, I.; Schorr, S., Infrared Spectroscopic Study of Vibrational Modes across the Orthorhombic-Tetragonal Phase Transition in Methylammonium Lead Halide Single Crystals. J. Phys. Chem. C. 2018, 122, 5227-5237. 
(31) Peng, W.; Wang, L.; Murali, B.; Ho, K. T.; Bera, A.; Cho, N.; Kang, C. F.; Burlakov, V. M.; Pan, J.; Sinatra, L., Solution-Grown Monocrystalline Hybrid Perovskite Films for HoleTransporter-Free Solar Cells. Adv. Mater. 2016, 28, 3383-3390.

(32) Rao, H-S., Chen, B-X., Wang, X-D., Kuang D-B., Su C-Y. A Micron-scale Laminar $\mathrm{MAPbBr}_{3}$ Single Crystal for an Efficient and Stable Perovskite Solar Cell. Chem Commun. 2017, $53,5163$.

(33) Chen, J.; Zhou, S.; Jin, S.; Li, H.; Zhai, T. Crystal Organometal Halide Perovskites with Promising Optoelectronic Applications. J. Mater. Chem. C 2016, 4, 11-27.

(34) Dang, Y.; Ju, D.; Wang, L.; Tao, X., Recent Progress in the Synthesis of Hybrid Halide Perovskite Single Crystals. CrystEng Comm 2016, 18, 4476-4484.

(35) Lian, Z.; Yan, Q.; Lv, Q.; Wang, Y.; Liu, L.; Zhang, L.; Pan, S.; Li, Q.; Wang, L.; Sun, J.-L., High-Performance Planar-Type Photodetector on (100) Facet of MAPbI 3 Single Crystal. Sci. Rep. 2015, 5, 16563.

(36) Saidaminov, M. I.; Abdelhady, A. L.; Murali, B.; Alarousu, E.; Burlakov, V. M.; Peng, W.; Dursun, I.; Wang, L.; He, Y.; Maculan, G. High-quality Bulk Hybrid Perovskite Single Crystals Within Minutes by Inverse Temperature Crystallization. Nat. Commun. 2015, 6, 7586.

(37) Liu, Y.; Zhang, Y.; Yang, Z.; Yang, D.; Ren, X.; Pang, L.; Liu, S. Thinness- and ShapeControlled Growth for Ultrathin Single-Crystalline Perovskite Wafers for Mass Production of Superior Photoelectronic Devices. Adv. Mater. 2016, 28, 9204-9209.

(38) Wang, Q.; Bai, D.; Jin, Z.; Liu, S. Single-Crystalline Perovskite Wafers With a Cr Blocking Layer for Broad and Stable Light Detection in a Harsh Environment. RSC Adv. 2018, 8, 1484814853.

(39) Chen, Y.-X.; Ge, Q.-Q.; Shi, Y.; Liu, J.; Xue, D.-J.; Ma, J.-Y.; Ding, J.; Yan, H.-J.; Hu, J.S.; Wan, L.-J., General Space-Confined On-Substrate Fabrication of Thickness-Adjustable Hybrid Perovskite Single-Crystalline Thin Films. J. Am. Chem. Soc. 2016, 138, 16196-16199.

(40) Rao, H.-S.; Li, W.-G.; Chen, B.-X.; Kuang, D.-B.; Su, C.-Y., In Situ Growth of $120 \mathrm{~cm}^{2}$ $\mathrm{CH}_{3} \mathrm{NH}_{3} \mathrm{PbBr}_{3}$ Perovskite Crystal Film on FTO Glass for Narrowband-Photodetectors. Adv. Mater. 2017, 29, 1602639.

(41) Saidaminov, M. I.; Haque, M. A.; Almutlaq, J.; Sarmah, S.; Miao, X.-H.; Begum, R.; Zhumekenov, A. A.; Dursun, I.; Cho, N.; Murali, B.; Mohammed, O. F.; Wu, T.; Bakr, O. M. Inorganic Lead Halide Perovskite Single Crystals: Phase-Selective Low-Temperature Growth, Carrier Transport Properties, and Self-Powered Photodetection. Adv. Opt. Mater. 2017, 5, 1600704.

(42) Nazarenko, O.; Yakunin, S.; Morad, V.; Cherniukh, I.; Kovalenko, M. V. Single Crystals of Caesium Formamidinium Lead Halide Perovskites: Solution Growth and Gamma Dosimetry. NPG Asia Mater. 2017, 9, e373-e373.

(43) Mitzi, D. B. A Layered Solution Crystal Growth Technique and the Crystal Structure of $\left(\mathrm{C}_{6} \mathrm{H}_{5} \mathrm{C}_{2} \mathrm{H}_{4} \mathrm{NH}_{3}\right)_{2} \mathrm{PbCl}_{4}$. J. Solid State Chem. 1999, 145, 694-704.

(44) Dirin, D. N.; Cherniukh, I.; Yakunin, S.; Shynkarenko, Y.; Kovalenko, M. V. Solution-Grown $\mathrm{CsPbBr}_{3}$ Perovskite Single Crystals for Photon Detection. Chem. Mater. 2016, 28, 8470-8474. 
(45) Zhao, Y.; Tan, H.; Yuan, H.; Yang, Z.; Fan, J. Z.; Kim, J.; Voznyy, O.; Gong, X.; Quan, L. N.; Tan, C. S.; Hofkens, J.; Yu, D.; Zhao, Q.; Sargent, E. H. Perovskite Seeding Growth of Formamidinium-Lead-Iodide-Based Perovskites for Efficient and Stable Solar Cells. Nat. Commun. 2018, 9, 1607.

(46) Ye, T.; Fu, W.; Wu, J.; Yu, Z.; Jin, X.; Chen, H.; Li, H. Single-Crystalline Lead Halide Perovskite Arrays for Solar Cells. J. Mater. Chem. A 2016, 4, 1214-1217.

(47) Ding, J.; Yan, Q. Progress in Organic-Inorganic Hybrid Halide Perovskite Single Crystal: Growth Techniques and Applications. Sci. China Mater. 2017, 1-16.

(48) Nguyen, V.-C.; Katsuki, H.; Sasaki, F.; Yanagi, H., Single-Crystal Perovskites Prepared by Simple Solution Process: Cast-Capping Method. J. Cryst. Growth 2017, 468, 796-799.

(49) Wu, J.; Ye, F.; Yang, W.; Xu, Z.; Luo, D.; Su, R.; Zhang, Y.; Zhu, R.; Gong, Q., Perovskite Single-Crystal Microarrays for Efficient Photovoltaic Devices. Chem. Mater. 2018, 30, 45904596.

(50) Dang, Y.; Liu, Y.; Sun, Y.; Yuan, D.; Liu, X.; Lu, W.; Liu, G.; Xia, H.; Tao, X., Bulk Crystal Growth of Hybrid Perovskite Material $\mathrm{CH}_{3} \mathrm{NH}_{3} \mathrm{PbI}_{3}$. Cryst. Eng. Comm. 2015, 17, 665-670.

(51) Saidaminov, M. I.; Abdelhady, A. L.; Maculan, G.; Bakr, O. M., Retrograde Solubility of Formamidinium and Methylammonium Lead Halide Perovskites Enabling Rapid Single Crystal Growth. Chem. Commun. 2015, 51, 17658-17661.

(52) Zhang, T.; Yang, M.; Benson, E. E.; Li, Z.; van de Lagemaat, J.; Luther, J. M.; Yan, Y.; Zhu, K.; Zhao, Y., A Facile Solvothermal Growth of Single Crystal Mixed Halide Perovskite $\mathrm{CH}_{3}$ $\mathrm{NH}_{3} \mathrm{~Pb}\left(\mathrm{Br}_{1-} \mathrm{Cl}_{\mathrm{x}}\right)_{3}$. Chem. Commun. 2015, 51, 7820-7823.

(53) Han, Q.; Bae, S. H.; Sun, P.; Hsieh, Y. T.; Yang, Y. M.; Rim, Y. S.; Zhao, H.; Chen, Q.; Shi, W.; Li, G., Single Crystal Formamidinium Lead Iodide $\left(\mathrm{FAPbI}_{3}\right)$ : Insight into the Structural, Optical, and Electrical Properties. Adv. Mater. 2016, 28, 2253-2258.

(54) Mastroianni, S.; Heinz, F.; Im, J.-H.; Veurman, W.; Padilla, M.; Schubert, M.; Würfel, U.; Grätzel, M.; Park, N.-G.; Hinsch, A. Analysing the Effect of Crystal Size and Structure in Highly Efficient $\mathrm{CH}_{3} \mathrm{NH}_{3} \mathrm{PbI}_{3}$ Perovskite Solar Cells by Spatially Resolved Photo-and Electroluminescence Imaging. Nanoscale 2015, 7, 19653-19662.

(55) Kim, H. D.; Ohkita, H.; Benten, H.; Ito, S. Photovoltaic Performance of Perovskite Solar Cells With Different Grain Sizes. Adv. Mater. 2016, 28, 917-922.

(56) Chen, J.; Shi, T.; Li, X.; Zhou, B.; Cao, H.; Wang, Y. Origin of the High Performance of Perovskite Solar Cells With Large Grains. Appl. Phys. Lett. 2016, 108, 053302.

(57) Yuyama, K.-i.; Islam, M. J.; Takahashi, K.; Nakamura, T.; Biju, V., Crystallization of Methylammonium Lead Halide Perovskites by Optical Trapping. Angew. Chem. Int. Ed. 2018, 57, 13424-13428.

(58) Lee, L.; Baek, J.; Park, K. S.; Lee, Y.-E.; Shrestha, N. K.; Sung, M. M., Wafer-Scale SingleCrystal Perovskite Patterned Thin Films Based on Geometrically-Confined Lateral Crystal Growth. Nat. Commun. 2017, 8, 15882. 
(59) Chen, F.; Xu, C.; Xu, Q.; Zhu, Y.; Zhu, Z.; Liu, W.; Dong, X.; Qin, F.; Shi, Z. Structure Evolution Of $\mathrm{CH}_{3} \mathrm{NH}_{3} \mathrm{PbBr}_{3}$ Single Crystal Grown in N,N-Dimethylformamide Solution. Cryst. Growth Des. 2018, 18, 3132-3137.

(61) Chen, H.; Ge, C.; Li, R.; Wang, J. Bridgman Growth of Lead Molybdate Ccrystals. J. Mater. Sci. 2006, 41, 5383-5385.

(62) Bridgman, P. W. In Certain Physical Properties of Single Crystals of Tungsten, Antimony, Bismuth, Tellurium, Cadmium, Zinc, and Tin, Proc. Am. Acad. Arts Sci. JSTOR 1925, 305-383.

(63) Stoumpos, C. C.; Malliakas, C. D.; Peters, J. A.; Liu, Z.; Sebastian, M.; Im, J.; Chasapis, T. C.; Wibowo, A. C.; Chung, D. Y.; Freeman, A. J., Crystal Growth of the Perovskite Semiconductor $\mathrm{CsPbBr}_{3}$ : A New Material for High-Energy Radiation Detection. Cryst. Growth. Des. 2013, 13, 2722-2727.

(64) Braescu, L. Shape of Menisci in Terrestrial Dewetted Bridgman Growth. J. Colloid and Inte. Sci. 2008, 319, 309-315.

(65) Lee, L.; Baek, J.; Park, K. S.; Lee, Y.-E.; Shrestha, N. K.; Sung, M. M., Wafer-Scale SingleCrystal Perovskite Patterned Thin Films Based on Geometrically-Confined Lateral Crystal Growth. Nat. Commun. 2017, 8, 15882.

(66) Li, Y.-J.; Wu, T.; Sun, L.; Yang, R.-X.; Jiang, L.; Cheng, P.-F.; Hao, Q.-Q.; Wang, T.-J.; Lu, R.-F.; Deng, W.-Q. Lead-Free And Stable Antimony-Silver-Halide Double Perovskite $\left(\mathrm{CH}_{3} \mathrm{NH}_{3}\right)_{2} \mathrm{AgSbI}_{6}$. RSC Adv. 2017, 7, 35175-35180.

(67) Chen, J.; Morrow, D. J.; Fu, Y.; Zheng, W.; Zhao, Y.; Dang, L.; Stolt, M. J.; Kohler, D. D.; Wang, X.; Czech, K. J.; Hautzinger, M. P.; Shen, S.; Guo, L.; Pan, A.; Wright, J. C.; Jin, S. SingleCrystal thin Films of Cesium Lead Bromide Perovskite Epitaxially Grown on Metal Oxide Perovskite ( $\left.\mathrm{SrTiO}_{3}\right)$. J. Am. Chem. Soc. 2017, 139, 13525-13532.

(68) Eames, C.; Frost, J. M.; Barnes, P. R. F.; O’Regan, B. C.; Walsh, A.; Islam, M. S. Ionic Transport in Hybrid Lead Iodide Perovskite Solar Cells. Nat. Commun. 2015, 6, 7497.

(69) Haruyama, J.; Sodeyama, K.; Han, L.; Tateyama, Y. First-Principles Study of Ion Diffusion in Perovskite Solar Cell Sensitizers. J. Am. Chem. Soc. 2015, 137, 10048-10051.

(70) Azpiroz, J. M.; Mosconi, E.; Bisquert, J.; De Angelis, F. Defect Migration in Methylammonium Lead Iodide and its Role In Perovskite Solar Cell Operation. Energy Environ. Sci. 2015, 8, 2118-2127.

(71) Delugas, P.; Caddeo, C.; Filippetti, A.; Mattoni, A. Thermally Activated Point Defect Diffusion in Methylammonium Lead Trihalide: Anisotropic and Ultrahigh Mobility of Iodine. $J$. Phys. Chem. Lett. 2016, 7, 2356-2361.

(72) Yang, D.; Ming, W.; Shi, H.; Zhang, L.; Du, M.-H. Fast Diffusion of Native Defects and Impurities in Perovskite Solar Cell Material $\mathrm{CH}_{3} \mathrm{NH}_{3} \mathrm{PbI}_{3}$. Chem. Mater. 2016, 28, 4349-4357.

(73) Meloni, S.; Moehl, T.; Tress, W.; Franckevičius, M.; Saliba, M.; Lee, Y. H.; Gao, P.; Nazeeruddin, M. K.; Zakeeruddin, S. M.; Rothlisberger, U.; Graetzel, M. Ionic PolarizationInduced Current-Voltage Hysteresis in $\mathrm{CH}_{3} \mathrm{NH}_{3} \mathrm{PbX}$ Perovskite Solar Cells. Nat. Commun. 2016, 7, 10334. 
(74) Pazoki, M.; Wolf, M. J.; Edvinsson, T.; Kullgren, J., Vacancy Dipole Interactions and the Correlation with Monovalent Cation Dependent Ion Movement in Lead Halide Perovskite Solar Cell Materials. Nano Energy 2017, 38, 537-543.

(75) Oranskaia, A.; Yin, J.; Bakr, O. M.; Brédas, J.-L.; Mohammed, O. F., Halogen Migration in Hybrid Perovskites: The Organic Cation Matters. J. Phys. Chem.Lett. 2018, 9, 5474-5480.

(76) Niu, G.; Guo, X.; Wang, L. Review of Recent Progress in Chemical Stability of Perovskite Solar Cells. J. Mater. Chem. A 2015, 3, 8970-8980.

(77) Bakr, O. M.; Mohammed, O. F. Powering Up Perovskite Photoresponse. Science 2017, 355, 1260-1261.

(78) Eperon, G. E.; Stranks, S. D.; Menelaou, C.; Johnston, M. B.; Herz, L. M.; Snaith, H. J. Formamidinium Lead Trihalide: A Broadly Tunable Perovskite For Efficient Planar Heterojunction Solar Cells. Energy Environ. Sci. 2014, 7, 982-988.

(79) Kim, H. B.; Im, I.; Yoon, Y.; Do Sung, S.; Kim, E.; Kim, J.; Lee, W. I. Enhancement of Photovoltaic Properties of $\mathrm{CH}_{3} \mathrm{NH}_{3} \mathrm{PbBr}_{3}$ Heterojunction Solar Cells by Modifying Mesoporous Tio2 2 Surfaces With Carboxyl Groups. J. Mater. Chem. A 2015, 3, 9264-9270.

(80) Christians, J. A.; Miranda Herrera, P. A.; Kamat, P. V. Transformation of The Excited State and Photovoltaic Efficiency of $\mathrm{CH}_{3} \mathrm{NH}_{3} \mathrm{PbI}_{3}$ Perovskite upon Controlled Exposure to Humidified Air. J. Am. Chem. Soc. 2015, 137, 1530-1538.

(81) Bryant, D.; Aristidou, N.; Pont, S.; Sanchez-Molina, I.; Chotchunangatchaval, T.; Wheeler, S.; Durrant, J. R.; Haque, S. A. Light and Oxygen Induced Degradation Limits the Operational Stability of Methylammonium Lead Triiodide Perovskite Solar Cells. Energy Environ. Sci. 2016, 9, 1655-1660.

(82) Du, S.; Jing, L.; Cheng, X.; Yuan, Y.; Ding, J.; Zhou, T.; Zhan, X.; Cui, H., Incorporation of Cesium Ions into $\mathrm{MA}_{1-\mathrm{x}} \mathrm{Cs}_{\mathrm{x}} \mathrm{PbI}_{3}$ Single Crystals: Crystal Growth, Enhancement of Stability, and Optoelectronic Properties. J. Phys. Chem. Lett. 2018, 9, 5833-5839.

(83) Noh, J. H.; Im, S. H.; Heo, J. H.; Mandal, T. N.; Seok, S. I., Chemical Management for Colorful, Efficient, and Stable Inorganic-Organic Hybrid Nanostructured Solar Cells. Nano. Lett. 2013, 13, 1764-1769.

(84) Zhao, J.; Kong, G.; Chen, S.; Li, Q.; Huang, B.; Liu, Z.; San, X.; Wang, Y.; Wang, C.; Zhen, Y. Single crystalline $\mathrm{CH}_{3} \mathrm{NH}_{3} \mathrm{PbI}_{3}$ Self-Grown on $\mathrm{FTO} / \mathrm{TiO}_{2}$ Substrate for High Efficiency Perovskite Solar Cells. Sci. Bull. 2017, 62, 1173-1176.

(85) Unger, E. L.; Hoke, E. T.; Bailie, C. D.; Nguyen, W. H.; Bowring, A. R.; Heumüller, T.; Christoforo, M. G.; McGehee, M. D., Hysteresis and Transient Behavior in Current-Voltage Measurements of Hybrid-Perovskite Absorber Solar Cells. Energy Environ. Sci. 2014, 7, 36903698.

(86) Xiao, Z.; Yuan, Y.; Shao, Y.; Wang, Q.; Dong, Q.; Bi, C.; Sharma, P.; Gruverman, A.; Huang, J., Giant Switchable Photovoltaic Effect in Organometal Trihalide Perovskite Devices. Nat. Mater. 2014, 14, 193. 
(87) Leijtens, T.; Eperon, G. E.; Pathak, S.; Abate, A.; Lee, M. M.; Snaith, H. J. J. N. c. Overcoming Ultraviolet Light Instability of Sensitized $\mathrm{TiO}_{2}$ With Meso-Superstructured Organometal Tri-Halide Perovskite Solar Cells. Nat. Commun. 2013, 4, 2885.

(88) Xiao, X.; Dai, J.; Fang, Y.; Zhao, J.; Zheng, X.; Tang, S.; Rudd, P. N.; Zeng, X. C.; Huang, J. Suppressed Ion Migration Along the in-Plane Direction in Layered Perovskites. ACS Energy Lett. 2018, 3, 684-688.

(89) Li, W.-G.; Rao, H.-S.; Chen, B.-X.; Wang, X.-D.; Kuang, D.-B. A FormamidiniumMethylammonium Lead Iodide Perovskite Single Crystal Exhibiting Exceptional Optoelectronic Properties And Long-Term Stability. J. Mater. Chem. A 2017, 5, 19431-19438.

(90) Haruyama, J.; Sodeyama, K.; Han, L.; Tateyama, Y. Termination Dependence of Tetragonal $\mathrm{CH}_{3} \mathrm{NH}_{3} \mathrm{PbI}_{3}$ Surfaces for Perovskite Solar Cells. J. Phys. Chem. Lett. 2014, 5, 2903-2909.

(91) Uratani, H.; Yamashita, K. Charge Carrier Trapping at Surface Defects of Perovskite Solar Cell Absorbers: A First-Principles Study. J. Phys. Chem. Lett. 2017, 8, 742-746.

(92) Mosconi, E.; Ronca, E.; De Angelis, F. First-Principles Investigation of The $\mathrm{TiO}_{2} /$ Organohalide Perovskites Interface: The Role of Interfacial Chlorine. J. Phys. Chem. Lett. 2014, 5, 2619-2625.

(93) Akbari, A.; Hashemi, J.; Mosconi, E.; De Angelis, F.; Hakala, M. First Principles Modelling of Perovskite Solar Cells Based on $\mathrm{TiO}_{2}$ and $\mathrm{Al}_{2} \mathrm{O}_{3}$ : Stability and Interfacial Electronic Structure. J. Mater. Chem. A 2017, 5, 2339-2345.

(94) Yin, J.; Cortecchia, D.; Krishna, A.; Chen, S.; Mathews, N.; Grimsdale, A. C.; Soci, C. Interfacial Charge Transfer Anisotropy in Polycrystalline Lead Iodide Perovskite Films. J. Phys. Chem. Lett. 2015, 6, 1396-1402.

(95) Quarti, C.; De Angelis, F.; Beljonne, D. Influence Of Surface Termination on the Energy Level Alignment at the $\mathrm{CH}_{3} \mathrm{NH}_{3} \mathrm{PbI}_{3}$ Perovskite/C 60 Interface. Chem. Mater. 2017, 29, 958-968.

(96) Myung, C. W.; Javaid, S.; Kim, K. S.; Lee, G. Rashba-Dresselhaus Effect in Inorganic/Organic Lead Iodide Perovskite Interfaces. ACS Energy Lett. 2018, 3, 1294-1300.

(97) Liu, Y.; Yang, Z.; Liu, S. Recent Progress In Single-Crystalline Perovskite Research Including Crystal Preparation, Property Evaluation, And Applications. Adv. Sci. 2018, 5, 1700471. (98) Yang, Y.; Yan, Y.; Yang, M.; Choi, S.; Zhu, K.; Luther, J. M.; Beard, M. C. Low Surface Recombination Velocity in Solution-Grown $\mathrm{CH}_{3} \mathrm{NH}_{3} \mathrm{PbBr}_{3}$ Perovskite Single Crystal. Nat. Commun. 2015, 6, 7961.

(99) Saidaminov, M. I.; Abdelhady, A. L.; Murali, B.; Alarousu, E.; Burlakov, V. M.; Peng, W.; Dursun, I.; Wang, L.; He, Y.; Maculan, G.; Goriely, A.; Wu, T.; Mohammed, O. F.; Bakr, O. M. High-Quality Bulk Hybrid Perovskite Single Crystals Within Minutes by Inverse Temperature Crystallization. Nat. Commun. 2015, 6, 7586.

(100) Lian, Z.; Yan, Q.; Gao, T.; Ding, J.; Lv, Q.; Ning, C.; Li, Q.; Sun, J.-L. Perovskite $\mathrm{CH}_{3} \mathrm{NH}_{3} \mathrm{PbI}_{3}(\mathrm{Cl})$ Single Crystals: Rapid Solution Growth, Unparalleled Crystalline Quality, and Low Trap Density Toward $108 \mathrm{~cm}^{-3}$. J. Am. Chem. Soc. 2016, 138, 9409-9412. 
(101) Xing, G.; Mathews, N.; Sun, S.; Lim, S. S.; Lam, Y. M.; Grätzel, M.; Mhaisalkar, S.; Sum, T. C. Long-Range Balanced Electron- and Hole-Transport Lengths in Organic-Inorganic $\mathrm{CH}_{3} \mathrm{NH}_{3} \mathrm{PbI}_{3}$. Science 2013, 342, 344-347.

(102) Schlipf, J.; Askar, A. M.; Pantle, F.; Wiltshire, B. D.; Sura, A.; Schneider, P.; Huber, L.; Shankar, K.; Müller-Buschbaum, P. Top-Down Approaches Towards Single Crystal Perovskite Solar Cells. Sci. Rep. 2018, 8, 4906.

(103) Chen, M.; Shan, X.; Geske, T.; Li, J.; Yu, Z. Manipulating Ion Migration for Highly Stable Light-Emitting Diodes with Single-Crystalline Organometal Halide Perovskite Microplatelets. ACS Nano 2017, 11, 6312-6318.

(104) Andričević, P.; Mettan, X.; Kollár, M.; Náfrádi, B.; Sienkiewicz, A.; Garma, T.; Rossi, L.; Forró, L.; Horváth, E. Light-Emitting Electrochemical Cells of Single Crystal Hybrid Halide Perovskite with Vertically Aligned Carbon Nanotubes Contacts. ACS Photonics 2019, 6, 967-975. (105) Cheng, X.; Jing, L.; Yuan, Y.; Du, S.; Yao, Q.; Zhang, J.; Ding, J.; Zhou, T. CentimeterSize Square 2D Layered Pb-Free Hybrid Perovskite Single Crystal $\left(\mathrm{CH}_{3} \mathrm{NH}_{3}\right)_{2} \mathrm{MnCl}_{4}$ for Red Photoluminescence. Cryst. Eng. Comm. 2019, 21, 4085-4091.

(106) Wang, Y.; Guan, X.; Li, D.; Cheng, H.-C.; Duan, X.; Lin, Z.; Duan, X. Chemical Vapor Deposition Growth of Single-Crystalline Cesium Lead Halide Microplatelets and Heterostructures for Optoelectronic Applications. Nano Res. 2017, 10, 1223-1233.

(107) Zhu, H.; Fu, Y.; Meng, F.; Wu, X.; Gong, Z.; Ding, Q.; Gustafsson, M. V.; Trinh, M. T.; Jin, S.; Zhu, X. Y. Lead Halide Perovskite Nanowire Lasers With Low Lasing Thresholds and High Quality Factors. Nat. Mater. 2015, 14, 636.

(108) Fu, Y.; Zhu, H.; Schrader, A. W.; Liang, D.; Ding, Q.; Joshi, P.; Hwang, L.; Zhu, X. Y.; Jin, S. Nanowire Lasers of Formamidinium Lead Halide Perovskites and Their Stabilized Alloys with Improved Stability. Nano Lett. 2016, 16, 1000-1008.

(109) Fu, Y.; Zhu, H.; Stoumpos, C. C.; Ding, Q.; Wang, J.; Kanatzidis, M. G.; Zhu, X.; Jin, S. Broad Wavelength Tunable Robust Lasing from Single-Crystal Nanowires of Cesium Lead Halide Perovskites ( $\mathrm{CsPbX}_{3}, \mathrm{X}=\mathrm{Cl}$, Br, I). ACS Nano 2016, 10, 7963-7972.

(110) Brenner, P.; Stulz, M.; Kapp, D.; Abzieher, T.; Paetzold, U. W.; Quintilla, A.; Howard, I. A.; Kalt, H.; Lemmer, U. Highly Stable Solution Processed Metal-Halide Perovskite Lasers on Nanoimprinted Distributed Feedback Structures. Appl. Phys. Lett. 2016, 109, 141106.

(111) Pan, J.; Sarmah, S. P.; Murali, B.; Dursun, I.; Peng, W.; Parida, M. R.; Liu, J.; Sinatra, L.; Alyami, N.; Zhao, C.; Alarousu, E.; Ng, T. K.; Ooi, B. S.; Bakr, O. M.; Mohammed, O. F. AirStable Surface-Passivated Perovskite Quantum Dots for Ultra-Robust, Single- and Two-PhotonInduced Amplified Spontaneous Emission. J. Phys. Chem. Lett. 2015, 6, 5027-5033.

(112) Sutherland, B. R.; Hoogland, S.; Adachi, M. M.; Wong, C. T.; Sargent, E. H. Conformal Organohalide Perovskites Enable Lasing on Spherical Resonators. ACS Nano 2014, 8, 10947 10952.

(113) Grattan, K.; Sun, T., Fiber Optic Sensor Technology: An Overview. Sens. Actuators A Phys. 2000, $82,40-61$. 
(114) Ghezzi, D.; Antognazza, M. R.; Dal Maschio, M.; Lanzarini, E.; Benfenati, F.; Lanzani, G., A Hybrid Bioorganic Interface for Neuronal Photoactivation. Nat. Commun. 2011, 2, 166.

(115) Razeghi, M.; Rogalski, A., Semiconductor Ultraviolet Detectors. J. Appl. Phys. 1996, 79, 7433-7473.

(116) Chen, G.; Liang, B.; Liu, X.; Liu, Z.; Yu, G.; Xie, X.; Luo, T.; Chen, D.; Zhu, M.; Shen, G., High-Performance Hybrid Phenyl-C61-Butyric Acid Methyl Ester/Cd $\mathrm{Cd}_{3} \mathrm{P}_{2}$ Nanowire UltravioletVisible-Near Infrared Photodetectors. ACS Nano. 2013, 8, 787-796.

(117) Maculan, G.; Sheikh, A. D.; Abdelhady, A. L.; Saidaminov, M. I.; Haque, M. A.; Murali, B.; Alarousu, E.; Mohammed, O. F.; Wu, T.; Bakr, O. M. $\mathrm{CH}_{3} \mathrm{NH}_{3} \mathrm{PbCl}_{3}$ Single Crystals: Inverse Temperature Crystallization and Visible-Blind UV-Photodetector. J. Phys. Chem. Lett. 2015, 6, 3781-3786.

(118) Shaikh, P. A.; Shi, D.; Retamal, J. R. D.; Sheikh, A. D.; Haque, M. A.; Kang, C.-F.; He, J.H.; Bakr, O. M.; Wu, T. Schottky Junctions on Perovskite Single Crystals: Light-Modulated Dielectric Constant and Self-Biased Photodetection. J. Mater. Chem. C 2016, 4, 8304-8312.

(119) Wang, H.; Kim, D. H. Perovskite-Based Photodetectors: Materials and Devices. Chem. Soc. Rev. 2017, 46, 5204-5236.

(120) Wu, T.; Ahmadi, M.; Hu, B. Giant Current Amplification Induced by Ion Migration in Perovskite Single Crystal Photodetectors. J. Mater. Chem. C 2018, 6, 8042-8050.

(121) Bakr, O. M.; Mohammed, O. F. Perovskite Solar Cells: Shedding Light on Film Crystallization. Nat. Mater. 2017, 16, 601-602.

(122) Murali, B.; Saidaminov, M. I.; Abdelhady, A. L.; Peng, W.; Liu, J.; Pan, J.; Bakr, O. M.; Mohammed, O. F. Robust and Air-Stable Sandwiched Organo-Lead Halide Perovskites for Photodetector Applications. J. Mater. Chem. C 2016, 4, 2545-2552.

(123) Yakunin, S.; Dirin, D. N.; Shynkarenko, Y.; Morad, V.; Cherniukh, I.; Nazarenko, O.; Kreil, D.; Nauser, T.; Kovalenko, M. V. Detection of gamma photons using solution-grown single crystals of hybrid lead halide perovskites. Nat. Photonics 2016, 10, 585.

(124) Hu, X.; Zhang, X.; Liang, L.; Bao, J.; Li, S.; Yang, W.; Xie, Y., High-Performance Flexible Broadband Photodetector Based on Organolead Halide Perovskite. Adv. Funct. Mater. 2014, 24, 7373-7380.

(125) Guo, Y.; Liu, C.; Tanaka, H.; Nakamura, E. Air-Stable and Solution-Processable Perovskite Photodetectors for Solar-Blind UV and Visible Light. J. Phys. Chem. Lett. 2015, 6, 535-539.

(126) Heiss, W.; Brabec, C., X-Ray Imaging: Perovskites Target X-Ray Detection. Nat. Photon. 2016, 10, 288-289.

(127) Birowosuto, M. D.; Cortecchia, D.; Drozdowski, W.; Brylew, K.; Lachmanski, W.; Bruno, A.; Soci, C., X-ray Scintillation in Lead Halide Perovskite Crystals. Sci. Rep. 2016, 6, 37254. (128) Murali, B.; Krupanidhi, S. B. Transport Properties of CuIn $\mathrm{I}_{1-\mathrm{X}} \mathrm{Al}_{\mathrm{X}} \mathrm{Se}_{2} / \mathrm{AlZnO}$ Heterostructure For Low Cost Thin Film Photovoltaics. Dalton Trans. 2014, 43, 1974-1983.

(129) Murali, B.; Krupanidhi, S. B. Tailoring The Band Gap And Transport Properties Of $\mathrm{Cu}_{3} \mathrm{BiS}_{3}$ Nanopowders For Photodetector Applications. J. Nanosci. Nanotechnol 2013, 13, 3901-3909. 
(130) Fang, Y.; Dong, Q.; Shao, Y.; Yuan, Y.; Huang, J., Highly Narrowband Perovskite SingleCrystal Photodetectors Enabled by Surface-Charge Recombination. Nat. Photonics 2015, 9, 679. (131) Huang, W.; Liu, Y.; Yue, S.; Zhu, L.; Jin, P.; Wu, Q.; Zhang, Y.; Qu, S.; Wang, Z.; Chen, Y., Optical Bandgap Energy of $\mathrm{CH}_{3} \mathrm{NH}_{3} \mathrm{PbI}_{3}$ Perovskite Studied by Photoconductivity and Reflectance Spectroscopy. Sci. China. Technol. 2018, 61, 886-892.

(132) Fang, H.; Li, Q.; Ding, J.; Li, N.; Tian, H.; Zhang, L.; Ren, T.; Dai, J.; Wang, L.; Yan, Q., A Self-Powered Organolead Halide Perovskite Single Crystal Photodetector Driven by a DVDbased Triboelectric Nanogenerator. J. Mater. Chem. C. 2016, 4, 630-636.

(133) Ding, J.; Fang, H.; Lian, Z.; Li, J.; Lv, Q.; Wang, L.; Sun, J.-L.; Yan, Q., A Self-Powered Photodetector Based on a $\mathrm{CH}_{3} \mathrm{NH}_{3} \mathrm{PbI}_{3}$ Single Crystal with Asymmetric Electrodes. Cryst. Eng. Comm. 2016, 18, 4405-4411.

(134) Cao, M.; Tian, J.; Cai, Z.; Peng, L.; Yang, L.; Wei, D., Perovskite Heterojunction Based on $\mathrm{CH}_{3} \mathrm{NH}_{3} \mathrm{PbBr}_{3}$ Single Crystal for High-Sensitive Self-Powered Photodetector. Appl. Phys. Lett. 2016, 109, 233-303.

(135) Ding, J.; Fang, H.; Lian, Z.; Li, J.; Lv, Q.; Wang, L.; Sun, J.-L.; Yan, Q., A Self-Powered Photodetector Based on a $\mathrm{CH}_{3} \mathrm{NH}_{3} \mathrm{PbI}_{3}$ Single Crystal with Asymmetric Electrodes. Cryst. Eng. Comm. 2016, 18, 4405-4411.

(136) Ding, J.; Du, S.; Zhao, Y.; Zhang, X.; Zuo, Z.; Cui, H.; Zhan, X.; Gu, Y.; Sun, H., HighQuality Inorganic-Organic Perovskite $\mathrm{CH}_{3} \mathrm{NH}_{3} \mathrm{PbI}_{3}$ Single Crystals for Photo-Detector Applications. J. Mater. Sci. 2017, 52, 276-284.

(137) Adinolfi, V.; Ouellette, O.; Saidaminov, M. I.; Walters, G.; Abdelhady, A. L.; Bakr, O. M.; Sargent, E. H., Fast and Sensitive Solution-Processed Visible-Blind Perovskite UV Photodetectors. Adv. Mater. 2016, 28, 7264-7268.

(138) Ding, J.; Du, S.; Zuo, Z.; Zhao, Y.; Cui, H.; Zhan, X., High Detectivity and Rapid Response in Perovskite $\mathrm{CsPbBr}_{3}$ Single-Crystal Photodetector. J. Phys. Chem. C 2017, 121, 4917-4923.

(139) Bao, C.; Zhu, W.; Yang, J.; Li, F.; Gu, S.; Wang, Y.; Yu, T.; Zhu, J.; Zhou, Y.; Zou, Z., Highly Flexible Self-Powered Organolead Trihalide Perovskite Photodetectors with Gold Nanowire Networks as Transparent Electrodes. ACS Appl. Mater. Interfaces 2016, 8, 23868-2387. (140) McIntyre, R., Recent Developments in Silicon Avalanche Photodiodes. Measuremet 1985, $3,146-152$.

(141) Domanski, K.; Tress, W.; Moehl, T.; Saliba, M.; Nazeeruddin, M. K.; Grätzel, M., Working Principles of Perovskite Photodetectors: Analyzing the Interplay Between Photoconductivity and Voltage-Driven Energy-Level Alignment. Adv. Funct. Mater. 2015, 25, 6936-6947.

(142) Chen, H.-W.; Sakai, N.; Jena, A. K.; Sanehira, Y.; Ikegami, M.; Ho, K.-C.; Miyasaka, T., A Switchable High-Sensitivity Photodetecting and Photovoltaic Device with Perovskite Absorber. $J$. Phys. Chem. Lett. 2015, 6, 1773-1779.

(143) Xia, H.-R.; Li, J.; Sun, W.-T.; Peng, L.-M., Organohalide Lead Perovskite Based Photodetectors with Much Enhanced Performance. Chem. Commun. 2014, 50, 13695-13697. 
(144) Zhang, Y.; Du, J.; Wu, X.; Zhang, G.; Chu, Y.; Liu, D.; Zhao, Y.; Liang, Z.; Huang, J., Ultrasensitive Photodetectors Based on Island-Structured $\mathrm{CH}_{3} \mathrm{NH}_{3} \mathrm{PbI}_{3}$ Thin Films. ACS Appl. Mater. Interfaces 2015, 7, 21634-21638.

(145) Wang, F.; Mei, J.; Wang, Y.; Zhang, L.; Zhao, H.; Zhao, D., Fast Photoconductive Responses in Organometal Halide Perovskite Photodetectors. ACS Appl. Mater. Interfaces 2016, 8, 2840-2846.

(146) Zhao, F.; Xu, K.; Luo, X.; Lv, W.; Peng, Y.; Wang, Y.; Lu, F.; Xu, S., Ultrasensitivity Broadband Photodetectors Based on Perovskite: Research on Film Crystallization and Electrode Optimization. Org. Electron. 2017, 46, 35-43.

(147) Bao, C.; Yang, J.; Zhu, W.; Zhou, X.; Gao, H.; Li, F.; Fu, G.; Yu, T.; Zou, Z., A Resistance Change Effect in Perovskite $\mathrm{CH}_{3} \mathrm{NH}_{3} \mathrm{PbI}_{3}$ Films Induced by Ammonia. Chem. Commun. 2015, 51, 15426-15429.

(148) Zheng, Z.; Zhang, S.; Zhang, M.; Zhao, K.; Ye, L.; Chen, Y.; Yang, B.; Hou, J., Highly Efficient Tandem Polymer Solar Cells with a Photovoltaic Response in the Visible Light Range. Adv. Mater. 2015, 27, 1189-1194.

(149) Wu, Z.; Luo, J.; Sun, N.; Zhu, L.; Sun, H.; Yu, L.; Yang, D.; Qiao, X.; Chen, J.; Yang, C., High-Performance Hybrid White Organic Light-Emitting Diodes with Superior Efficiency/Color Rendering Index/Color Stability and Low Efficiency Roll-off Based on a Blue Thermally Activated Delayed Fluorescent Emitter. Adv. Funct. Mater. 2016, 26, 3306-3313.

(150) Lu, H.; Tian, W.; Cao, F.; Ma, Y.; Gu, B.; Li, L., A Self-Powered and Stable All-Perovskite Photodetector-Solar Cell Nanosystem. Adv. Funct. Mater. 2016, 26, 1296-1302.

(151) Kwon, K. C.; Hong, K.; Van Le, Q.; Lee, S. Y.; Choi, J.; Kim, K. B.; Kim, S. Y.; Jang, H. W., Inhibition of Ion Migration for Reliable Operation of Organolead Halide Perovskite-Based Metal/Semiconductor/Metal Broadband Photodetectors. Adv. Funct. Mater. 2016, 26, 4213-4222. (152) Saidaminov, M. I.; Haque, M.; Savoie, M.; Abdelhady, A. L.; Cho, N.; Dursun, I.; Buttner, U.; Alarousu, E.; Wu, T.; Bakr, O. M., Perovskite Photodetectors Operating in Both Narrowband and Broadband Regimes. Adv. Mater. 2016, 28, 8144-8149.

(153) Kang, D.-H.; Pae, S. R.; Shim, J.; Yoo, G.; Jeon, J.; Leem, J. W.; Yu, J. S.; Lee, S.; Shin, B.; Park, J.-H. An Ultrahigh-Performance Photodetector based on a Perovskite-Transition-MetalDichalcogenide Hybrid Structure. Adv. Mater. 2016, 28, 7799-7806.

(154) Deng, W.; Huang, L.; Xu, X.; Zhang, X.; Jin, X.; Lee, S.-T.; Jie, J. Ultrahigh-Responsivity Photodetectors from Perovskite Nanowire Arrays for Sequentially Tunable Spectral Measurement. Nano Lett. 2017, 17, 2482-2489.

(155) Yakunin, S.; Sytnyk, M.; Kriegner, D.; Shrestha, S.; Richter, M.; Matt, G. J.; Azimi, H.; Brabec, C. J.; Stangl, J.; Kovalenko, M. V., Detection of X-Ray Photons by Solution-Processed Lead Halide Perovskites. Nat. Photon. 2015, 9, 444-449.

(156) Fang, Y.; Huang, J. Resolving Weak Light of Sub-picowatt per Square Centimeter by Hybrid Perovskite Photodetectors Enabled by Noise Reduction. Adv. Mater. 2015, 27, 2804-2810.

(157) Yu, J.; Chen, X.; Wang, Y.; Zhou, H.; Xue, M.; Xu, Y.; Li, Z.; Ye, C.; Zhang, J.; van Aken, P. A.; Lund, P. D.; Wang, H. A High-Performance Self-Powered Broadband Photodetector Based 
on $\mathrm{A} \mathrm{CH}_{3} \mathrm{NH}_{3} \mathrm{PbI}_{3}$ Perovskite/ZnO Nanorod Array Heterostructure. J. Mater. Chem. C 2016, 4 , 7302-7308.

(158) Lin, Q.; Armin, A.; Lyons, D. M.; Burn, P. L.; Meredith, P., Low Noise, IR-Blind Organohalide Perovskite Photodiodes for Visible Light Detection and Imaging. Adv. Mater. 2015, 27, 2060-2064.

(159) Gao, L.; Zeng, K.; Guo, J.; Ge, C.; Du, J.; Zhao, Y.; Chen, C.; Deng, H.; He, Y.; Song, H.; Niu, G.; Tang, J. Passivated Single-Crystalline $\mathrm{CH}_{3} \mathrm{NH}_{3} \mathrm{PbI}_{3}$ Nanowire Photodetector with High Detectivity and Polarization Sensitivity. Nano Lett. 2016, 16, 7446-7454.

(160) Deng, W.; Zhang, X.; Huang, L.; Xu, X.; Wang, L.; Wang, J.; Shang, Q.; Lee, S.-T.; Jie, J. Aligned Single-Crystalline Perovskite Microwire Arrays for High-Performance Flexible Image Sensors with Long-Term Stability. Adv. Mater. 2016, 28, 2201-2208.

(161) Sutherland, B. R.; Johnston, A. K.; Ip, A. H.; Xu, J.; Adinolfi, V.; Kanjanaboos, P.; Sargent, E. H. Sensitive, Fast, and Stable Perovskite Photodetectors Exploiting Interface Engineering. ACS Photonics 2015, 2, 1117-1123.

(162) Li, X.; Bi, D.; Yi, C.; Décoppet, J.-D.; Luo, J.; Zakeeruddin, S. M.; Hagfeldt, A.; Grätzel, M. A Vacuum Flash-Assisted Solution Process for High-Efficiency Large-Area Perovskite Solar Cells. Science 2016, 353, 58.

(163) Jang, Y. J.; Kim, E.; Ahn, S.; Chung, K.; Kim, J.; Kim, H.; Wang, H.; Lee, J.; Kim, D.-W.; Kim, D. H. Upconversion-Triggered Charge Separation in Polymer Semiconductors. J. Phys. Chem. Lett. 2017, 8, 364-369.

(164) Wang, H.; Lim, J. W.; Mota, F. M.; Jang, Y. J.; Yoon, M.; Kim, H.; Hu, W.; Noh, Y.-Y.; Kim, D. H. Plasmon-Mediated Wavelength-Selective Enhanced Photoresponse in Polymer Photodetectors. J. Mater.Chem. C 2017, 5, 399-407.

(165) Peng, W.; Miao, X.; Adinolfi, V.; Alarousu, E.; El Tall, O.; Emwas, A.-H.; Zhao, C.; Walters, G.; Liu, J.; Ouellette, O.; Pan, J.; Murali, B.; Sargent, E. H.; Mohammed, O. F.; Bakr, O. M., Engineering of $\mathrm{CH}_{3} \mathrm{NH}_{3} \mathrm{PbI}_{3}$ Perovskite Crystals by Alloying Large Organic Cations for Enhanced Thermal Stability and Transport Properties. Angew. Chem. Int. Ed. 2016, 55, 1068610690.

(166) Peng, W.; Yin, J.; Ho, K.-T.; Ouellette, O.; De Bastiani, M.; Murali, B.; El Tall, O.; Shen, C.; Miao, X.; Pan, J.; Alarousu, E.; He, J.-H.; Ooi, B. S.; Mohammed, O. F.; Sargent, E.; Bakr, O. M., Ultralow Self-Doping in Two-Dimensional Hybrid Perovskite Single Crystals. Nano Lett. 2017, 17, 4759-4767.

(167) Sarmah, S. P.; Burlakov, V. M.; Yengel, E.; Murali, B.; Alarousu, E.; El-Zohry, A. M.; Yang, C.; Alias, M. S.; Zhumekenov, A. A.; Saidaminov, M. I.; Cho, N.; Wehbe, N.; Mitra, S.; Ajia, I.; Dey, S.; Mansour, A. E.; Abdelsamie, M.; Amassian, A.; Roqan, I. S.; Ooi, B. S.; Goriely, A.; Bakr, O. M.; Mohammed, O. F., Double Charged Surface Layers in Lead Halide Perovskite Crystals. Nano Lett. 2017, 17, 2021-2027.

(168) Gao, H.; Feng, J.; Pi, Y.; Zhou, Z.; Zhang, B.; Wu, Y.; Wang, X.; Jiang, X.; Jiang, L., Bandgap Engineering of Single-Crystalline Perovskite Arrays for High-Performance Photodetectors. Adv. Funct. Mater. 2018, 28, 1804349. 
(169) Kim, H.-S.; Lee, C.-R.; Im, J.-H.; Lee, K.-B.; Moehl, T.; Marchioro, A.; Moon, S.-J.; Humphry-Baker, R.; Yum, J.-H.; Moser, J. E., Lead Iodide Perovskite Sensitized All-Solid-State Submicron Thin Film Mesoscopic Solar Cell with Efficiency Exceeding 9\%. Sci. Rep. 2012, 2, 591.

(170) Zhou, H.; Chen, Q.; Li, G.; Luo, S.; Song, T.-b.; Duan, H.-S.; Hong, Z.; You, J.; Liu, Y.; Yang, Y., Interface Engineering of Highly Efficient Perovskite Solar Cells. Science 2014, 345, 542-546.

(171) Liu, M.; Johnston, M. B.; Snaith, H. J. Efficient planar heterojunction perovskite solar cells by vapour deposition. Nature 2013, 501, 395 .

(172) Huang, F.; Dkhissi, Y.; Huang, W.; Xiao, M.; Benesperi, I.; Rubanov, S.; Zhu, Y.; Lin, X.; Jiang, L.; Zhou, Y., Gas-Assisted Preparation of Lead Iodide Perovskite Films Consisting of a Monolayer of Single Crystalline Grains for High Efficiency Planar Solar Cells. Nano Energy 2014, $10,10-18$.

(173) Zhou, Y.; Yang, M.; Vasiliev, A. L.; Garces, H. F.; Zhao, Y.; Wang, D.; Pang, S.; Zhu, K.; Padture, N. P., Growth Control of Compact $\mathrm{CH}_{3} \mathrm{NH}_{3} \mathrm{PbI}_{3}$ Thin Films via Enhanced Solid-State Precursor Reaction for Efficient Planar Perovskite Solar Cells. J. Mater. Chem. A 2015, 3, 92499256.

(174) Jeon, N. J.; Noh, J. H.; Kim, Y. C.; Yang, W. S.; Ryu, S.; Seok, S. I., Solvent Engineering for High-Performance Inorganic-Organic Hybrid Perovskite Solar Cells. Nat. Mater. 2014, 13, 897-903.

(175) Xiao, M.; Huang, F.; Huang, W.; Dkhissi, Y.; Zhu, Y.; Etheridge, J.; Gray-Weale, A.; Bach, U.; Cheng, Y. B.; Spiccia, L., A Fast Deposition-Crystallization Procedure for Highly Efficient Lead Iodide Perovskite Thin-Film Solar Cells. Angew. Chem. Int. Ed. 2014, 126, 10056-10061. (176) Abrusci, A.; Stranks, S. D.; Docampo, P.; Yip, H.-L.; Jen, A. K.-Y.; Snaith, H. J., HighPerformance Perovskite-Polymer Hybrid Solar Cells via Electronic Coupling with Fullerene Monolayers. Nano. Lett. 2013, 13, 3124-3128.

(177) Chen, Q.; Zhou, H.; Hong, Z.; Luo, S.; Duan, H.-S.; Wang, H.-H.; Liu, Y.; Li, G.; Yang, Y., Planar Heterojunction Perovskite Solar Cells via Vapor-Assisted Solution Process. J. Am. Chem. Soc. 2013, 136, 622-625.

(178) Wang, Q. K.; Wang, R. B.; Shen, P. F.; Li, C.; Li, Y. Q.; Liu, L. J.; Duhm, S.; Tang, J. X. Energy Level Offsets at Lead Halide Perovskite/Organic Hybrid Interfaces and their Impacts on Charge Separation. Adv. Mater. Interfaces 2015, 2, 1400528.

(179) Wang, R.; Wu, C.; Hu, Y.; Li, J.; Shen, P.; Wang, Q.; Liao, L.; Liu, L.; Duhm, S. $\mathrm{CH}_{3} \mathrm{NH}_{3} \mathrm{PbI}_{3-\mathrm{x}} \mathrm{Cl}_{\mathrm{x}}$ under Different Fabrication Strategies: Electronic Structures and Energy-Level Alignment with an Organic Hole Transport Material. ACS Appl. Mater. Interfaces 2017, 9, 78597865.

(180) Chen, Y.; He, M.; Peng, J.; Sun, Y.; Liang, Z. Structure and Growth Control of OrganicInorganic Halide Perovskites for Optoelectronics: From Polycrystalline Films to Single Crystals. Adv. Sci. 2016, 3, 1500392. 
(181) Bi, Z.; Liang, Z.; Xu, X.; Chai, Z.; Jin, H.; Xu, D.; Li, J.; Li, M.; Xu, G., Fast Preparation of Uniform Large Grain Size Perovskite Thin Film in Air Condition via Spray Deposition Method for High Efficient Planar Solar Cells. Sol. Energy Mater. Sol. Cells. 2017, 162, 13-20.

(182) Kim, J. H.; Williams, S. T.; Cho, N.; Chueh, C. C.; Jen, A. K. Y., Enhanced Environmental Stability of Planar Heterojunction Perovskite Solar Cells Based on Blade-Coating. Adv. Energy Mater. 2015, 5, 1401229.

(183) Cho, N.; Li, F.; Turedi, B.; Sinatra, L.; Sarmah, S. P.; Parida, M. R.; Saidaminov, M. I.; Murali, B.; Burlakov, V. M.; Goriely, A.; Mohammed, O. F.; Wu, T.; Bakr, O. M., Pure Crystal Orientation and Anisotropic Charge Transport in Large-Area Hybrid Perovskite Films. Nat. Commun. 2016, 7, 13407.

(184) Deng, Y.; Peng, E.; Shao, Y.; Xiao, Z.; Dong, Q.; Huang, J., Scalable Fabrication of Efficient Organolead Trihalide Perovskite Solar Cells with Doctor-Bladed Active Layers. Energy Environ. Sci. 2015, 8, 1544-1550.

(185) Hwang, K.; Jung, Y. S.; Heo, Y. J.; Scholes, F. H.; Watkins, S. E.; Subbiah, J.; Jones, D. J.; Kim, D. Y.; Vak, D. Toward Large Scale Roll-to-Roll Production of Fully Printed Perovskite solar cells. Adv. Mater. 2015, 27, 1241-1247.

(186) Zheng, Y. C.; Yang, S.; Chen, X.; Chen, Y.; Hou, Y.; Yang, H. G., Thermal-Induced Volmer-Weber Growth Behavior for Planar Heterojunction Perovskites Solar Cells. Chem. Mater. 2015, 27, 5116-5121.

(187) Dualeh, A.; Tétreault, N.; Moehl, T.; Gao, P.; Nazeeruddin, M. K.; Grätzel, M., Effect of Annealing Temperature on Film Morphology of Organic-Inorganic Hybrid Pervoskite Solid-State Solar Cells. Adv. Funct. Mater. 2014, 24, 3250-3258.

(188) Zuleeg, R.; Knoll, P., Space-Charge-Limited Currents in Heteroepitaxial Films of Silicon Grown on Saphirre. Appl. Phys. Lett. 1967, 11, 183-185.

(189) Geurst, J., Theory of Space-Charge-Limited Currents in Thin Semiconductor Layers. Phys. Status Solidi (b) 1966, 15, 107-118.

(190) Liu, Y.; Yang, Z.; Cui, D.; Ren, X.; Sun, J.; Liu, X.; Zhang, J.; Wei, Q.; Fan, H.; Yu, F., Two-Inch-Sized Perovskite $\mathrm{CH}_{3} \mathrm{NH}_{3} \mathrm{PbX}_{3}(\mathrm{X}=\mathrm{Cl}, \mathrm{Br}, \mathrm{I})$ Crystals: Growth and Characterization. Adv. Mater. 2015, 27, 5176-5183.

(191) Peng, W.; Wang, L.; Murali, B.; Ho, K. T.; Bera, A.; Cho, N.; Kang, C. F.; Burlakov, V. M.; Pan, J.; Sinatra, L., Solution-Grown Monocrystalline Hybrid Perovskite Films for HoleTransporter-Free Solar Cells. Adv. Mater. 2016, 28, 3383-3390.

(192) Murali, B.; Yengel, E.; Peng, W.; Chen, Z.; Alias, M. S.; Alarousu, E.; Ooi, B. S.; Burlakov, V.; Goriely, A.; Eddaoudi, M., Temperature-Induced Lattice Relaxation of Perovskite Crystal Enhances Optoelectronic Properties and Solar Cell Performance. J. Phys. Chem. Lett. 2016, 8, 137-143.

(193) Murali, B.; Dey, S.; Abdelhady, A. L.; Peng, W.; Alarousu, E.; Kirmani, A. R.; Cho, N.;

Sarmah, S. P.; Parida, M. R.; Saidaminov, M. I., Surface Restructuring of Hybrid Perovskite Crystals. ACS Energy Lett. 2016, 1, 1119-1126 
(194) Ruecroft, G.; Hipkiss, D.; Ly, T.; Maxted, N.; Cains, P. W., S Onocrystallization: The Use of Ultrasound for Improved Industrial Crystallization. Org. Process Res. Dev. 2005, 9, 923-932.

(195) Plesset, M. S.; Chapman, R. B., Collapse of an Initially Spherical Vapour Cavity in the Neighbourhood of a Solid Boundary. J. Fluid. Mech. 1971, 47, 283-290.

(196) Dymshits, A.; Rotem, A.; Etgar, L., High Voltage in Hole Conductor Free Organo Metal Halide Perovskite Solar Cells. J. Mater. Chem. A 2014, 2, 20776-20781.

(197) Snaith, H. J.; Abate, A.; Ball, J. M.; Eperon, G. E.; Leijtens, T.; Noel, N. K.; Stranks, S. D.; Wang, J. T.-W.; Wojciechowski, K.; Zhang, W., Anomalous Hysteresis in Perovskite Solar Cells. J. Phys. Chem. Lett. 2014, 5, 1511-1515.

(198) Sanchez, R. S.; Gonzalez-Pedro, V.; Lee, J.-W.; Park, N.-G.; Kang, Y. S.; Mora-Sero, I.; Bisquert, J., Slow Dynamic Processes in Lead Halide Perovskite Solar Cells. Characteristic Times and Hysteresis. J. Phys. Chem. Lett. 2014, 5, 2357-2363.

(199) Almora, O.; Zarazua, I.; Mas-Marza, E.; Mora-Sero, I.; Bisquert, J.; Garcia-Belmonte, G., Capacitive Dark Currents, Hysteresis, and Electrode Polarization in Lead Halide Perovskite Solar Cells. J. Phys. Chem. Lett. 2015, 6, 1645-1652.

(200) Xiao, Z.; Yuan, Y.; Shao, Y.; Wang, Q.; Dong, Q.; Bi, C.; Sharma, P.; Gruverman, A.; Huang, J., Giant Switchable Photovoltaic Effect in Organometal Trihalide Perovskite Devices. Nat. Mater. 2015, 14, 193-198.

(201) Röhm, H.; Leonhard, T.; Hoffmann, M. J.; Colsmann, A., Ferroelectric Domains in Methylammonium Lead Iodide Perovskite Thin-Films. Energy Environ. Sci. 2017, 10, 950-955.

(202) Rao, H.-S.; Chen, B.-X.; Wang, X.-D.; Kuang, D.-B.; Su, C.-Y. A Micron-Scale Laminar $\mathrm{MAPbBr}_{3}$ Single Crystal for an Efficient and Stable Perovskite Solar cell. Chem. Comm. 2017, 53, 5163-5166.

(203) Lee, L.; Baek, J.; Park, K. S.; Lee, Y.-E.; Shrestha, N. K.; Sung, M. M., Wafer-Scale SingleCrystal Perovskite Patterned Thin Films Based on Geometrically-Confined Lateral Crystal Growth. Nat. Commun. 2017, 8, 15882.

(204) Chen, Z.; Turedi, B.; Alsalloum, A. Y.; Yang, C.; Zheng, X.; Gereige, I.; AlSaggaf, A.; Mohammed, O. F.; Bakr, O. M. Single-Crystal MAPbI 3 Perovskite Solar Cells Exceeding 21\% Power Conversion Efficiency. ACS Energy Lett. 2019, 4, 1258-1259.

(205) Chen, Z.; Dong, Q.; Liu, Y.; Bao, C.; Fang, Y.; Lin, Y.; Tang, S.; Wang, Q.; Xiao, X.; Bai, Y.; Deng, Y.; Huang, J., Thin Single Crystal Perovskite Solar Cells to Harvest Below-Bandgap Light Absorption. Nat. Commun. 2017, 8, 1890.

(206) Eperon, G. E.; Habisreutinger, S. N.; Leijtens, T.; Bruijnaers, B. J.; van Franeker, J. J.; deQuilettes, D. W.; Pathak, S.; Sutton, R. J.; Grancini, G.; Ginger, D. S., The Importance of Moisture in Hybrid Lead Halide Perovskite Thin Film Fabrication. ACS Nano 2015, 9, 9380-9393. (207) Pathak, S.; Sepe, A.; Sadhanala, A.; Deschler, F.; Haghighirad, A.; Sakai, N.; Goedel, K. C.; Stranks, S. D.; Noel, N.; Price, M., A Tmospheric Influence upon Crystallization and Electronic Disorder and Its Impact on the Photophysical Properties of Organic-Inorganic Perovskite Solar Cells. ACS Nano 2015, 9, 2311-2320. 
(208) Tian, Y.; Merdasa, A.; Unger, E.; Abdellah, M.; Zheng, K.; McKibbin, S.; Mikkelsen, A.; Pullerits, T. n.; Yartsev, A.; Sundström, V., Enhanced Organo-Metal Halide Perovskite Photoluminescence from Nanosized Defect-Free Crystallites and Emitting Sites. J. Phys. Chem. 2015, 6, 4171-4177.

(209) Müller, C.; Glaser, T.; Plogmeyer, M.; Sendner, M.; Döring, S.; Bakulin, A. A.; Brzuska, C.; Scheer, R.; Pshenichnikov, M. S.; Kowalsky, W., Water Infiltration in Methylammonium Lead Iodide Perovskite: Fast and Inconspicuous. Chem. Mater. 2015, 27, 7835-7841.

(210) Grancini, G.; D'Innocenzo, V.; Dohner, E.; Martino, N.; Kandada, A. S.; Mosconi, E.; De Angelis, F.; Karunadasa, H.; Hoke, E.; Petrozza, A., $\mathrm{CH}_{3} \mathrm{NH}_{3} \mathrm{PbI}_{3}$ Perovskite Single Crystals: Surface Photophysics and Their Interaction with the Environment. Chem. Sci. 2015, 6, 7305-7310. (211) Fang, H.-H.; Adjokatse, S.; Wei, H.; Yang, J.; Blake, G. R.; Huang, J.; Even, J.; Loi, M. A., Ultrahigh Sensitivity of Methylammonium Lead Tribromide Perovskite Single Crystals to Environmental Gases. Sci. Adv. 2016, 2, 1600534.

(212) Murali, B.; Yengel, E.; Yang, C.; Peng, W.; Alarousu, E.; Bakr, O. M.; Mohammed, O. F., The Surface of Hybrid Perovskite Crystals: A Boon or Bane. ACS Energy Lett. 2017, 2, 846-856. (213) Tian, Y.; Peter, M.; Unger, E.; Abdellah, M.; Zheng, K.; Pullerits, T.; Yartsev, A.; Sundström, V.; Scheblykin, I. G., Mechanistic Insights into Perovskite Photoluminescence Enhancement: Light Curing with Oxygen Can Boost Yield Thousandfold. Phys. Chem. Chem. Phys. 2015, 17, 24978-24987.

(214) Galisteo-López, J. F.; Anaya, M.; Calvo, M.; Míguez, H., Environmental Effects on the Photophysics of Organic-Inorganic Halide Perovskites. J. Phys. Chem. 2015, 6, 2200-2205.

(215) Leguy, A. 1. M.; Hu, Y.; Campoy-Quiles, M.; Alonso, M. I.; Weber, O. J.; Azarhoosh, P.; Van Schilfgaarde, M.; Weller, M. T.; Bein, T.; Nelson, J., Reversible Hydration of $\mathrm{CH}_{3} \mathrm{NH}_{3} \mathrm{PbI}_{3}$ in Films, Single Crystals, and Solar Cells. Chem. Mater. 2015, 27, 3397-3407.

(216) Gangishetty, M. K.; Scott, R. W.; Kelly, T. L., Effect of Relative Humidity on Crystal Growth, Device Performance and Hysteresis in Planar Heterojunction Perovskite Solar Cells. Nanoscale 2016, 8, 6300-6307.

(217) Yang, J.; Siempelkamp, B. D.; Liu, D.; Kelly, T. L., Investigation of $\mathrm{CH}_{3} \mathrm{NH}_{3} \mathrm{PbI}_{3}$ Degradation Rates and Mechanisms in Controlled Humidity Environments Using in Situ Techniques. ACS Nano 2015, 9, 1955-1963.

(218) Wu, B.; Nguyen, H. T.; Ku, Z.; Han, G.; Giovanni, D.; Mathews, N.; Fan, H. J.; Sum, T. C., Discerning the Surface and Bulk Recombination Kinetics of Organic-Inorganic Halide Perovskite Single Crystals. Adv. Energy Mater. 2016, 6, 1600551.

(219) Zhao, L.; Kerner, R. A.; Xiao, Z.; Lin, Y. L.; Lee, K. M.; Schwartz, J.; Rand, B. P., Redox Chemistry Dominates the Degradation and Decomposition of Metal Halide Perovskite Optoelectronic Devices. ACS Energy Lett. 2016, 1, 595-602.

(220) Yakunin, S.; Protesescu, L.; Krieg, F.; Bodnarchuk, M. I.; Nedelcu, G.; Humer, M.; De Luca, G.; Fiebig, M.; Heiss, W.; Kovalenko, M. V., Low-Threshold Amplified Spontaneous Emission and Lasing from Colloidal Nanocrystals of Caesium Lead Halide Perovskites. Nat. Commun. 2015, 6,8056 . 
(221) Walters, G.; Sutherland, B. R.; Hoogland, S.; Shi, D.; Comin, R.; Sellan, D. P.; Bakr, O. M.; Sargent, E. H., Two-Photon Absorption in Organometallic Bromide Perovskites. ACS Nano 2015, 9, 9340-9346.

(222) Yang, Y.; Yang, M.; Li, Z.; Crisp, R.; Zhu, K.; Beard, M. C., Comparison of Recombination Dynamics in $\mathrm{CH}_{3} \mathrm{NH}_{3} \mathrm{PbBr}_{3}$ and $\mathrm{CH}_{3} \mathrm{NH}_{3} \mathrm{PbI}_{3}$ Perovskite Films: Influence of Exciton Binding Energy. J. Phys. Chem. Lett. 2015, 6, 4688-4692.

(223) Oesinghaus, L.; Schlipf, J.; Giesbrecht, N.; Song, L.; Hu, Y.; Bein, T.; Docampo, P.; MüllerBuschbaum, P., Toward Tailored Film Morphologies: The Origin of Crystal Orientation in Hybrid Perovskite Thin Films. Adv. Mater. Interfaces 2016, 3, 1600403.

(224) Giesbrecht, N.; Schlipf, J.; Oesinghaus, L.; Binek, A.; Bein, T.; Müller-Buschbaum, P.; Docampo, P., Synthesis of Perfectly Oriented and Micrometer-Sized $\mathrm{MAPbBr}_{3}$ Perovskite Crystals for Thin-Film Photovoltaic Applications. ACS Energy Lett. 2016, 1, 150-154.

(225) Duim, H.; Fang, H.-H.; Adjokatse, S.; Brink, G. H. t.; Marques, M. A. L.; Kooi, B. J.; Blake, G. R.; Botti, S.; Loi, M. A. Mechanism of Surface Passivation of Methylammonium Lead Tribromide Single Crystals by Benzylamine. Appl. Phys. Rev. 2019, 6, 031401.

(226) Yang, S.; Chen, S.; Mosconi, E.; Fang, Y.; Xiao, X.; Wang, C.; Zhou, Y.; Yu, Z.; Zhao, J.; Gao, Y.; De Angelis, F.; Huang, J. Stabilizing Halide Perovskite Surfaces for Solar Cell Operation With Wide-Bandgap Lead Oxysalts. Science 2019, 365, 473.

(227) Yang, C.; El-Demellawi, J. K.; Yin, J.; Velusamy, D. B.; Emwas, A.-H. M.; El-Zohry, A. M.; Gereige, I.; AlSaggaf, A.; Bakr, O. M.; Alshareef, H. N.; Mohammed, O. F. MAPbI 3 Single Crystals Free from Hole-Trapping Centers for Enhanced Photodetectivity. ACS Energy Lett. 2019, 4, 2579-2584.

(228) El-Ballouli, A. O.; Bakr, O. M.; Mohammed, O. F. Compositional, Processing, and Interfacial Engineering of Nanocrystal- and Quantum-Dot-Based Perovskite Solar Cells. Chem. Mater. 2019, 31, 6387-6411.

(229) Zai, H.; Zhu, C.; Xie, H.; Zhao, Y.; Shi, C.; Chen, Z.; Ke, X.; Sui, M.; Chen, C.; Hu, J.; Zhang, Q.; Gao, Y.; Zhou, H.; Li, Y.; Chen, Q., Congeneric Incorporation of $\mathrm{CsPbBr}_{3}$ Nanocrystals in a Hybrid Perovskite Heterojunction for Photovoltaic Efficiency Enhancement, ACS Energy Lett. 2018, 3, 30-38. 